\title{
ASSESSING BIOFILM ON BIOFILTER MEDIA (GRANULAR ACTIVATED CARBON AND ANTHRACITE) FROM A PILOT SCALE DRINKING WATER TREATMENT PLANT
}

\author{
By Nick Dimas \\ Bachelor of Science, Ryerson University, 2013

\begin{abstract}
A thesis
presented to Ryerson University

in partial fulfillment of the requirements for the degree of

Master of Applied Science

in the Program of

Environmental Applied Science and Management
\end{abstract}

Toronto, Ontario, Canada, 2016

CNick Dimas, 2016 


\section{AUTHOR'S DECLARATION}

I hereby declare that I am the sole author of this thesis. This is a true copy of the thesis, including any required final revision, as accepted by my examiners.

I authorize Ryerson University to lend this thesis to other institutions or individuals for the purpose of scholarly research.

I further authorize Ryerson University to reproduce this thesis by photocopying or by other means, in total or in part, at the request of other institutions or individuals for the purpose of scholarly research. I understand that my thesis may be made electronically available to the public. 


\title{
ASSESSING BIOFILM ON BIOFILTER MEDIA (GRANULAR ACTIVATED CARBON AND ANTHRACITE) FROM A PILOT SCALE DRINKING WATER TREATMENT PLANT
}

\author{
Nick Dimas \\ Master of Applied Science, Environmental Applied Science and Management, \\ Ryerson University 2016
}

\begin{abstract}
Drinking Water Treatment Plants employ biofiltration systems to increase water quality through nutrient reduction. Microbial biofilms housed in biofilter media, are responsible for nutrient uptake and biodegradation. The purpose of this study was to re-evaluate the function and efficiency of biofilter media and investigate seasonal changes in the microbial populations. TOC and DO were more reduced in Granular Activated Carbon (GAC) media than in anthracite. Heterotrophic plate counts (HPC) were conducted to establish seasonal trends on microbial population. PCR-amplified 16S rRNA fragments were sequenced to compare microbial communities. Summer samples have higher HPC than winter samples. Summer samples yielded a reduction in microbial diversity and no detectable overlap with winter samples. Confocal microscopy conducted to qualitatively visualize the structure of biofilms was complemented by quantitative COMSTAT analysis showing GAC with double the biomass due to a greater level of attachment sites. GAC outcompetes anthracite in chemical adsorption and biological activity.
\end{abstract}




\section{Acknowledgements}

Over the last two and a half years this thesis has been the ongoing and primary focus of my life but would not have been possible without the combined efforts and support of a select few.

First and foremost I would like to extend the deepest gratitude to my supervisors, Dr. Martina Hausner and Otini Kroukamp. You have both given me so much help and guidance for this study, making me very knowledgeable in microbiology and water treatment. Your dedication has inspired me to conquer challenges I faced and made me think critically. Thank you for all the time and effort you invested in me. You both have helped shape my love for academia and my inquisitiveness and thirst for knowledge.

A special thanks to David Scott, operator of the pilot plant at the R.C. Harris Drinking Water Treatment Plant. Dave, you were an invaluable component to this study and have provided me with critical samples, information, and data that were essential for my research. You always made yourself available to me for any questions I needed answered, as well as continuously made me feel welcome to come back to the plant. Your hands on experience as well as your passion has made you an essential part of this team.

I would also like to thank Dr. Gideon Wolfaardt who made the formal introduction between me and Dave, as well as meeting with me and help me think of how to establish the core elements of my project. In addition I would also like to thank Dr. Andrew Laursen who helped me so much with the statistical analysis of my data and use of ANOVA; this project's statistical significance, is all thanks to him. Furthermore, I would like to thank Evan Ronan who has spent many hours training me with microscopy as well as teaching me how to use COMSTAT, many of these results were thanks to him. I would also like to thank all the members of the Wolfaardt/Gilbride Lab as well as the Haunser Lab who have been always been helpful and made working in the lab a pleasure.

I would like to give special recognition and thank my family, but especially my parents, Who have continuously been there to support me no matter what. Their love, support, and encouragement gave me all the strength to carry on these past two and half years, and I could not have done it without them. Finally, I would like to thank my close friends who have been a constant source of motivation for me. You have all been there for me through the good times and the bad times. The laughter and jokes as well as advice has always kept me on track and no matter what happens I know, I can count on you guys for anything: Dragan Miscevic, Hirak Saxena, Paul Proios, Thierry Spiess, Brian Moroz, Tom Perivolaris, Theodore Nanos, and Devi Odisho. 


\section{TABLE OF CONTENTS}

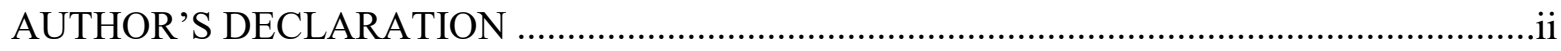

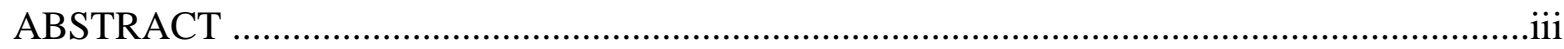

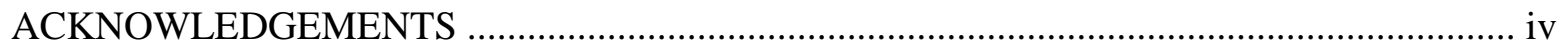

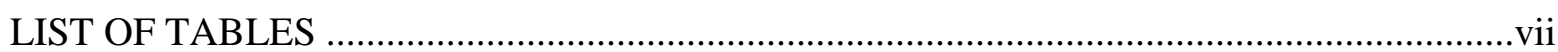

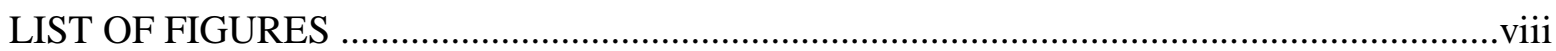

LIST OF ABBREVIATIONS ………………………..................................................

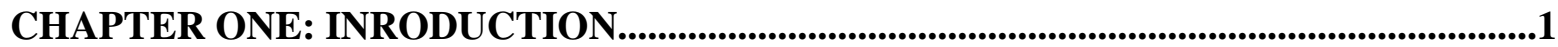

1.1 WATER SCARCITY AND DRINKING WATER CONDITIONS....................................

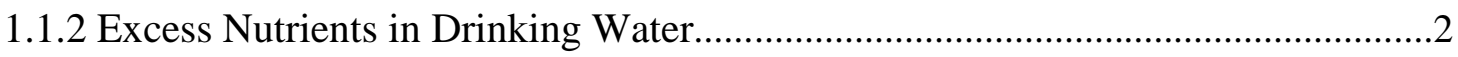

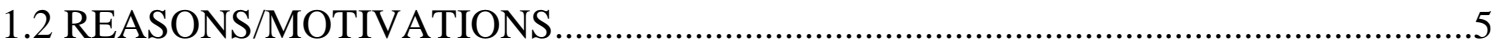

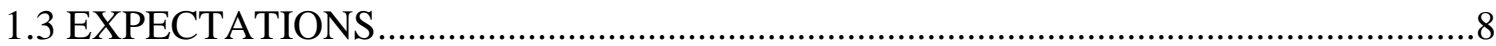

1.4 SCOPE OF WORK AND OBJECTIVES...................................................................11

CHAPTER TWO: LITERATURE REVIEW............................................................................14

2.1 TIMELINE OF BIOFILTRATION APPLICATIONS..................................................14

2.2 R.C. HARRIS WATER TREATMENT PROCESS......................................................15

2.2.1 The Pilot Scale

2.3 BIOFILMS

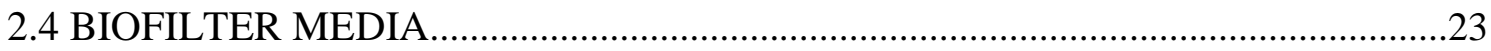

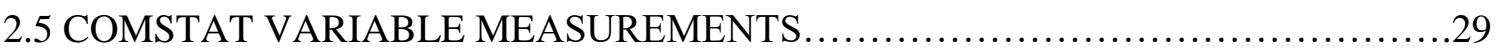

CHAPTER THREE: METHODS AND MATERIALS......................................................32

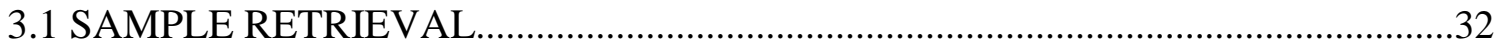

3.2 HETEROTROPHIC PLATE COUNTS..................................................................

3.3 DNA AMPLIFICATION AND SEQUENCING .....................................................3

3.4 CONFOCAL LASER SCANNING MICROSCOPY ....................................................35

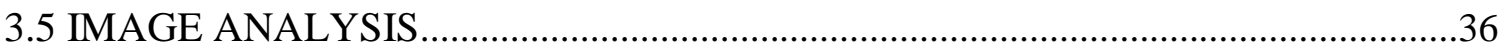

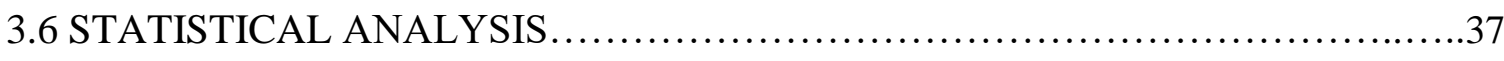

CHAPTER FOUR: RESULTS...................................................................................................38

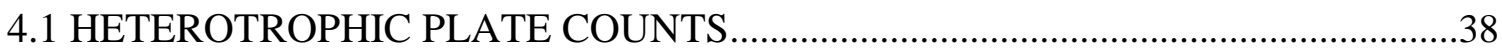

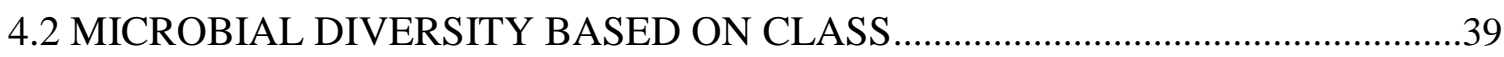

4.3 CONFOCAL LASER SCANNING MICROSCOPY .................................................41

4.4 IMAGE QUANTIFICATION................................................................................ 


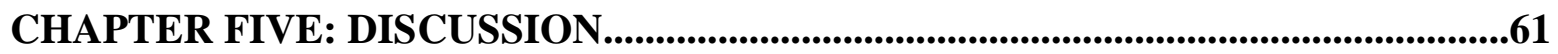

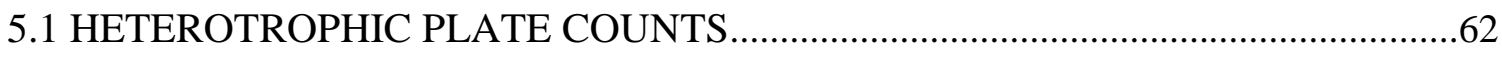

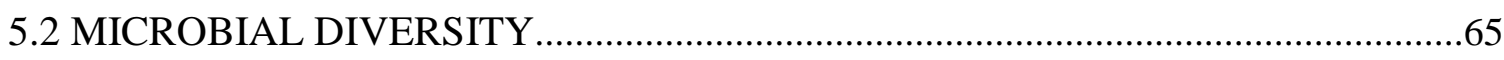

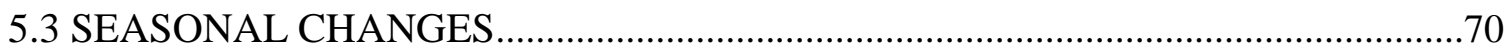

5.4 CLSM \& IMAGE QUANTIFICATION OF BIOFILM PARAMETERS.................72

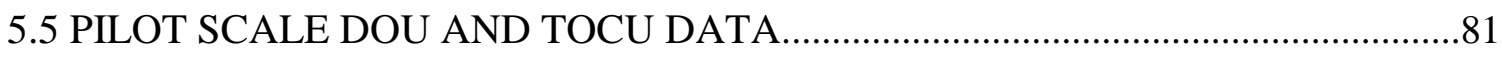

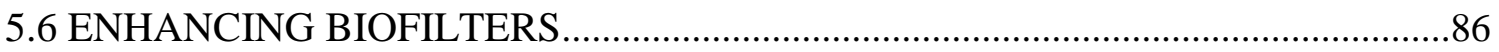

CHAPTER SIX: CONCLUSIONS AND FUTURE WORK...............................................89

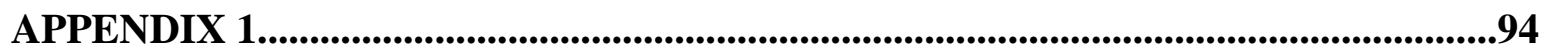

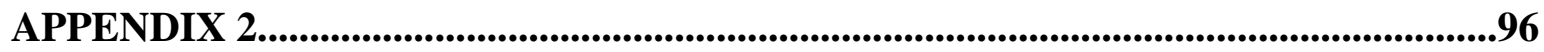

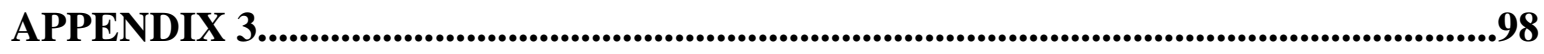

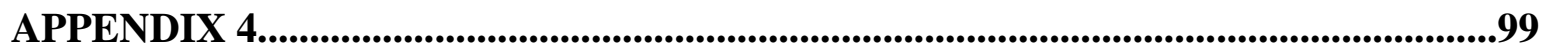

APPENDIX 5.....................................................................................................................................100

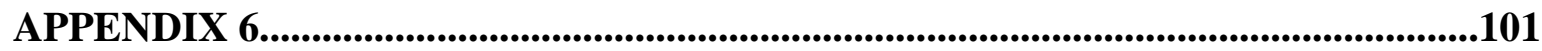

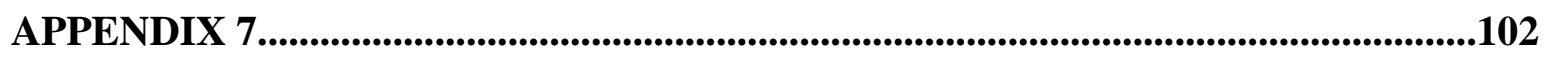

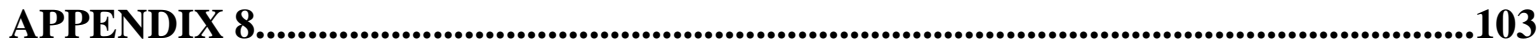

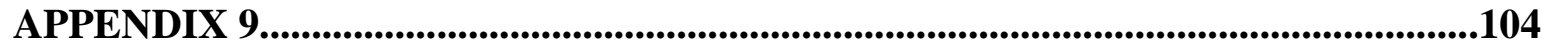

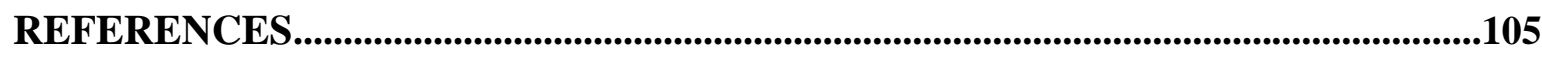




\section{List of Tables}

Table 4.1: Statistical Analysis of Data Determining Statistical Significance........................59

Table A1.1: DNA sequence and microbial identification of winter 2014 sampling set.......94

Table A2.1: DNA sequence and microbial identification of summer 2014 sampling set......96

Table A4.1: Dissolved oxygen uptake (mg/L) during high temperature ranges...................99

Table A4.2: Dissolved oxygen uptake (mg/L) during medium temperature ranges..............99

Table A4.3: Dissolved oxygen uptake (mg/L) during low temperature ranges...................99

Table A5.1: Total organic carbon uptake $(\mathrm{mg} / \mathrm{L})$ during high temperature ranges..............100

Table A5.2: Total organic carbon uptake (mg/L) during medium temperature ranges.........100

Table A5.3: Total organic carbon uptake $(\mathrm{mg} / \mathrm{L})$ during low temperature ranges...............100 


\section{List of Figures}

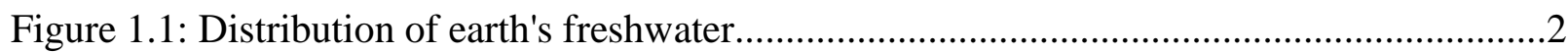

Figure 1.2a: SEM of activated carbon's highly porous surface................................................

Figure 1.2b: An image of the granular form of activated carbon (GAC)....................................

Figure 2.1: Current treatment process implemented at the R.C. Harris WTP.............................16

Figure 2.2: Pilot scale biofilter schematic............................................................................17

Figure 2.3: Scanning electron micrograph of activated carbon.................................................26

Figure 4.1: HPC of water samples from the pilot scale..........................................................38

Figure 4.2: Distribution of phylogenetic diversification based on microbial class. The origins of biofilm communities for winter 2014 samples.........................................................................39

Figure 4.3: Distribution of phylogenetic diversification based on microbial class. The origins of biofilm communities for summer 2014 samples...................................................................

Figure 4.4a \& 4.4b: Winter 2015 anthracite before backwash...................................................41

Figure 4.5a \& 4.5b: Winter 2015 anthracite after backwash....................................................42

Figure 4.6a \& 4.6b: Winter 2015 GAC before backwash.......................................................43

Figure 4.7a \& 4.7b: Winter 2015 GAC after backwash............................................................4

Figure 4.8a \& 4.8b: Summer 2015 anthracite before backwash..............................................45

Figure 4.9a \& 4.9b: Summer 2015 anthracite after backwash.................................................46

Figure 4.10a \& 4.10b: Summer 2015 GAC before backwash.................................................4

Figure 4.11a \& 4.11b: Summer 2015 GAC after backwash.....................................................48

Figure 4.12: COMSTAT analysis comparing of seasonal changes for biovolume, for respective biofilter media before and after a backwash event..................................................49

Figure 4.13: COMSTAT analysis comparing average biofilm thickness before and after a backwash event on GAC and anthracite filter media seasonally..........................................50

Figure 4.14: COMSTAT analysis comparing roughness of a biofilm's surface on GAC and anthracite filter media, pre and post backwash, during winter and summer seasons.

Figure 4.15: COMSTAT analysis comparing the surface to volume ratio coverage on biofilter media, before and after a backwashing event, while evaluating seasonal differences 
Figure 4.16: DO uptake correlated to TOC removal for GAC and anthracite media..............53

Figure 4.17: DO and TOC removal plotted for anthracite and GAC at different flow rates.............54

Figure 4.18: Biofilter media responding to nutrient spikes and backwashing.......................55

Figure 4.19: Summary of data for DOU average; comparison between GAC and anthracite during low, medium, and high water temperatures....................................................56

Figure 4.20: Summary of data for TOCU average; comparison between GAC and anthracite during low, medium, and high water temperatures......................................................58

Figure 4.21: Representation of TOCU as a function of biomass levels and temperature

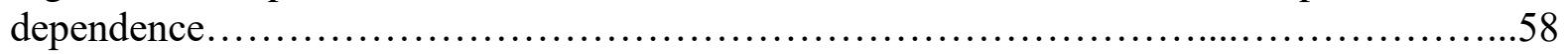

Figure 5.1: Biomass and organic content entrenched in the pores of the GAC granules.........78

Figure 5.2: Schematic of biomass detachment from a biofilm during a backwash event........80

Figure A3.1: Control sample for GAC before backwash.............................................98

Figure A3.2: Control sample for anthracite before backwash...........................................98

Figure A6.1: Statistical Analysis of 3 way ANOVA for biovolume variable tested with independent factors of season, filter media type, and backwashing .....................101

Figure A7.1: Statistical Analysis of 3 way ANOVA for average thickness variable tested with independent factors of season, filter media type, and backwashing .................. 102

Figure A8.1: Statistical Analysis of 3 way ANOVA for roughness coefficient variable tested with independent factors of season, filter media type, and backwashing.............103

Figure A9.1: Statistical Analysis of 3 way ANOVA for surface to volume ratio variable tested with independent factors of season, filter media type, and backwashing.............104 


\section{LIST OF ABBREVIATIONS}

ADP Adenosine Diphosphate

AOC Assimilable Organic Carbon

ATP Adenosine Triphosphate

BAC Biologically Activated Carbon

BDOC Biodegradable Dissolved Organic Carbon

BLAST Basic Local Alignment Search Tool

BOD Biochemical Oxygen Demand

BOM Biodegradable Organic Matter

BSA Bovine Serum Albumin

CDW Committee on Drinking Water

CFU Colony Forming Units

CLSM Confocal Laser Scanning Microscopy

DBP Disinfection By-Products

DGGE Denaturing Gradient Gel Electrophoresis

DNA Deoxyribonucleic Acid

DO Dissolved Oxygen

DOC Dissolved Organic Carbon

DOU Dissolved Oxygen Uptake

DWDS Drinking Water Distribution System

DWTP Drinking Water Treatment Plant

EFM Epi-fluorescence Microscopy

EPA Environmental Protection Agency

EPS Extracellular Polymeric Substance 
EDTA Ethylenediaminetetraacetic acid

GAC Grandular Activated Carbon

HAA Haloacetic Acid

HPC Heterotrophic Plate Counts

MAC Maximum Acceptable Concentration

MCLG Maximum Concentration Level Goal

NOM Natural Organic Matter

ORP Oxidation Reduction Potential

PBS Phosphate Buffer Saline

PCP Personal Care Products

PCR Polymerase Chain Reaction

PhAC Pharmaceutically Active Compounds

RNA Ribonucleic Acid

TAE Tris Base, Acetic Acid, and EDTA buffer

TCAG The Centre for Applied Genomics

TOC Total Organic Carbon

TOCU Total Organic Carbon Uptake

USEPA United States Environmental Protection Agency

VOC Volatile Organic Compounds

WTP Water Treatment Plant 


\section{Chapter One: Introduction}

\subsection{Water Scarcity and Drinking Water Conditions}

Clean water is one of the parameters which define a nation's status and ability to provide its residents with a high standard of living. A nation fortunate enough to have clean drinking water, is a factor which often translates the metaphorical socioeconomic divide between developed and developing countries (Gadgil, 1998). Drinkable water is an essential commodity and has shaped the way and location in which communities are formed. Water occupies $71 \%$ of the earth's surface. However, most of this water is situated in oceans and seas and $97 \%$ of all water on earth is in saline form and not readily consumable (Figure 1.1) (Gleick, 1996). The majority of the fresh water is trapped in glaciers and at the poles, making less than $1 \%$ of all fresh water accessible and readily consumable state for human use (Gleick, 1996). Surface water (from lakes and rivers) as well as ground water (from aquifers) are the predominant sources of potable water.

However, availability and proximity to a freshwater source is not the only factor; water must also be free of harmful chemicals or microorganisms that can cause health issues. Therefore, water must be treated prior to consumption, in order to reduce the risk of waterborne illnesses. Water utilities, such as treatment plants, are responsible for the sanitation of water and transport through the distribution system which delivers it to the residents in the community. A water treatment plant's main priority is to eliminate and filter out any chemical and biological agents which can adversely impact human health. Many biological agents such as microorganisms are naturally found in the water. These microorganisms are generally not pathogenic however, they may be opportunistic; this means they will only cause illness if they invade a host with low resistance (Lane, 2011). 


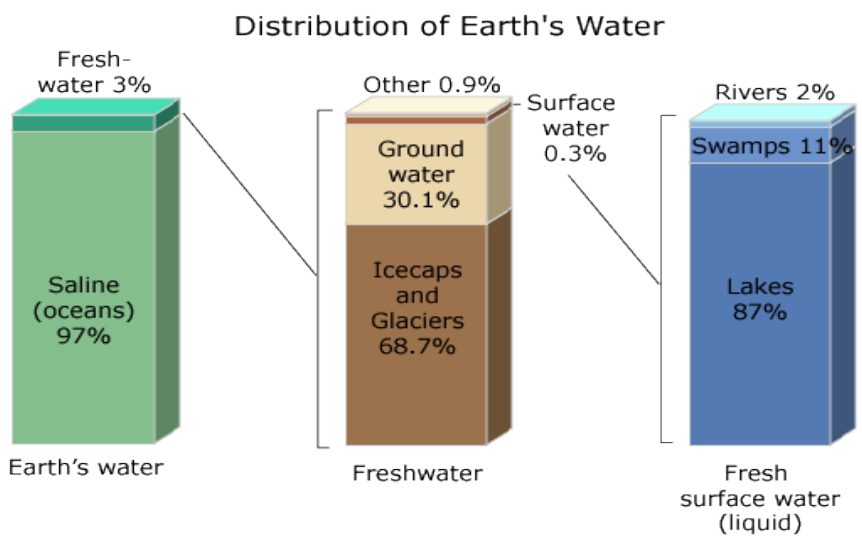

Figure 1.1: Distribution of Earth's Freshwater. (Adopted from Gleick, 1996)

\subsubsection{Excess Nutrients in Drinking Water}

In addition to microorganisms, nutrients in the form of carbon containing compounds, phosphates, and nitrates, are commonly found in the water, such as lake water or groundwater, which is used as a source of drinking water. These nutrients provide an environment in which bacteria can live and replicate in. Drinking water harbouring high levels of nutrients can lead to the exponential growth of microorganisms, which can lead to many unwanted health risks. The excess nutrients which provide microorganisms with a source of sustenance must therefore be removed in order to ensure their numbers in drinking water remain as low as possible.

Excess nutrients enter the drinking water supply particularly when indirect water re-use occurs. Indirect waste water re-use is a term used to describe the conditions where waste water and sewage effluent are deposited into rivers or lakes that flow into a main body of water which is the raw water source for drinking water. Indirect water use takes place predominantly in industrialized or rural farm areas where waste and fertilizer run off, enter the water system further upstream. 
Biological treatment can be defined as a method in which microorganisms colonizing carrier material in a biofilter utilize nutrients to fuel their metabolic activities, resulting in a reduction of the nutrient load. This kind of treatment is often used to consume nutrients before water enters the distribution system. Nutrient removal generally reduces chlorine demand, regrowth in the distribution system and the formation of disinfection by-products. In general, water treated with biofiltration contributes to harm reduction making it better suited for consumption. Nutrient removal alleviates the nutrient load in water producing a purer form of water. Nutrient limited water is also termed oligotrophic.

Achieving oligotrophic water quality is the primary goal of the biofiltration treatment process. Most nations have strict regulations for specific nutrients, metals, and other contaminants that must be below a specified concentration. These limits are in place in order for water quality conditions to be deemed as safe and therefore acceptable for consumption. The permissible concentrations vary, and are known as maximum acceptable concentration (MAC) which is the highest concentration that a particular contaminant's presence is allowed in drinking water (Health Canada, 2004). The MCLG (maximum concentration level goal) however, is a criterion at which a contaminant in drinking water can be present with no known health risk (USEPA, 2009). This is a non-enforceable standard that provides a margin of safety for the public. The guidelines for Canadian Drinking Water Quality were set by the Federal-ProvincialTerritorial Committee on Drinking Water (CDW) and published by Health Canada. Health Canada shares many similar conditions and guidelines with the United States Environmental Protection Agency (USEPA) which devises and regulates standards for biological contaminants such as microorganisms as well as chemical and physical contaminants. The guideline for treatment for various microbiological parameters varies dependent on the microorganism. For 
instance, enteric protozoa such as giardia and cryptosporidium have a treatment goal for a minimum $3 \log$ removal as well as inactivation of oocysts. E. coli and total colifoms on the other hand, have a MAC of 0 per $100 \mathrm{~mL}$ (Health Canada, 2004). The MAC for some main inorganics such as arsenic, fluoride, lead, and copper are $0.01 \mathrm{mg} / \mathrm{L}, 1.5 \mathrm{mg} / \mathrm{L}, 0.01 \mathrm{mg} / \mathrm{L}$, and $0 \mathrm{mg} / \mathrm{L}$ respectively (Health Canada, 2004). Limiting nutrients such as nitrate and nitrite are at $10 \mathrm{mg} / \mathrm{L}$ and $1 \mathrm{mg} / \mathrm{L}$ respectively (Health Canada, 2004). While phosphate doesn't have an MAC, the recommended maximum concentration should be approximately $0.1 \mathrm{mg} / \mathrm{L}$ (USEPA, 2009). Although the enforcement of these standards does not completely rid the water of all nutrients and contaminants, it ensures the water is maintained in a high quality condition with low nutrient availability and sufficient oxygen. Biofiltration treatment maintains such conditions and therefore will help to contribute to the oligotrophic state of the drinking water.

This study examined the effects of biofiltration at a pilot scale placed in the R.C. Harris WTP on total organic carbon (TOC) levels and dissolved oxygen (DO) concentration. The R. C. Harris, is situated on the north shore of Lake Ontario, which is surrounded by the industrial city sectors of Toronto, Hamilton, and other cities. Southern Ontario is the third largest agricultural producer, after British Columbia (40\%) and Alberta (30\%), with 13\% of all irrigated crops (Statistics Canada, 2011). Therefore the R.C. Harris WTP takes treated waste water which has been recycled and subjected to many anthropogenic practices making excess nutrients a relevant concern for its consumers.

Biofiltration can help significantly reduce this issue by implementing microbiological techniques to reduce the nutrient load. Biofilters are systems which utilize microorganisms to improve air or water quality by filtering out contaminants in solution. These contaminants are either adsorbed, biodegraded, or converted to less harmful compounds, while the solvent passes 
through. Biofilters utilize carrier materials, or media, comprised of a highly absorbent, porous, and carbon based tiny granules resembling gravel (Figure 1.2a and 1.2b below). Two filter media will be examined on their nutrient removal ability as well as on their microbiological profiles during winter and summer seasons. The two filter media analyzed in this study were granular activated carbon and anthracite.

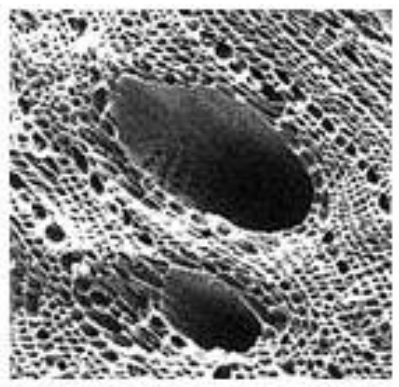

Figure 1.2a

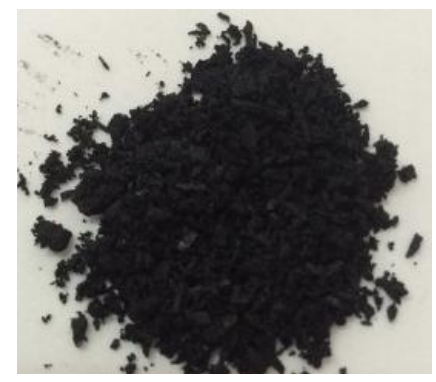

Figure 1.2 b

Figure 1.2a: SEM of activated carbon's highly porous surface. Upon activation, many tiny pores open up in the carbon, greatly increasing the surface area. Activation occurs by selective oxidation with steam or carbon dioxide to develop the pore structure. Figure 1.2b: An image of the granular form of activated carbon (GAC). GAC takes on a pebble or gravel like form when it is crushed and processed. Adopted from Abdulqadir, 2014

\subsection{Reasons/Motivations}

Currently biofiltration is a well sought after treatment process by many DWTPs that are looking to fortify sanitation efforts and increase overall water quality. Biofiltration is gaining widespread recognition on an international level as a viable treatment option for drinking water. However, concentrated efforts in Canada and the United States to implement biofilters are making the most headway (Mir, 2013). By adding additional measures of quality control that are consistent with reformed legislature pertaining to the multiple barriers approach, drinking water is made safer and more reliable (Hallé, 2009). The multiple barriers approach was conceived post Walkerton tragedy and stipulates a diverse treatment process can secure a higher standard product (O'Connor, 2002). Walkerton was a town afflicted by water contamination which lead to cases of enteric illness. This occurred due to inadequate chlorination and disinfectant dosages. In 
order to ensure quality conditions and that such issues are prevented, a series of defense measures were erected that targeted various fronts of the drinking water treatment process (O'Connor, 2002). The components of the multiple barriers approach include, the selection process assuring a quality source (body of water or aquifer), protection from contamination, effective treatment, and prevention of quality deterioration in the drinking water distribution systems (DWDS). The last two components can be facilitated with biofiltration. These barriers work to together to assure a higher standard of potable water long term.

Despite biofiltration having become the default option plants resort to after traditional means of treatment through disinfection, it still remains a relatively novel technique that has a lot of room for improvement and optimization. This biotechnology is still in the early stages, where not a lot is known about it and many skeptics still doubt it. In addition, biofiltration is still vastly unregulated and unstandardized (Smil, 2008). Merely knowing something works is not good enough when it comes to the pristine condition of a city's water supply. To try to better understand biofiltration, it has to be tested under different conditions and with multiple parameters. To try to optimize its functionality it has to be closely analyzed and its variables, in this case different biofilter media, must be compared. Finally, this study aims to give a comprehensive understanding of different filter media and the seasonal effects on drinking water biofilm architecture, abundance, and diversity, all factors and correlated to nutrient removal.

Excess nutrients in the water are known to negatively impact the aesthetic properties of the water. Visually, the water becomes turbid while also developing an offensive odor and earthy taste (Rai, 2009). This can be prevented however by removing the majority of the carbon compounds and limiting nutrients, maintaining a suitable chlorine residual will also control regrowth. A nutrient surplus can occur mostly in the summer months where anthropogenic 
pollution are at higher levels, precipitation increases, and warmer temperatures promote growth. In most cases this increase in nutrients is followed by an explosion of cyanobacteria and algae. These two microorganisms as well as actinomycetes are known for releasing wastes and byproducts known as geosmin and methylisoborneol into the water that are responsible for the murky appearance and displeasing odours and tastes (Davis and Shaw, 2006). These contaminants have a very low odor threshold of 10 parts per trillion (ng/L) making their removal, increasingly difficult to deal with (Young et al., 1996). In addition, targeting nutrients which promote for biofilm regrowth in the DWDS such as biodegradable organic matter (BOM), $\mathrm{NH}_{4}^{+}$, $\mathrm{Fe}^{2+}, \mathrm{Mn}^{2+}, \mathrm{NO}_{2}{ }^{-}, \mathrm{H}_{2}$, and several reduced forms of sulphur is also necessary to ensure quality conditions are kept high (Chaudhary et al., 2003).

Biological and chemical agents are found in the raw water after indirect water re-use. Biofiltration can help in the removal of both of these agents. Natural organic matter (NOM) can be subdivided into two categories, biodegradable and refractory. Biodegradable dissolved organic carbon (BDOC) includes assimilable organic carbon (AOC) which is considered to be the most readily available source of carbon containing compounds for which bacteria can break down and incorporate as an energy source (Thiel et al., 2006). Chemical agents such as personal care products (PCPs) which are not readily broken down are oxidized by chlorine and ozone within the treatment process. Oxidation of these chemical compounds breaks them down into compounds which can be broken down by microorganisms in the filtration units (Hallé, 2009). Therefore, biofiltration to an extent can also play a role in mitigating harmful chemicals, pharmaceutically active compounds (PhACs) (such as antibiotics, vitamins and supplements), and PCPs (such as cosmetics, fragrances, lotions, shampoos, toothpastes, and female menstrual care products) as well as biological and organic agents such as carbon containing compounds, 
amino acids, humic acids, phosphates and nitrates. When biofiltration precedes membrane filtration the best results for the removal of PCPs and PhACs are observed (Hallé, 2009). For the purpose of this study however, the biofiltration pilot was assessed on its organic, specifically its TOC removal ability.

Biofiltration in conjunction with ozonation, is useful in eliminating parasites such as cryptosporidium. In 1996, residents of Collingwood, Ontario, were urged and issued warnings to boil their water due to a potential outbreak of the aforementioned parasite. Unfortunately this parasite is not susceptible to chlorination and only filtration is seen to be successful at removing it from the water. Biofiltration helps remove these unwanted parasites as well as other protozoan parasites such as giardia, in addition to some removal of viruses and bacteria (Wendt et al., 2015). Through examples such as Collingwood and the Walkerton crisis, it can be seen that traditional methods of chlorination as a disinfecting agent cannot always be relied upon and novel processes such biofiltration, ozonation and UV disinfection could be used as an effective backup treatment method (City of Toronto, 2015). UV disinfection administers short wavelength ultraviolet (UV-C) light to destroy nucleic acids of the cell that are particularly vulnerable to irradiation. This disables them from caring out vital cellular processes, rendering them inactive (Shang et al., 2009).

\subsection{Expectations}

This overall aim of this study was to provide a comprehensive understanding of drinking water biofilms on two biofilter media, namely GAC and anthracite, and compare their abundance, diversity, structure and performance in nutrient removal during seasonal change. The following two hypotheses were formulated: 
The first hypothesis dealt with predictions which were drawn based on seasonal changes.

It was hypothesized that biofilter effluent in the summer would have a significantly higher microbial abundance due to increased temperature conditions favoring growth from the raw water. Furthermore, it was hypothesized that summer sample effluent from the pilot plant, would have a more diverse culturable microbial community compared to winter samples, again due to the warmer temperatures. Microbial abundance was determined by heterotrophic plate counts (HPC) and biodiversity was tested based on culturing and DNA sequencing of isolates. Both of these predictions were formulated based on higher temperatures in the summer season.

In addition, although nutrient levels shown to be steady throughout the year in this inlet of the north shore of Lake Ontario during the time of sampling and data analysis, nutrient availability does play a role in both abundance and biodiversity. Higher temperatures were seen to boost diversity as well as growth rates of mesophillic bacteria (Kelly et al., 2014). Increased nutrient availability, higher temperature and more sunlight, and greater precipitation levels, are all factors brought on by warmer seasonal change which increase biomass (Miettinen et al., 1997; Niquette et al., 2001). In turn, this promotes a higher net primary production in warmer temperatures leading to a surge in microbial growth. Increased primary production results in more carbon dioxide entering the system. In addition, more sunlight will allow for an increase in algae and other photoautrophic primary producers. Consequently this will fuel the food chain supplying higher order consumers with more energy, which would allow for influx of nutrient availability throughout the system. What is hypothesized is that higher microbial biodiversity and abundance will be accompanied with these suitable conditions that are brought on in the summer. 
Second, it was hypothesized that GAC would demonstrate superior performance with regards to nutrient reduction which can be attributed to higher biomass levels. Moreover, it was predicted that there would be a strong correlation between higher levels of biomass and enhanced biofilter performance through DOU (dissolved oxygen uptake) and TOCU (total organic carbon uptake). Based on a previous study (Chaudhary et al., 2003), the main expectation was that GAC would show a higher level of biomass attachment due to the macroporous structure and activated sites. GAC's increased surface area is attributed to a rugged exterior and heightened porosity through macropores, mesopores, and micropores, which creates more attachment sites for microbes. Therefore the second hypothesis assumes that there will be a strong correlation between GAC which harnesses these structural advantages (mentioned above) and therefore promotes an increased level of biomass. This will be tested through analysis of media samples using confocal microscopy and subsequent quantification of the biofilm parameters.

Since higher bacterial concentrations were hypothesized to be within the GAC, it was predicted that this filter media would achieve an increased level of biological activity. Analysis of data from the pilot scale was compiled and summarized to observe which filter media had the best uptake and removal capacity. Finally, the filter media that had the aforementioned features of more attachment sites and bacterial abundance was proposed to yield the highest nutrient removal from the effluent.

This study differed from others at a few main junctions. Previous studies have focused on quantification of biomass on biofilter media through direct methods such as epifluorescence microscopy (EFM) or indirect methods such as ATP measurements or phospholipid analysis (Cecen \& Aktas, 2011). However, this study will use confocal microscopy to visualize a three 
dimensional representation of the biofilms on filter media and quantify the images with a computer software application known as COMSTAT. The key factor bringing novelty to this project is incorporating qualitative and quantitative evidence through CLSM images, as well as including data from a pilot plant to provide further support and understanding of the images captured. Using both molecular data and images, this combined approach will bridge the gap and draw a solid conclusion why one media has better performance. In addition, this experimental study is conceptualizing the diversity housed in each respective media through DNA characterization profiling which will ultimately demonstrate if biodiversity within filtration units influences nutrient uptake.

\subsection{Scope of Work and Objectives}

The overall objective of this study was to compare the two different biofilter media at the pilot plant with regards to the microbial communities they harbour as well as their respective removal ability on organic matter. This study was intimately associated the pilot plant and the results obtained were reflective of the samples derived from it.

This study was accomplished through a series of experimental objectives, which compare various factors influencing performance on granular activated carbon (GAC) and anthracite filter media. Three experimental objectives were completed throughout the course of this project.

(I) Identified the culturable constituents of the microbiological communities of both respective media to determine similarity and differences throughout seasonal temperature changes. The species composition of microorganisms and potential changes brought on by temperature fluctuations, may influence uptake of nutrients and biofilter performance. Microbial enumeration, through units of colony forming units (CFU) per millilitre, was conducted in order 
to establish an understanding of seasonal effect on bacterial concentration within each biofilter as well as the effect of backwashing the filtration system in the effluent.

(II) Determined the structure of the biofilm residing within the respective media using qualitative and quantitative assessment based on biofilm images and quantitative data obtained utilizing confocal microscopy and quantitative image processing. Visualization allowed to gain an appreciation for the structural architecture of the biofilm. Furthermore, quantifying the differences within the various biofilm properties, such as biovolume (also referred to as biomass), average thickness, roughness coefficient, and surface to volume ratio (also referred to as surface coverage), revealed which filter media best accommodated its microbial community.

(III) Utilized the pilot scale data, to monitor the filter media's performance of TOC and DO up-take, biodegradation, and successive removal. This information was particularly important due to nutrient removal being the primary function of biofiltration. Therefore, a comparative analysis on the media's biochemical absorptive and nutrient removal capabilities dependent on seasonal changes was necessary. Effluent DO and TOC concentrations were correlated with the type of filter media, temperature, flow rate, and the rate of uptake and biodegradation. DO and TOC consumption are indirect measures that can be used to monitor a biofilm's metabolic activity.

Winter and summer sampling and analysis were undertaken to deduce if there was in fact a difference within performance between the two filter media, and if it was influenced by seasonal variation. This would allow for future experts to take the position on deciding if GAC's higher price is worthwhile, or if anthracite can deliver equal or comparable performance at a more affordable cost. The working hypothesis stipulated that there was indeed a difference in 
the nature of the biofilm physical architecture as well as its community diversity, resulting in different performance within each respective biofilter. Higher abundance of microbes were predicted to be present during the summer sampling as well as a higher community diversity. 


\section{Chapter Two: Literature Review}

\subsection{Timeline of Biofiltration Applications}

Biofiltration was first introduced in 1893 in England as a trickling filter for waste water treatment. In its early stages biofilter media were composed of either rock or slag. Presently however, many forms of carbon based media in addition to plastic media are all widely available depending on the nature of filtration required (Chaudhary et al., 2003). In 1923, biofiltration was proposed for the improvement of aesthetic properties of water but mainly for odor control (Mir, 2013). Specifically, the biologically active filter was intended to curtail hydrogen sulfide emissions from wastewater treatment plants. In 1955, biofiltration was implemented in Germany to treat for odours. During the 1960's biofiltration applications had become more diverse and they were now being used to treat gaseous micropollutants (Mir, 2013). During the next couple of decades, biofiltration for both air and water treatment became more established throughout Northern Europe. In the 1980's, biofiltration was repurposed for the treatment of toxic emissions as well as volatile compounds and installations in some industries had begun (Mir, 2013). The 1990's saw an explosion of growth in the biofiltration sector with over 500 biofilteration facilities operating in Europe. Extensive research had been undertaken by many North American establishments to bring over the innovative concept. Presently, more and more wastewater and drinking water treatment plants are making the step to provide a biofiltration step in their treatment process and the number continues to increase annually (Mir, 2013). A lot of funding and research is going into examining this alternative treatment which does not require chemicals and is steadily becoming very popular. 


\subsection{R.C. Harris Water Treatment Process}

The R. C. Harris Water Treatment Plant (WTP) provides clean water to over 2.3 million residences, including commercial, industrial, public, and government buildings. Currently the R.C. Harris Water Treatment employs a variety of water sanitation techniques which are administered in sequential order as water passes the different stages of purification. Refer to Figure 2.1 below for an illustration of the treatment process described. Initially, water in Lake Ontario (point A in Figure 2.1) is collected through the intake pipes $2.6 \mathrm{~km}$ offshore and at a depth of $20 \mathrm{~m}$, (City of Toronto, 2014). Once the water has entered the treatment plant, a pre-chlorination step is used to ensure that zebra mussels are removed (point B). From there, it undergoes a screening process where large debris and contaminants are physically removed (point C) (City of Toronto, 2014). Following this, a coagulant, known as alum, is added as well as chlorine, to disinfect the water of microorganisms (point D).

The water then travels to settling basin and filtration tanks where again another round of physical removal occurs (Point E and F). Here, flocs, algae, and other organic impurities are removed based on their weight as they sink to the bottom. The filtration tanks contain a sub-layer of gravel a mid-layer of sand and a top layer of anthracite or some form of activated carbon (most likely GAC). Subsequently, the addition of chlorine, fluoride, and sulphur dioxide are added to the water before it is stored in a holding tank (point G and H) (City of Toronto, 2014). Sulphur dioxide is added as a reducing agent, to ensure that the final concentration of chlorine is kept low at $1.5 \mathrm{mg} / \mathrm{L}$ and thereby reducing chlorine to chloride. Subsequent addition of ammonia is added in order to stabilize the chlorine and other disinfectants and make the water safe for consumption (point I). Treated water is regularly tested to ensure quality standards are met (point J) and once the water has been deemed permissible by the guidelines, the water is transported to 
reservoirs and pumping stations (point $\mathrm{K}$ ) available for commercial, industrial, or residential use (point L).

Currently, biofiltration, is not on the roster of cleaning strategies employed at the R.C. Harris. Nutrient removal would help out in a number of ways further improving upon the quality and drinkability of the water. Adding this step into the treatment process would help out enormously with the appearance, odour and taste of the water in addition to preventing re-growth of organic content in the DWDS (City of Toronto, 2014). Biofiltration would probably substitute regular filtration (point $\mathrm{F}$ ) or be a supplementary pre or post filtration process alongside the current implemented filtration process. Typically biofiltratin treatment is referred to as a tertiary treatment option and is located somewhere in the middle of the treatment train (Hallé, 2009).

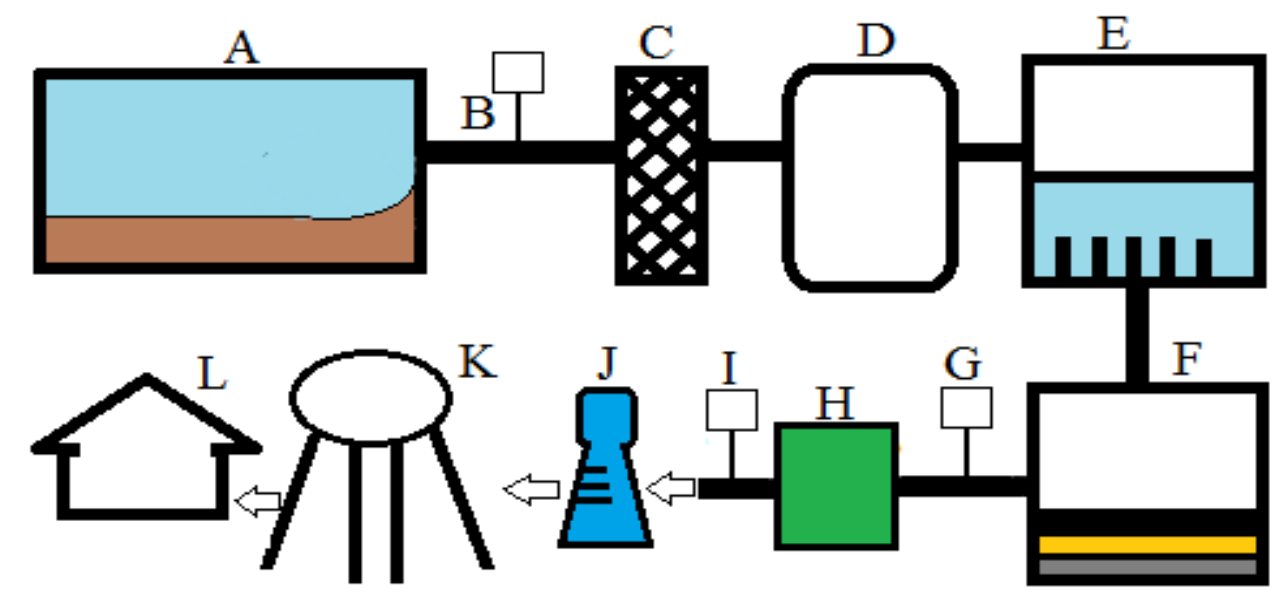

Figure 2.1: Current treatment process implemented at the R.C. Harris WTP

\subsubsection{The Pilot Scale}

Water from Lake Ontario is cleaned at the R.C. Harris, before it is distributed to local residents. The pilot scale plant (Figure 2.2), at the R.C. Harris WTP is fully operational and uses two different kinds of filter media known as granular activated carbon (GAC) and anthracite. 
These two media will be used for a comparative analysis in the study. Microbial communities congregate in structures known as biofilms. Biofilms, naturally found in the water, build up and reside in the biofilter. They were spontaneously inoculated onto the filter media by passing the lake water through the filtration system. Biofilms harness this water flow to their advantage and use it as a delivery system to bring them the desired nutrients they need to survive. Consequently this reduces the nutrient load from the water, effectively stripping the water clean of any excess contaminants and leaving it purer for consumers. Furthermore, this keeps the microbial biofilms in the DWDS nutrient limited and starved, making sure their numbers are as low as possible. As a result, this may limit the number of cells shed from biofilms into drinking water. Currently this is a pilot scale being run inside the main WTP but, it is not integrated into the water treatment process and therefore this biofiltered effluent is not connected to the DWDS reaching consumers.

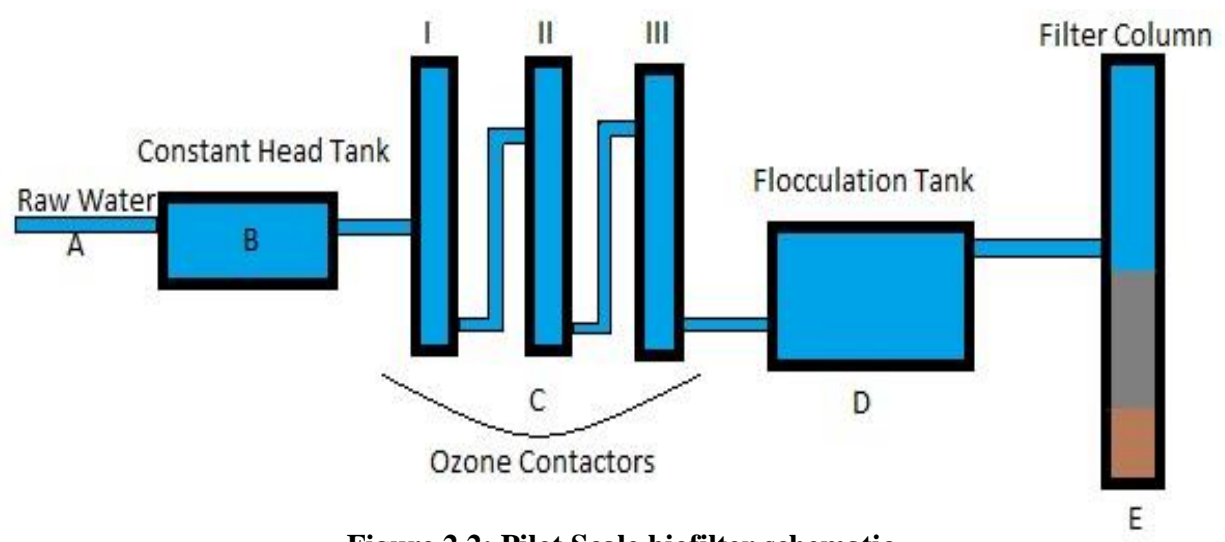

Figure 2.2: Pilot Scale biofilter schematic

Figure 2.2: A) Raw Water comes from the source which is Lake Ontario. The influent enters the pilot with a prechlorination step of $0.8 \mathrm{mg} / \mathrm{L}$ of chlorine. B) Raw water is transported to the constant head tank which contains instruments such as a turbimeter, particle counter, $\mathrm{pH}$ meter, and thermometer to measure the various parameters of the influent. C) Water subsequently enters the ozone contactors at a flow rate of $25 \mathrm{~L} / \mathrm{min}$. D) The water enters the flocculation tank at a reduced flow rate of $12 \mathrm{~L} / \mathrm{min}$. The flocculator contains a mixer which stirs the water and keeps it well aerated as well as serves the purpose of ensuring the coagulant is well mixed throughout the entire tank. E) In this last step the treated water passes through the biofilter and goes through the filter media where the microbial biofilms can uptake and thus remove nutrients which they use as an energy source. 
Once raw water comes into the pilot plant, it passes through the head tank which assesses various parameters through certain probes and then stores the data. Part $\mathrm{C}$ of the treatment process entails ozonation for disinfection as well as its subsequent removal. The ozone contactors are divided into three separate chambers. The first chamber is responsible for aerating the water providing compressed oxygen and $10 \%$ ozone (D. Scott, personal communication, May $\left.19^{\text {th }}, 2015\right)$. Ozone is a strong oxidant which makes it a very good disinfectant. Ozone is good for breaking up organics as well as microorganisms and it is preferred over conventional chemical agents because it can be made on site, eliminating both storage and handling hazards. The other benefit with ozone is that it eventually decomposes into oxygen which is environmentally friendly. The second contactor involves a quenching step where hydrogen peroxide and sodium bisulfite (SBS) are used to remove any residual ozone. Ozone must be removed because it can affect machinery as well as reverse osmosis membranes in downstream treatment processes. Finally, the third one contains aqueous and gaseous ozone analyzers as well as instruments measuring oxidation reduction potential (ORP) for confirming if the ozone is quenched. If the ozone is quenched, the ORP value will be low. Due to the added aeration and ozone, DO concentration peaks at almost $120 \%$ oxygen saturation. Ozonation with an oxygen/ozone gas mixture (90\% oxygen and $10 \%$ ozone) was responsible for the high concentration levels and bubbles present allowed for the water to go beyond saturation. (D. Scott, personal communication, May $\left.19^{\text {th }}, 2015\right)$.

Part $\mathrm{D}$ of the treatment process requires a coagulant which in this case is polyaluminum chloride (PACl). A dose of $0.8 \mathrm{mg} / \mathrm{L}$ of $\mathrm{PACl}$ is typically added to the flocculation tank (D. Scott, personal communication, May $\left.19^{\text {th }}, 2015\right)$. In this chemical reaction, the compound alum produces aluminum hydroxide. This then precipitates out of solution and neutralizes the 
negatively charged dirt particles as aggregates. The result is the formation of flocs which create

for a turbid appearance in the tank. A floc is a much larger, clustered mass of dirt and organics. It is easier to remove these larger particles through sedimentation and they settle to the bottom of the tank. The water can then be filtered allowing for the water to pass on through as the larger contaminants are separated out (D. Scott, personal communication, May $\left.19^{\text {th }}, 2015\right)$.

\subsection{Biofilms}

Biofilms are an assortment of microorganisms which have collectively come together to cohabitate. A biofilm is essentially a fully functional micro-scale ecosystem which contains a microbial community that is embedded in a material known as extracellular polymeric substance (EPS) (Harrison et al., 2005). A microbial community fixed in EPS has a plethora of advantages in comparison to planktonic cells. EPS helps adhere microbes of the biofilm to a surface. In this way they are not easily scraped off by any pressure or shear force. EPS is also a physical barrier which provides the first line of defence from predation, chemicals such as chlorination or antibiotics or even some irradiation (Harrison et al., 2005). EPS therefore, contributes to the recalcitrant behaviour observed in biofilms. This decreased sensitivity to antimicrobials is in part due to microbes being shielded from the diffusion of nutrients, effectively keeping them in a dormant state (Bester et al., 2010). The microorganisms inhabiting a biofilm almost never exist as a pure culture. Microorganisms exist in diverse communities coexisting in synergistic relationships. This further complicates the virulence and pathogenicity of biofilms.

The ubiquity of biofilms and their persistence despite increased efforts to overcome them has labelled them as a dangerous entity. The ubiquity of biofilms has shaped the way many fields of study conduct research and influence many industries. Aside from water treatment, their 
presence and adverse effects resonate powerfully within the food industry especially food packaging sectors (Chmielewski et. al., 2003). In addition, biofilms are known to be the direct cause of many hospital infections especially after prosthesis related surgeries. Contamination during invasive procedures such as hip and knee joint (ball socket replacements) can cause biofilm growth which results in successive treatments or operations (Song et al., 2013).

Biofilms are not all bad news. A deeper understanding of how biofilms operate has allowed for many new partnerships to form between these microbial communities and humans. Biofilms are exploited in certain industries where there is a lot to gain from their proliferation. Biofilms have increasingly been incorporated in the cleanup process of soil and ground water contamination due to their specific nutritional needs. The application of bacteria into contaminated sites for treatment is known as bioremediation (Kurisu and Yagi, 2010). Environmental contaminants leaching into ground water or soil is the most common set of conditions to employ bioremediation. Treatment for volatile organic compounds (VOCs) which entered into soil by irresponsible dumping or leaks in underground gasoline and oil reserves as well as landfills, are a primary example where bioremediation can take place (Kurisu and Yagi, 2010).

Microbial leaching used in biomining, is another process employing biofilms in the mining industry (Bellenberg et al., 2014). Precious metals are found in very small quantities mixed within rocks and dirt. Biofilms are used to extract the desired metals from the heterogeneous rock mixture, known as ore. Previous methods still frequently in use today, involve toxic and harmful acids to remove desired minerals and metals. The accumulated waste from this extraction process are known as tailings which cause environmental destruction to fresh water ecosystems, soil, and nearby vegetation. Biofilms are used for recovering metals such 
as copper, nickel, or zinc from low grade ore in a biooxidation process. Acidophilic mineraloxiding biofilms oxidize the ore and release water soluble minerals as a by-product which can be recovered from the water (Bellenberg et al., 2014).

Biofilms are also used in the treatment of both waste water as well as drinking water. In waste water, sewage is passed along tanks which are lined with biofilms in order to remove solubilized organic impurities (Andersson, 2009). Using aerobic activated sludge treatment processes, the biofilms supplied oxygen from an aeration tank and held within a bioreactor can degrade organic compounds. Bioreactors housing a specific consortium of microbes are being used in many aspects of biotechnology including the food and pharmaceutical industries as well as in the energy sector through the production of biofuels (Rosche et al., 2009).

Within water treatment, biofilms can be seen as either good news or bad news, depending on their location. Biofilms can pose health concerns when they are found in the DWDS and are therefore undesirable. Water passing through the pipes at a high velocity will slough off a few cells which adhere to the inner pipe wall surface. These cells then become planktonic and can eventually be consumed along with the water. The subsequent contamination of microorganisms in the effluent is known as biofouling. Conversely, biofilms entrenched within the biofilter are the functional workhorses of this filtration process (Cohen, 2001). Biofilms in biofilters are kept comfortable and metabolically active so as to enhance their growth and community diversity to promote for higher yields of nutrient uptake.

Intraspecific and interspecific relationships between the various species members of the microbial consortium are what make biofilms such effective mechanisms which can strip the water clean of organic micropollutants and excess nutrients (Wingender et al., 2010). Once a 
microorganism of a certain species has completed the breakdown of a specific molecule, its byproducts are metabolized and subsequently left for other organisms of a different species to feed on. Thus, breakdown of primary and secondary metabolites is effortlessly accomplished by the utilization of these mutualistic and commensalistic relationships (Wingender et al., 2010).

Drinking water treatment plants employ methodologies such as biofiltration as a means to remove nutrients. Biofiltration`s primary functions are through the utilization of biofilms. Biofilms are deposited onto the media bed by constantly passing the raw water (in this case the lake water) through the pilot scale system. Consequently, the media over time is inoculated with the microbial consortium which is representative of the epilithic biofilms of the benthic zone of the lake. These microbial communities would proliferate and naturally adapt due to the similar environments replicated in the biofilter media bed. These specific microbial biofilms attach to and grow on solid and partially submerged substrata.

Such biofilms are known to house algae which comprise up to $30 \%$ of the total biomass in addition to fungi and bacteria (Graba et al., 2014). The algae are a key factor because they influence diversity of a biofilm by providing themselves as a food source as well as adding to the structural integrity of the biofilm and allowing more locations for the microbes to physically latch on to. Epilithic biofilms are the predominant source of carbon cycling and are responsible for almost all primary production in oligotrophic lakes (Graba et al., 2014). The microbial consortium in these biofilms is also integral to secondary production, decomposition, and nutrient retention. These parameters, regulated by biofilms, are indicative of their central role as the essential life line of the aquatic ecosystem and vital to the food chain sustaining the aquatic community (Graba et al., 2014). 
Biofilm uptake of nutrients can happen through a variety of mechanisms and it is imperative that microorganisms in biofilms utilize these processes optimally to maximize nutrient removal efficiency. Microorganisms release enzymes for the acquisition of essential nutrients such as carbon, phosphorus and nitrogen (Lehto and Hill, 2013). These organic nutrients can be broken down with hydrolyzing enzymes such as glycosidases, phosphatases, and amino-peptidases respectively (Lehto and Hill, 2013). Quantifying this can often be done by measuring the rate of extracellular enzyme activity from the surrounding water and sediment of the biofilm, in order to determine the biological activity of the ecosystem (Lehto and Hill, 2013). An alternative approach, in which microorganisms attain the desired sustenance, is through the process of diffusion. Direct uptake is mostly for small inorganic forms of nitrogen and phosphorus along the concentration gradient through passive transport (Petroff et al., 2011). The nutrients are consumed at a rate which is proportionate with its concentration in the system based on concentration gradients. Measuring this nutrient uptake is possible using the reactiondiffusion model to see which microorganisms have the highest rate of nutrient uptake (Petroff et al., 2011). Finally active transport is also used in which molecules such as complex sugars, proteins, and ions are transported against the concentration gradient requiring energy. This include processes such as endocytosis, pinocytosis, and usage of the sodium potassium pump.

\subsection{Biofilter Media}

A system of filtration and monitoring currently on the rise takes into consideration the biological aspects of microbial community, nutrient absorption, and biological metabolic activity (Wingender et al., 2010). Using biofilters, a large quantity of contaminants comprising of excess nutrients and other dissolved compounds in the water, are picked up by a biological consortium. Therefore this prevents the harmful contaminants from being eluted into the final product 
prepared for consumption. Carbon is the base material used in both the filter media in this study. Carbon's reputation as a powerful absorbent is what sets it apart from other materials. Carbon also has immense surface area making it further enticing to use as the prime media filter. One gram of activated carbon has an estimated internal and external surface area of $500 \mathrm{~m}^{2}$ (Paul \& Jhadhav, 2010).

Factors affecting performance of carbon based filter media include the amount of carbon within the media (D. Scott, personal communication, September $\left.1^{\text {st }}, 2015\right)$. The more carbon within the filter the more absorptive capacity and therefore the higher the uptake of contaminants and nutrients via physico-chemical processes. In addition, the contact time between the contaminants and filter media is an important factor. The amount of time that the water is in contact with the filter media is a crucial parameter that plays a role in nutrient removal; this parameter is heavily dependent on flow rate. Therefore lower flow rates allow for longer periods of contact and have more absorption taking place; this variable is measured as empty bed contact time (EBCT). EBCT can be calculated by dividing the volume of the empty bed by the flow rate of water. EBCT becomes of particular importance when it comes to looking at surrogate parameters such as AOC and BDOC is also influenced by filter bed depth and media grain size (amount of surface area). Currently, the pilot is operating with a flow rate through the biofilter of 1.2 $\mathrm{L} / \mathrm{min}$. Therefore, the EBCT is 26 minutes in these filters (D. Scott, personal communication, May $\left.19^{\text {th }}, 2015\right)$.

Biofilters are very effective at lowering biological oxygen demand (BOD) and total organic carbon (TOC) (Chaudhary et al., 2003). Both of these factors play a major role in facilitating microbial growth when they are in optimal concentrations. The biofilms latched onto the biofilter media, help clean the water, ridding it of any excess organic molecular biomass 
which they use in order to survive. There are a few different types of biofilter media beds which serve as the primary sites for biofilm attachment. Some of the common used biofilter media are known as GAC, BAC (biological activated carbon), and anthracite.

One of the main materials used in the formation of GAC is coal, almost entirely formed of carbon. Other organic materials such as coconut shells and wood are also used and then subsequently crushed into small granules (Cochran, 2008). GAC is essentially a material which provides a habitat for microbial communities and given its highly rugged, porous nature, provides for increased housing of these microbes due to its ample surface area (Chaudhary et al., 2003) (Figure 2.3). GAC is taken from lower grades of coal such as bituminous and lignite coal.

GAC's micropores which span 1-100nm are too small for microorganisms. Typically a prokaryote such as E. coli is $2 \mu \mathrm{m}$ and therefore too large to reside in the micropores (Kubitschek, 1990). However, GAC's central advantage lies with its macroporous structure and highly irregular surface, enabling microorganisms to penetrate and inhabit (Figure 2.3). Consequently, this biofilter medium provides increased sites that are suitable for biomass attachment (Chaudhary et al., 2003). The rough exterior additionally provides more protection to the microbial colonies from forces and pressure (such as currents and filter draining) preventing shear loss of biomass. GAC`s rough exterior offers for higher surface area and allows for molecular adsorption of organics (Chaudhary et al., 2003). The rough surface gives rise to what are known as activated sites. The activated sites capture organic molecules and provide a "workbench" for the bacteria to biodegrade and uptake the sorbed nutrients and organics more effectively (D. Scott, personal communication, October $22^{\text {nd }}, 2015$ ). Once the organic molecule has been biodegraded, the activated site is clear in preparation for the next organic molecule. Oxygen is depleted from these sites making them suitable for facultative anaerobes to continue 
further breakdown of incoming organics. This concept of continuous break down is known as bioregeneration, and allows GAC to continue to function even after the absorptive capacity is spent (Chaudhary et al., 2003). The rugged texture of the mesoporous surface was also seen to enhance biomass attachment as well as serve to reduce the sloughing off of microbial colonies (Wang et al., 1995).

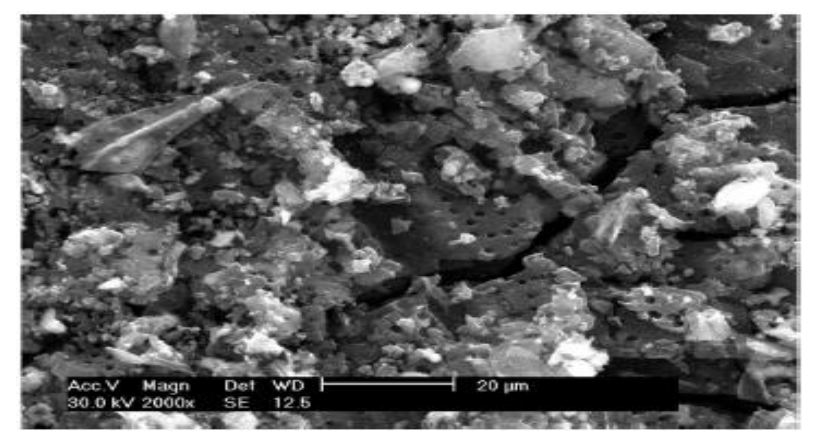

Figure 2.3: Scanning Electron Micrograph of activated carbon. Physical morphology of the irregular porous surface and external macropores. Image adopted from Wang et al, 2013.

GAC`s competitive edge on the other two filter media is its performance on reduction in oxygen levels as well as with BDOC (Thiel et al., 2006). Moreover, when considering a media for the purpose of water filtration, GAC's molecular adsorptive qualities further attribute to its exemplary performance in producing low-nutrient filtrate. Because of this, the rate of flow is representative of the uptake of particulate matter. Therefore, due to GAC's effectiveness in adsorption, it is primarily used for filtration at the molecular level (Chaudhary et al., 2003). GAC's adsorptive nature and positive charge, grants it a heightened catchment ability, removing negatively charged particles. Consequently, this reduces the amount of chlorine in the effluent, leading to less trihalomethane (THM) formation. THM's, are environmental pollutants and may have adverse health effects (Thiel et al., 2006). Adsorption can bond many compounds such as chlorine, carbon, organics, and ozone (Cochran, 2008). DBPs (disinfectant by-products) are molecules formed when natural organic matter (NOM) reacts with disinfectants agents such as 
chlorine and chloramine. These two agents in particular are used in water treatment due to their strong oxidation ability which destroys microbes but maintain the disinfection by remaining as residual in the DWDS to reach the residents and consumers safe from contamination. GAC's ability to remove precursors of DBPs such as TOC (which are part of the NOM found in raw water) is very important. By lowering TOC levels, the EPA stage II regulations are met, which are guidelines to lowering DBPs (Cochran, 2008). Some of the most prevalent DBPs include THMs, haloacetic acids (HAAs), and chlorite.

There is one drawback to GAC's cleaning process. Since it has been specially designed and processed for molecular adsorption, the particulate matter taken up is not easily stripped from it and therefore, backwashing does not provide the full solution to cleaning this media. Consequently, this adsorptive capacity is what leads the media to saturation, putting the GAC life expectancy at generally under a year (approximately 10 months) but with proper maintenance such as frequent backwashing, it can be extended to 2 - 5 years (Gillogly et al., 1999). In addition, GAC is a very expensive biofilter media and this cost will be incurred often to replenish the overloaded media. The average price of GAC is approximately $\$ 3,300.00$ per metric tonne. However, this price is subject to change depending on the supplier, quantity ordered, packaging, and freight charges (S. Wildey, personal communication, August $4^{\text {th }}, 2015$ ).

BAC is a biofilter which uses pre-ozonation methods in conjunction with the GAC material. This pre-ozonation treatment enhanced the biodegradability of the pre-existing GAC by increasing biological activity. The wide spread use of ozone as a disinfectant is a novel implementation on the rise. This disinfectant has begun to replace other disinfectants due to concerns that re-growth is a prevalent issue within the distribution system. A pre-ozonation step assures that the biodegradability of refractory organic matter is greatly improved (Li et al., 
2010). The benefits of utilizing BAC extend to the increased biological activity allowing for the removal of a significant amount of dissolved organic carbon (DOC).

Anthracite is also a form of biofilter media which is also a derivative of high-carbon coal. Anthracite is very porous and therefore has an extensively large surface area for a residing biological community. Anthracite has micropores which are too small for molecular particulate matter to pass through. Consequently, this inhibits anthracite's uptake potential compared to GAC adsorption of chemicals and small particulates of organic matter suspended throughout the column (Chaudhary et al., 2003). Therefore, anthracite functions more through mechanical filtration and biological activity. Anthracite may minimally remove particulate matter through adsorption of the water it comes in contact with, but only at the surface level due to the lack of diffusion into the pores. Often this adsorbed particulate matter however is easily removed during a backwash. Because Anthracite has little to no adsorptive capabilities and it is a harder substance, its life expectancy is greatly improved and with proper maintenance, can last up to 40 years (D. Scott, personal communication, September $\left.1^{\text {st }}, 2015\right)$.

Anthracite is a common component of slow sand filter systems and can be cleaned using the backwashing method (Chaudhary et al., 2003). Anthracite is a much cheaper alternative than its counterpart and it only costs $\$ 900.00$ per metric tonne (S. Wildey, personal communication, August $\left.4^{\text {th }}, 2015\right)$. Most of the industry to produce both of these filter media is based out of mainland China. There are a few local suppliers in Canada such as in Brantford, Ontario as well as some in the United States. However, if the supplier is from a foreign country, currency and taxes on imports will play a role in addition to shipping costs. 


\subsection{COMSTAT Variable Measurements}

Image analysis using COMSAT assessed different parameters of the biofilm on the filter media, all of which are measured using different algorithms or equations. The biofilm parameters examined were relevant to structure and included biovolume (biomass), average thickness, surface to volume ratio (surface coverage), and roughness. These are all important constituents of a biofilm that dictate a biofilm's age, composition, and proliferation. Biomass represented by the overall volume of the biofilm, or as bio-volume, can be defined as the summation of pixels representing organic matter in all compiled slices of an image stack. It is measured by multiplying the biomass pixels with voxel size $\left[(\text { pixel size })_{x} \mathrm{x}(\text { pixel size })_{y} \mathrm{x}(\text { pixel size })_{z}\right]$ and divided by the substratum area of the entire image stack (Heydorn et al., 2000). The unit of measure for this variable is $\mu \mathrm{m}^{3} / \mu \mathrm{m}^{2}$. The resultant is an approximation of biomass or the volume of the biofilm residing in the given image stack (Heydorn et al., 2000).

The next variable assessed was average thickness. This can be defined as the maximum thickness (height measured in $\mu \mathrm{m}$ ), over a given area excluding pores and voids within the biofilm. Mean thickness is measured by locating the highest point (in $\mu \mathrm{m}$ ) above each pixel (representative of biomass), in a 2-D orientation ( $\mathrm{x}$ and $\mathrm{y}$ axis), within the bottom layer of the biomass (lowest point of each stack) (Heydorn et al., 2000). This parameter can be used as a function to calculate many other biofilm components biofilm roughness and mean biofilm thickness. Average thickness is measured in units of $\mu \mathrm{m}$ (Heydorn et al., 2000).

The roughness variable is derived from the thickness distribution, a variable calculated during the acquisition of the mean thickness (Heydorn et al., 2000). This variable is actually 
identified as the roughness coefficient of a biofilm and is calculated using the following equation;

$$
\mathrm{R}^{*} \alpha=\frac{1}{N} \sum_{i=1}^{N}\left(\frac{\left|\mathrm{L}_{\mathrm{fi}}-\mathrm{L}_{\mathrm{f}}\right|}{L_{f}}\right)
$$

In this equation $\mathrm{L}_{\mathrm{fi}}$ denotes the specific thickness measurement of the stack and $\mathrm{L}_{\mathrm{f}}$ is the mean thickness, while $\mathrm{N}$ is the total number of thickness measurements. Biofilm roughness coefficient is a good indicator for structural heterogeneity. Higher values for roughness coefficient represent a more heterogeneous surface. Additionally, roughness coefficient shows how variable the biofilm thickness is (Heydorn et al., 2000).

The last parameter assessed was surface coverage, measured in units of $\mu \mathrm{m}^{2} / \mu \mathrm{m}^{3}$. The surface of a biofilm is defined as the number of pixels which have one or more background pixels adjacent to them (Heydorn et al., 2000). In order to attain surface area coverage, the ratio of biomass to area, occupying each stack of every image, must be compiled. COMSTAT labels all bordering sides as biomass with the exception of the top side, which is considered as background. This exclusion is done to take into consideration only surfaces exposed to nutrient flow (in this case the water coming in contact with biofilm) as part of the surface coverage variable. To calculate surface coverage, a box encompassing the desired location, known as the voxel, assesses all three axes and incorporates the dimensions (pixel size) $x$ (pixel size) $)_{y} \mathrm{x}(\mathrm{pixel}$ size $)_{z}$ (Heydorn et al., 2000). Thus, the surface of the biofilm is then identified as the entire summation of all biomass voxels which are exposed to the background. The unit of measure for this variable is $\mu \mathrm{m}^{2} / \mu \mathrm{m}^{3}$. Finally, when using COMSTAT, connected volume filtration of the image stacks was disabled. This function only interprets biomass above the set threshold which has pixilation directly connecting it to the substratum thereby filtering out background noise 
(Heydorn et al., 2000). The problem with this is that the biofilm residing on such a heterogeneous surface and with the presence of microcolonies may not all have parts of it directly rooted to the substratum. Therefore, by deselecting this default option, but increasing the threshold, it allows for all biomass to be accounted for while also removing unwanted noise due to the elevated threshold. 


\section{Chapter Three: Methods and Materials}

\subsection{Sample Retrieval}

Samples were taken from the pilot plant located within the R.C. Harris DWTP at 2701 Queen St E, Toronto, ON M4E 1H4, transported to the lab in a cooler and stored at $4^{\circ} \mathrm{C}$ until further processing. The following samples were collected: (i) raw water, (ii) deozonated water, (iii) effluent GAC before backwash, (iv) effluent GAC backwash, (v) effluent anthracite before backwash, (vi) effluent anthracite backwash, (vii) GAC before backwash media, (viii) media GAC backwash, (ix) media anthracite before backwash, (x) media anthracite backwash. The retrieval of samples incorporated aseptic techniques to ensure no cross contamination between anthracite and GAC filters took place. Filtered effluent was taken from both filter columns (Figure 2.2). A small tap at the base of the filter columns was let run for approximately 15 seconds followed by placing a sterile glass bottle underneath to accumulate a volume of $1 \mathrm{~L}$. This was done for both GAC and anthracite filter columns. Following this, a backwash was performed. It is important to note that backwashing was done with unchlorinated water. After obtaining the filter effluent samples, both column filters were drained leaving the filter columns and media bed dry. A sample port was opened allowing approximately $50 \mathrm{~g}$ of filter media to be removed and placed in a small sterile container. Subsequently, the sample ports were resealed, the appropriate valves were turned, and filter backwashing was initiated. Backwashing forced previously filtered water upwards through the filter media "fluidizing" or resuspending all the media. The same procedure for effluent was then carried out again only this time backwash water was collected. 
Biofilm media samples were extracted from biofilter columns approximately two thirds of the way up by unscrewing a valve and subsequently shoveling approximately 50 grams of filter media into sterile tubes. The tubes and bottles were then appropriately labeled based on the sample they were holding. Finally untreated raw water was collected from a tap connected to the reservoir and the temperature was recorded. The samples were stored on ice as they were transported back to the labs where they were kept at $4^{\circ} \mathrm{C}$.

\subsection{Heterotrophic Plate Counts}

R2A agar (VWR, Mississauga, ON) was prepared and plates were subsequently made. A dilution series using raw water, deozonated water, and the effluent samples was carried out where $1 \mathrm{~mL}$ of the effluent sample was sequentially transferred through six $10 \mathrm{~mL}$ Falcon Tubes (Cedarlane, Burlington, ON) containing $9 \mathrm{~mL}$ of $0.9 \%$ saline. Following this, $0.1 \mathrm{~mL}$ of respective tube was then plated on plate with R2A media. The plates were then let to incubate at room temperature for 5 days. Lastly, the formed colonies were counted on the plates and the Colony Forming Unit equation was used to derive how many bacterial cells were present per millilitre. This experiment was repeated and carried out in triplicates.

\subsection{DNA Amplification and Sequencing}

Water and media samples were plated on minimal agar R2A and incubated for five days. Microbial colonies were re-streaked on R2A media to attain pure cultures. DNA was extracted from pure cultures of the raw water, deozonated, and effluent samples using the Zymo Soil DNA Extraction Kit (Cedarlane, Burlington, ON) following the manufacturers protocol. The genomic DNA was then kept at $-20^{\circ} \mathrm{C}$ until further analysis. 
The extracted DNA subsequently underwent polymerase chain reaction (PCR) to amplify a 418 base pair fragment of the $16 \mathrm{~S}$ rRNA. Both forward and reverse primers were synthesized and purchased from New England BioLabs in Pickering ON. The forward primer used was U341F ( $5^{\circ-}$-CCTACGGGAGGCAGCAG-3") and the reverse primer used was U758R (5"e-CTACCAGGGTATCTAATCC-3" ${ }^{\text {ec }}$ (Muyzer et al., 1993). The protocol followed required $27.875 \mu \mathrm{L}$ of MilliQ water, $25 \mathrm{pmol}$ of both forward and reverse primers, $200 \mu \mathrm{M}$ of each of the four (ATP, CTP, TTP, GTP) dNTPs (New England BioLabs, Pickering, ON), $0.6875 \mu \mathrm{L}$ of 10 mM BSA (New England BioLabs, Pickering, ON), and 2.5 units of Taq DNA Polymerase in 1X Taq buffer for every sample (New England BioLabs, Pickering, ON). The $50 \mu \mathrm{L}$ samples were then placed in the thermocycler and a series of temperature specific steps followed through in which denaturing and annealing of the DNA with its respective reagents reoccurred over a three hour time period. The process initially began with an initialization step at $96^{\circ} \mathrm{C}$ for $5 \mathrm{~min}$ followed by 20 denaturing cycles at $94^{\circ} \mathrm{C}$ for $1 \mathrm{~min}$, an annealing step at $65^{\circ} \mathrm{C}$ for $1 \mathrm{~min}$, and an elongation step for $3 \mathrm{~min}$ at $72^{\circ} \mathrm{C}$. The temperature subsequently decreased by $1^{\circ} \mathrm{C}$ every cycle for the first 10 cycles and remained at a constant temperature of $55^{\circ} \mathrm{C}$ for the remaining cycles, which numbered 20 cycles in total. Samples were then kept at $4^{\circ} \mathrm{C}$ until ready for further processing (Yeung et al., 2010).

In order to confirm successful DNA amplification, samples were run on a $1 \%$ agarose gel using the DNA stain Red Safe (Froggabio, North York, ON) as well as DNA loading dye (Froggabio, North York, ON) and the DNA Ladder (Froggabio, North York, ON). The gel was then imaged and the PCR products were quantified using a standard curve along with the three 100 base pair DNA ladder dilutions. 
Upon successful DNA amplification, samples were submitted for sequencing to SickKids Centre for Applied Genomic, TCGA, synthesis facility in Toronto, ON. Finally, the retrieved sequences were entered into the NCBI BLAST application to determine the respective microbial identities by comparative sequence analysis.

\subsection{Confocal Laser Scanning Microscopy}

Confocal images have been taken to assess both qualitative and quantitative parameters of the biofilm during summer and winter seasons on both GAC and anthracite filter media. These images were also taken before and after a backwashing in order to analyze the effect of biomass reduction due to shear force. Winter and summer biofilm sampling sessions for imaging, took place throughout the year of 2015. The winter sampling of the filter media took place on January $22^{\text {nd }}$ when the temperature average of the water, for that week, was $3.1^{\circ} \mathrm{C}$. The summer sampling of the filter media took place on August $31^{\text {st }}$ when the temperature average of the water, for that week, was $15.3^{\circ} \mathrm{C}$.

Imaging of biofilm attachment on different biofilter media were acquired in-situ with a Nikon Eclipse 80i-C1 confocal laser scanning microscope (Nikon Instruments Inc., Melville, NY). First a sample of media (a few granules of GAC or anthracite with biofilm attached) was stained with Syto 9, a general nucleic acid stain. Originally 3.34 mM Syto 9 (Invitrogen Canada Inc., Burlington, $\mathrm{ON}$ ) was prepared by diluting $20 \mu \mathrm{L}$ of stain with $980 \mu \mathrm{L}$ of distilled water. The stained sample was then incubated under dark conditions at room temperature for 15 minutes and subsequently washed lightly with distilled water for 30 seconds. The software application EZ-C1, was used for altering settings and image acquisition in conjunction with the NIS-Elements software application (Nikon Instruments Inc., Melville, NY) that was employed for image processing. The $488 \mathrm{~nm}$ green laser was used for excitation of the Syto 9 (excitation 
between 485-498nm). Syto 9 is a green fluorescent nucleic acid stain which stained viable and nonviable cells, Gram negatives and Gram positives, and prokaryotic and eukaryotic cells. A 40X dry objective lens was used to generate images were captured by sampling at random positions across the respective filter media.

Microscope settings were kept consistent between different samples as best as possible to reduce bias results. Distance and resolution variables were kept within similar and comparable values. Distance between $x-y$ sections within stacks was kept between $0.4 \mu \mathrm{m}-0.5 \mu \mathrm{m}$ while image resolution was 512 X 512 pixels. The brightness intensity was kept between 7 or 8 out of 10 and the pinhole size was selected to medium for all images taken. Finally, image stack size and depth were standardized by keeping them within a range of 120 - 200 x-y sections per stack, which resulted in a final depth of 50 to $80 \mu \mathrm{m}$.

\subsection{Image Analysis}

The image's many stacks were all converted to grey scale tagged image files (TIF) by the application Irfanview (Version 4.35, www.irfanview.com). Following this, the image analysis software COMSTAT in MatLab (Version 8.1, MatLab R2013a) (The MathWorks, Natick, MA) was utilized to quantify specific parameters of biofilm growth from the image by allowing the user to set a threshold on the brightness and intensity of the image. COMSTAT processed qualitative data and converted it into quantitative values by implementing a binary system to interpret the pixilation and brightness intensity of the image as biomass to measure the structural components of the biofilm. Quantitative data was kept consistent and therefore comparable by keeping variables such as the threshold same. The threshold intensity values were all kept at very similar range (25-30) reducing biased interpretation. COMSTAT allowed for quantification of 
various structural components of the biofilm. In this study, biofilm biovolume $\left(\mu \mathrm{m}^{3} / \mu \mathrm{m}^{2}\right)$, average thickness $(\mu \mathrm{m})$, roughness coefficient (a dimensionless variable), and surface to volume

ratio $\left(\mu \mathrm{m}^{2} / \mu \mathrm{m}^{3}\right)$, were determined for all biofilm samples investigated. Due to the heterogeneous nature of the biofilms under investigation, the connected volume filtration function between stacks, was disabled. Image analysis was carried out on the raw images prior to their alteration. Finally brightness and contrast of all images was enhanced for clarity.

\subsection{Statistical Analysis}

ANOVA was run to determine if there is a significant statistical difference between two or more treatment groups. The p-value was set a 0.05 . A three way analysis of variance was conducted with the independent factors of season, media type and backwashing with dependent variables such as biovolume, average thickness, roughness, and surface to volume ratio. The interactions between the independent factors was also taken into consideration with these tests.

Analysis on residuals was performed for two reasons; the first was to determine if the residuals had a normal distribution. The second was to find if there was a systematic pattern between model predicted of a dependent variable and variance in residuals. If there was an indication of either of these two, transformation of the variance was carried out. If the residual values increased with predicted mean, a log transformation was done. If the residual values decreased with predicted mean, a power transformation was done. 


\section{Chapter Four: Results}

\subsection{Heterotrophic Plate Counts}

Water samples consisting of raw water, deozonated, and effluent from biofiltration units before and after a backwash, were plated in triplicate on R2A media (Figure 4.1).

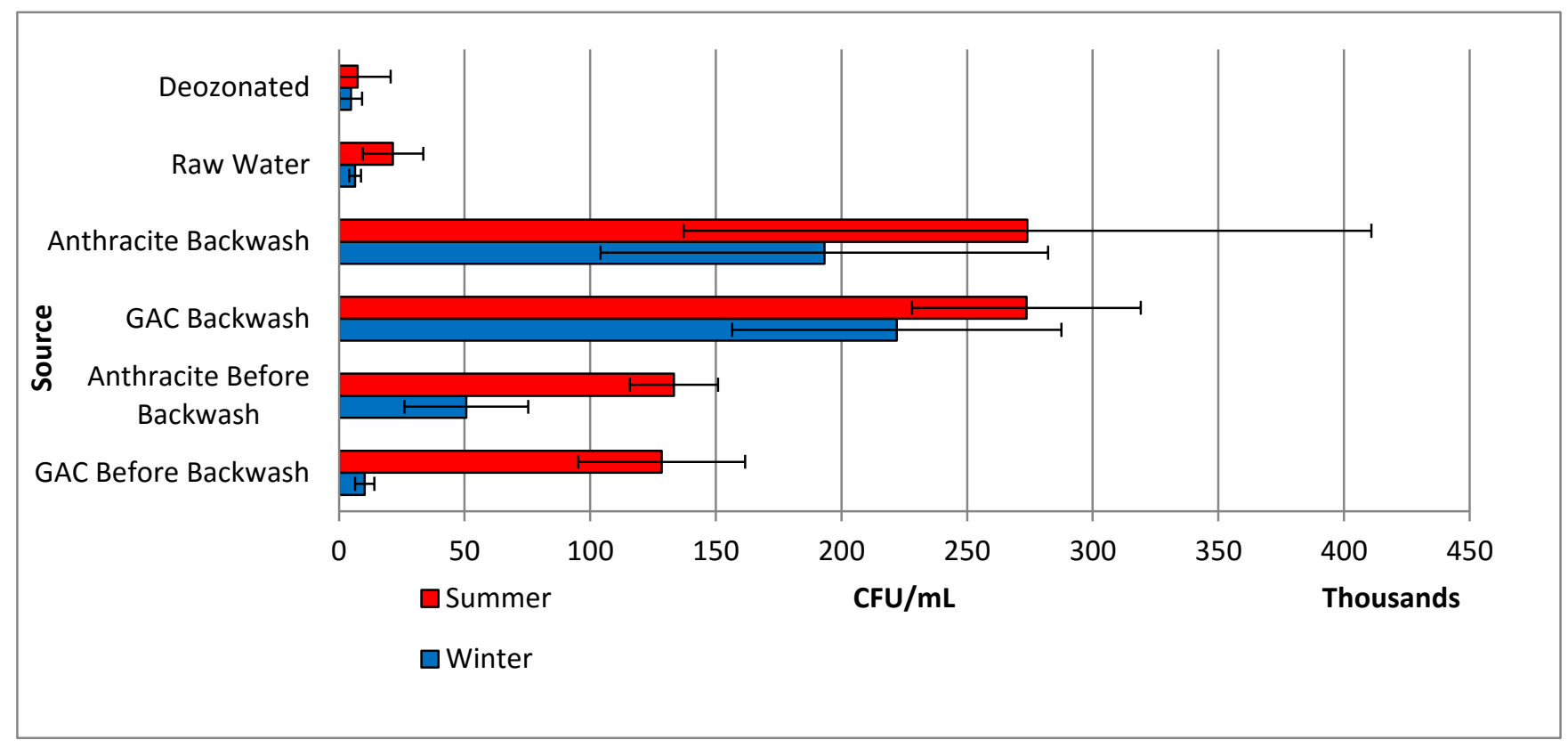

Figure 4.1: HPC of water samples from the pilot plant. i.e. the two biofilter media before and after backwash as well as raw and deozonated water.

Summer samples gave a higher colony count than winter samples for all cultures.

Effluents collected from anthracite biofilters before backwashing, gave higher HPCs than those collected from GAC biofilters, before a backwash for the winter samples, by one whole order of magnitude. Interestingly, both anthracite and GAC seem to have similar HPCs after a backwash event for both summer and winter seasons. 


\subsection{Microbial Diversity Based on Class}

DNA sequencing from colonies isolated on R2A agar allowed distinction between the summer and winter microbial communities (Figure 4.2). The winter sampling set taken on February $11^{\text {th }}$ of 2014 was shown to have a diverse collection of microorganisms. When the samples were taken, the temperature of the water in the constant head tank (Figure 2.2), from within the pilot plant, was $4.2^{\circ} \mathrm{C}$.

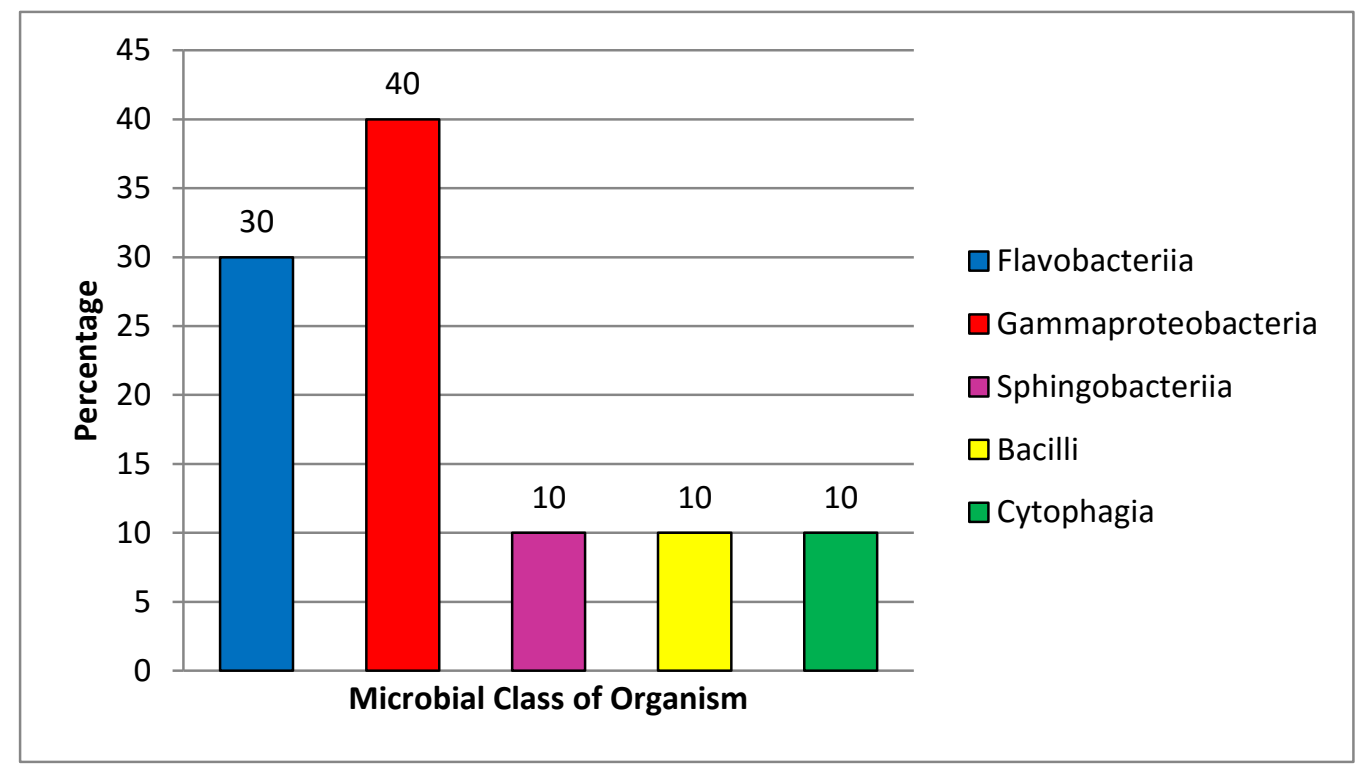

Figure 4.2: Winter 2014 pilot plant water distribution of phylogenetic diversity based on microbial class.

The water temperature is slightly warmer from the pilot than from when it is first taken up through the intake pipe however not by more than 1-2 degrees Celsius. The winter consortium had 5 dominant classes of microorganisms present in the samples. The five classes of phylogeny consisted of Flavobacteriia, Gammaproteobacteria, Sphinobacteriia, Bacilli, and Cytophagia. The phyla the microgoransisms belonged to were Proteobacteria, Firmicutes, and Bacteriodetes. The majority of microorganisms belonged to the class of Gammaproteobacteria with almost half of them falling into this category. Thirty percent of the isolates belonged to the class 
Flavobacteriia, while the other three classes held a significant minority of $10 \%$ with the same number of representatives for each (Figure 4.2).

The summer sampling set was obtained on August $27^{\text {th }}$ of 2014 . At the time of sampling, the temperature measured was $19.6^{\circ} \mathrm{C}$ in the constant head tank, within the pilot. Upon successful sequencing the microbial community fingerprints were identified. Only two phylogentic classes were identified for the summer sampling set; Alphaproteobacteria and Betaproteobacteria (Figure 4.3).

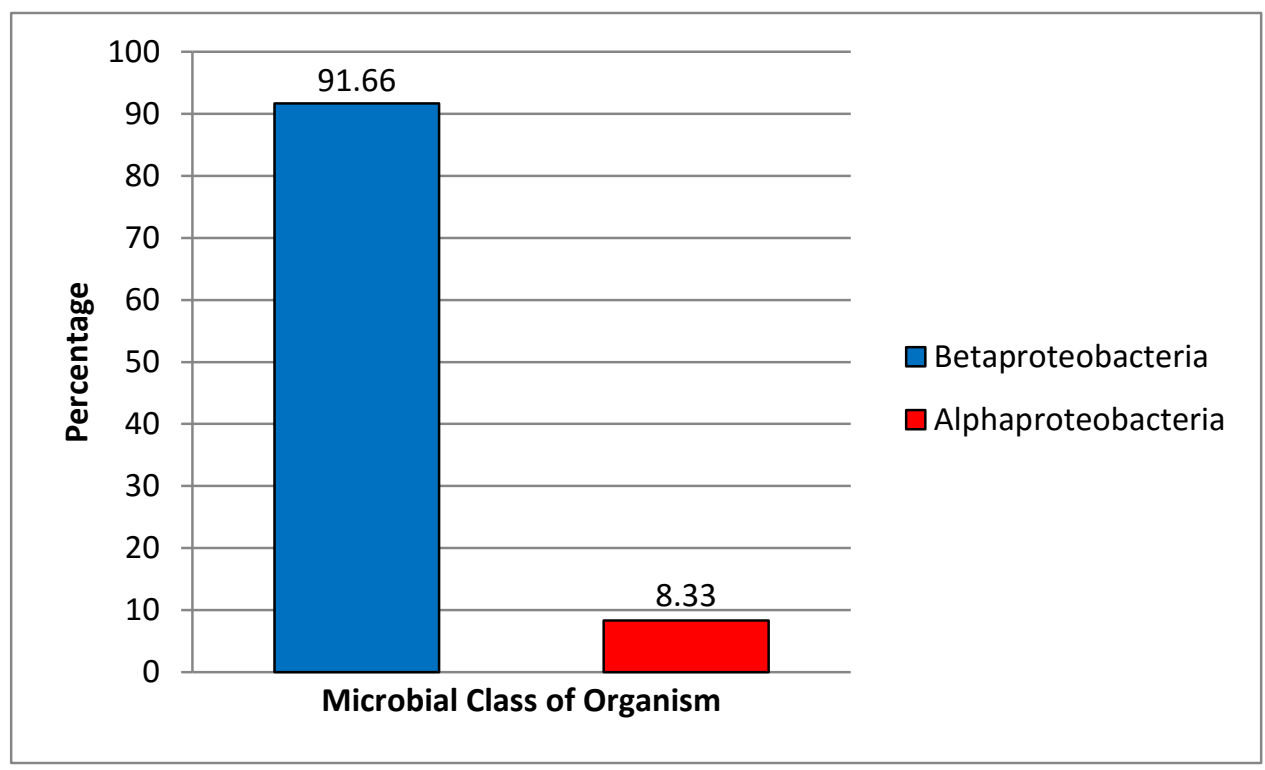

Figure 4.3: Summer 2014 pilot plant water distribution of phylogenetic diversity based on microbial class.

These microorganisms both belong to the Phylum Proteobacteria. The microorganisms identified showed an extreme bias to the Betaproteobacteria with over $90 \%$ of the specimens representing this class. Alphaproteobacteria was the only other class identified and it held only a small representative of the total. 


\subsection{Confocal Laser Scanning Microscopy}

Figure A3.1 and Figure A3.2 in Appendix 3 show stack images of the filter media without staining. This can be used as a control to gain an understanding for how much autofluorescence the particular sample emits, in order to see how much true biomass is in the sample and take into consideration any background noise. A total of eight different kind of samples were imaged; (i) anthracite before backwash winter, (ii) anthracite after backwash winter, (iii) GAC before backwash winter, (iv) GAC after a backwash winter, (v) anthracite before backwash summer, (vi) anthracite after backwash summer, (vii) GAC before backwash summer, (viii) GAC after a backwash summer.

\section{Winter 2015 CLSM Images}

Figures 4.4a and 4.4b show biofilm on anthracite filter media before a backwash event but were samples taken on different granules. Figures $4.4 \mathrm{a}$ and $4.4 \mathrm{~b}$ are of the same type of sample (winter anthracite before backwash), however they were taken from different granules.
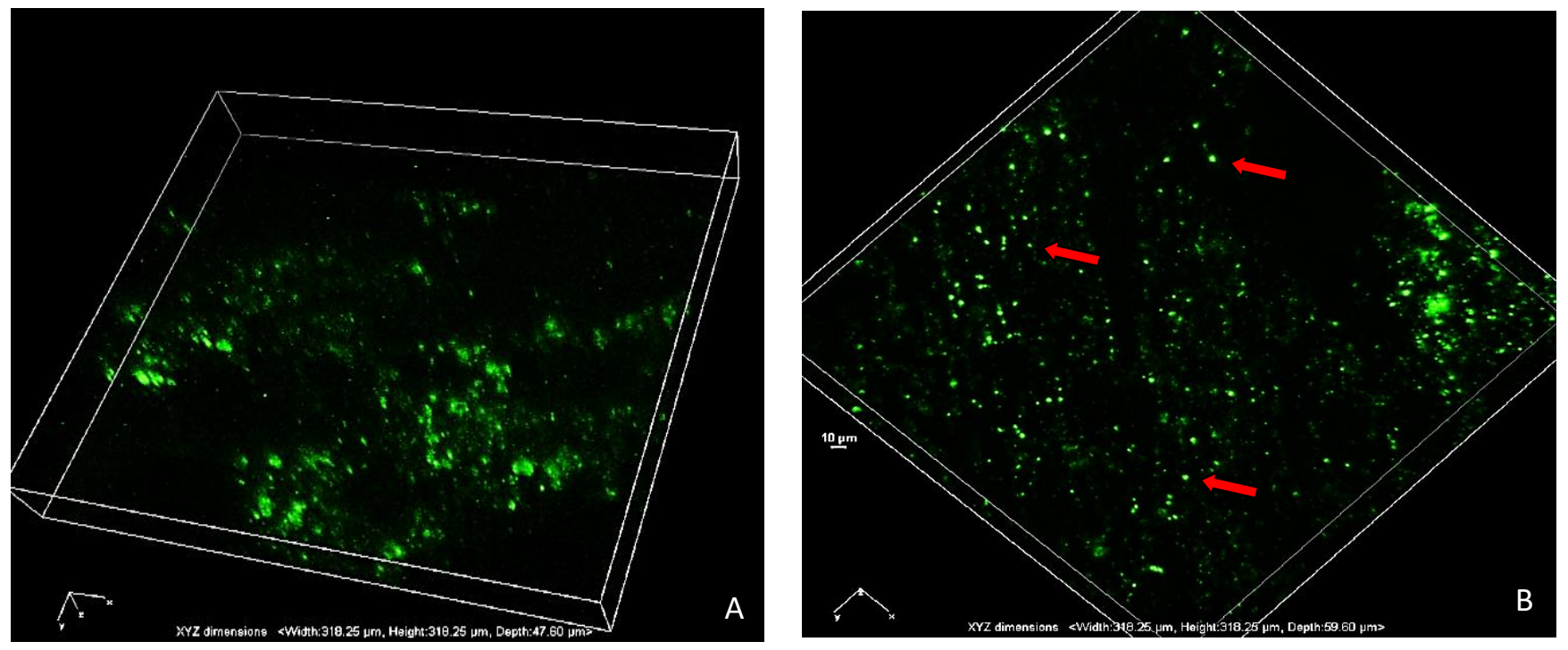

Figure 4.4a \& 4.4b: CLSM image of granule media sample during winter 2015 of anthracite before backwash using $40 \mathrm{X}$ objective and excitation of $488 \mathrm{~nm}$ laser 
The green coloration indicates biomass and the stain revealed the cellular morphology of a coccoid shape, indicated by the red arrows (Figure 4.4b). In addition, the biofilm appeared to be compact and dense. Figure $4.4 \mathrm{~b}$ has concentrated growth with many well defined individual cells or clusters of microbes separated from one another. A total of 6 different image stacks were taken, each from different media granules for this sample in 2015.

Figures $4.5 \mathrm{a}$ and $4.5 \mathrm{~b}$ depict the biofilm structure after a backwashing event, with both of these samples imaged from different granules. Figures $4.5 \mathrm{a}$ and $4.5 \mathrm{~b}$ are of the same type of sample (winter anthracite post backwash), however they were taken from different granules.
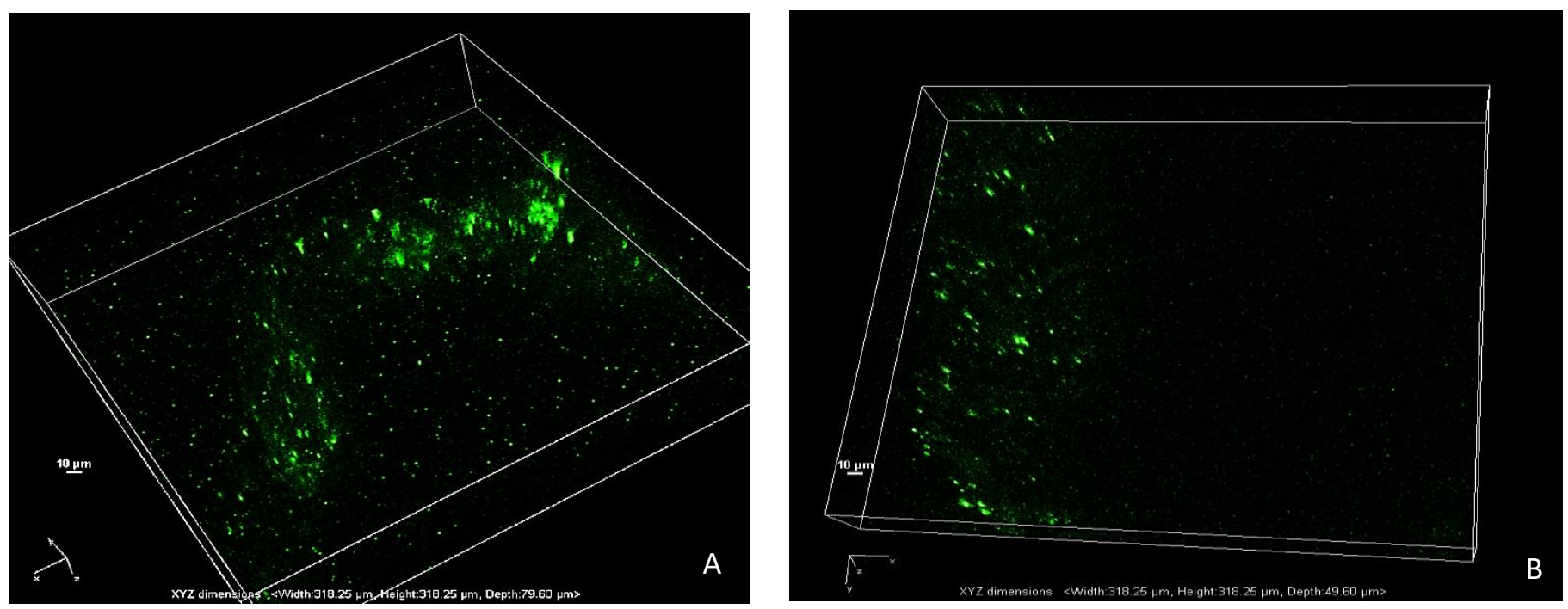

Figure 4.5a \& 4.5b: CLSM image of granule media sample during winter 2015 of anthracite after backwash using $40 \mathrm{X}$ objective and excitation of $488 \mathrm{~nm}$ laser

The above images qualitatively show a reduction in biomass levels and individual cells that were sparsely distributed. This biofilm was less compact and had less biofilm coverage when compared qualitatively to before a backwashing as in Figures 4.4a and 4.4b. Upon further visual assessment, biofilm architecture lacked confluent growth with many regions of darkness indicating absence of biomass. A decrease in the "fluffy" texture possibly indicated a reduction 
in EPS. A total of 7 different image stacks, each derived from separate media granules, were taken for this sample in 2015.

Figures $4.6 \mathrm{a}$ and $4.6 \mathrm{~b}$ show the biofilm residing on GAC filter media before a backwashing event. Figures $4.6 \mathrm{a}$ and $4.6 \mathrm{~b}$ are of the same type of sample (winter GAC before backwash), however they were taken from different granules.
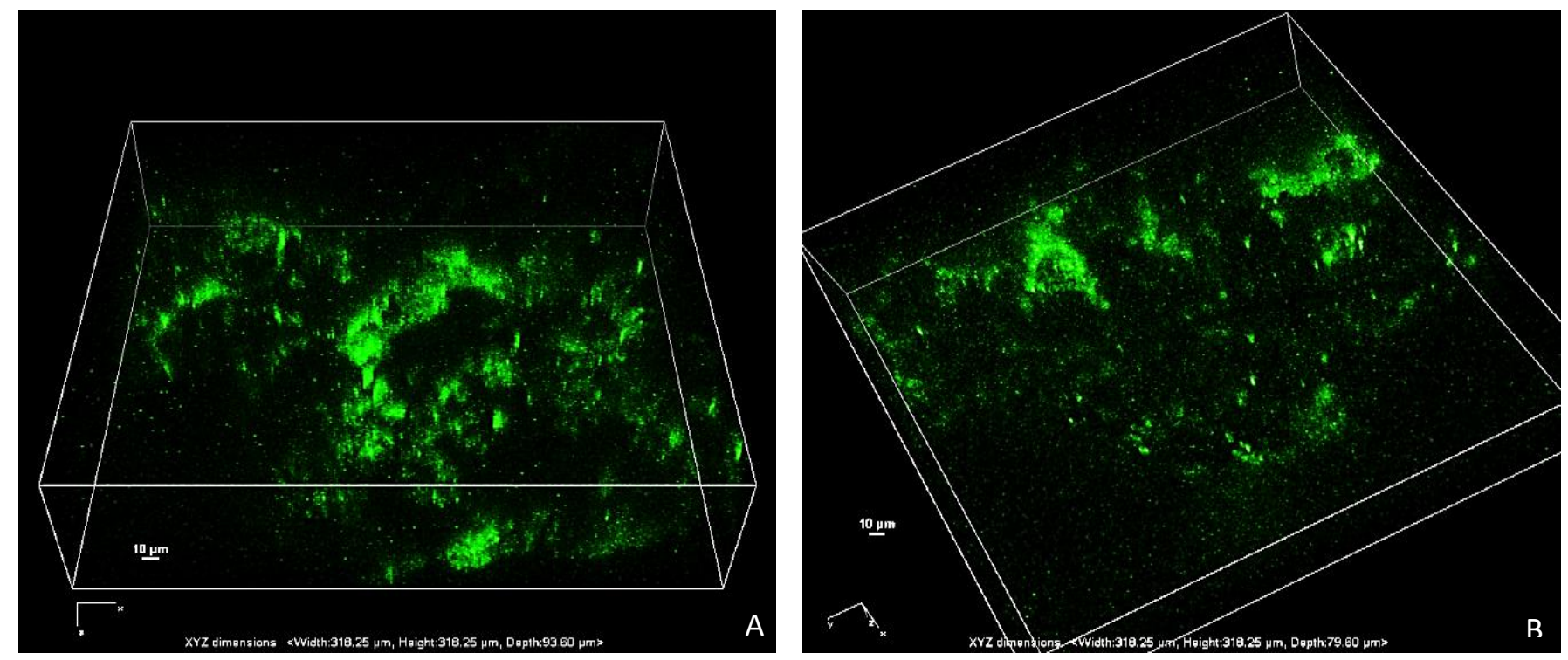

Figure 4.6a \& 4.6b: CLSM image of granule media sample during winter 2015 of GAC before backwash using 40X objective and excitation of 488nm laser

Both of these images were acquired from different granules. The brightness intensity from the stain indicated a large amount of biomass (Figure 4.6a). The fluffy appearance possibly attributes to the presence of EPS. Figure 4.6a showed a more fluffy structure indicating that some of the stained DNA may possibly be located within EPS. The biofilm structure appeared dense and thick with only few regions of low biofilm coverage. A total of 7 different image stacks were taken for this sample in 2015. 
Figures $4.7 \mathrm{a}$ and $4.7 \mathrm{~b}$ show the remnants of a biofilm after a backwashing event on the GAC, taken from different media granules. Figures $4.7 \mathrm{a}$ and $4.7 \mathrm{~b}$ are of the same type of sample (winter GAC post backwash), however they were taken from different granules.
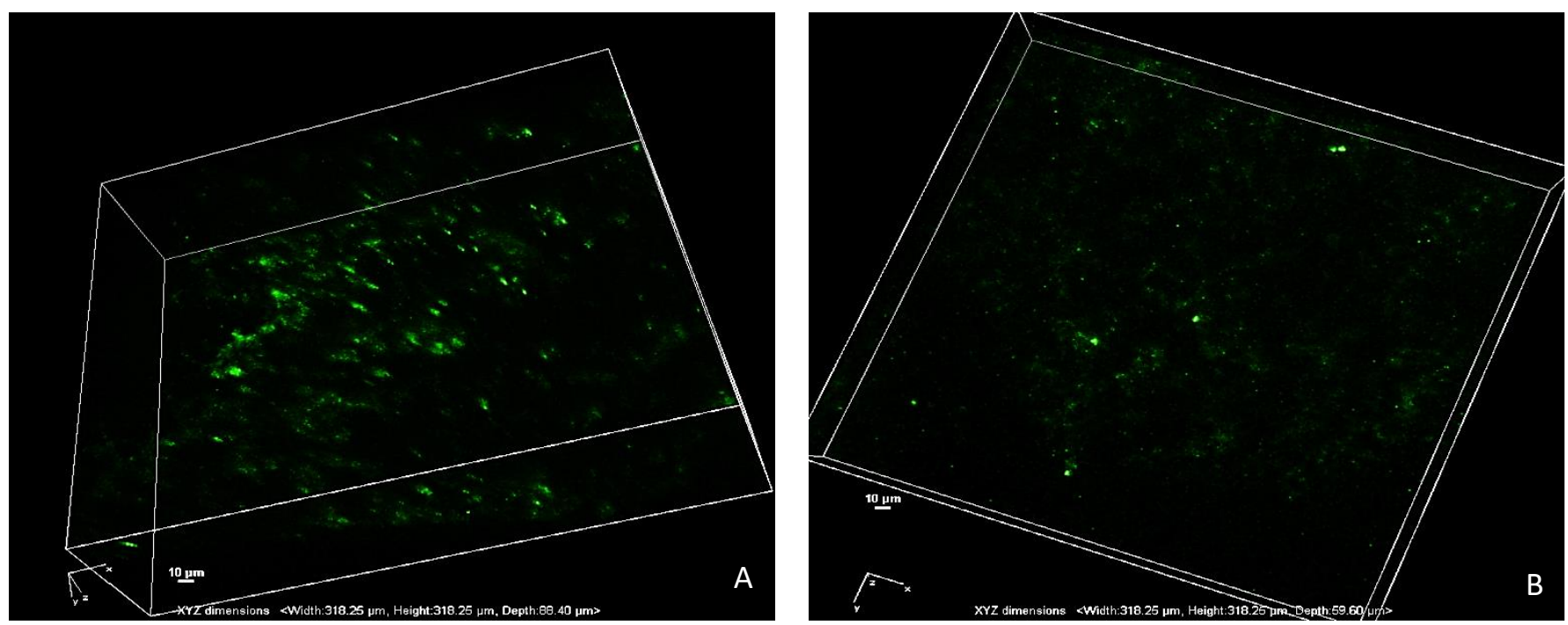

Figure 4.7a \& 4.7b: CLSM image of granule media sample during winter 2015 of GAC after backwash using 40X objective and excitation of $488 \mathrm{~nm}$ laser

The large regions of darkness and drop in brightness and intensity are indicative of absence of biomass. Decreased fluffy texture yielded distinguishable cell morphology (Figure 4.7b) correlating to a reduction of EPS. The backwashing drastically reduced the biomass presence on the GAC leaving only a few individual microbes very thinly distributed along the surface (see Figure 4.13, quantification of images revealed a $75 \%$ reduction in average thickness of biofilm). A total of 6 different image stacks were taken for this sample in 2015 . 


\section{Summer 2015 CLSM images}

Figures $4.8 \mathrm{a}$ and $4.8 \mathrm{~b}$ show biomass on the anthracite filter media during the summer season, taken on separate granules. Figures $4.8 \mathrm{a}$ and $4.8 \mathrm{~b}$ are of the same type of sample (summer anthracite before backwash), however they were taken from different granules.
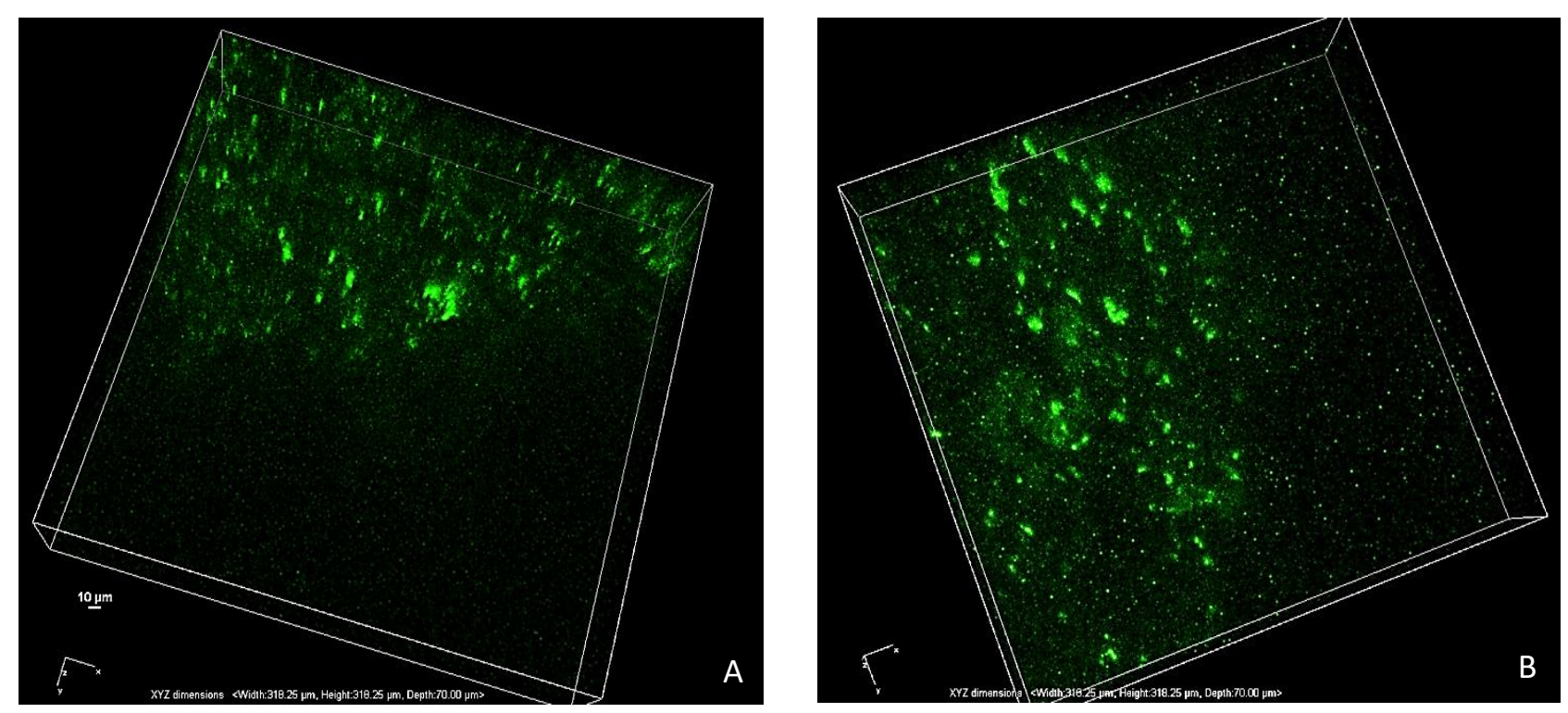

Figure 4.8a \& 4.8b: CLSM image of granule media sample during summer 2015 of anthracite before backwash using $40 \mathrm{X}$ objective and excitation of $488 \mathrm{~nm}$ laser

Growth appeared somewhat confluent while a lack of distinct cell shape attributed to presence of EPS. Biofilm coverage spanning significant portions of the surface can also be observed. Patchy growth with few isolated cells and clusters was observed in areas with little growth. A total of 9 different image stacks were taken for this sample in 2015. Qualitative assessment depicted a lack in distinction in cellular morphology when compared to anthracite before a backwash in the winter. However, no net difference can be established qualitatively on a basis of biomass or surface coverage between the two seasons for anthracite.

Figures $4.9 \mathrm{a}$ and $4.9 \mathrm{~b}$ show biomass after a backwash on anthracite filter media, on two separate granules, in the summer season. Figures $4.9 \mathrm{a}$ and $4.9 \mathrm{~b}$ are of the same type of sample 
(summer anthracite post backwash), however they were taken from different granules. Sparsely distributed cells show significantly reduced biomass.
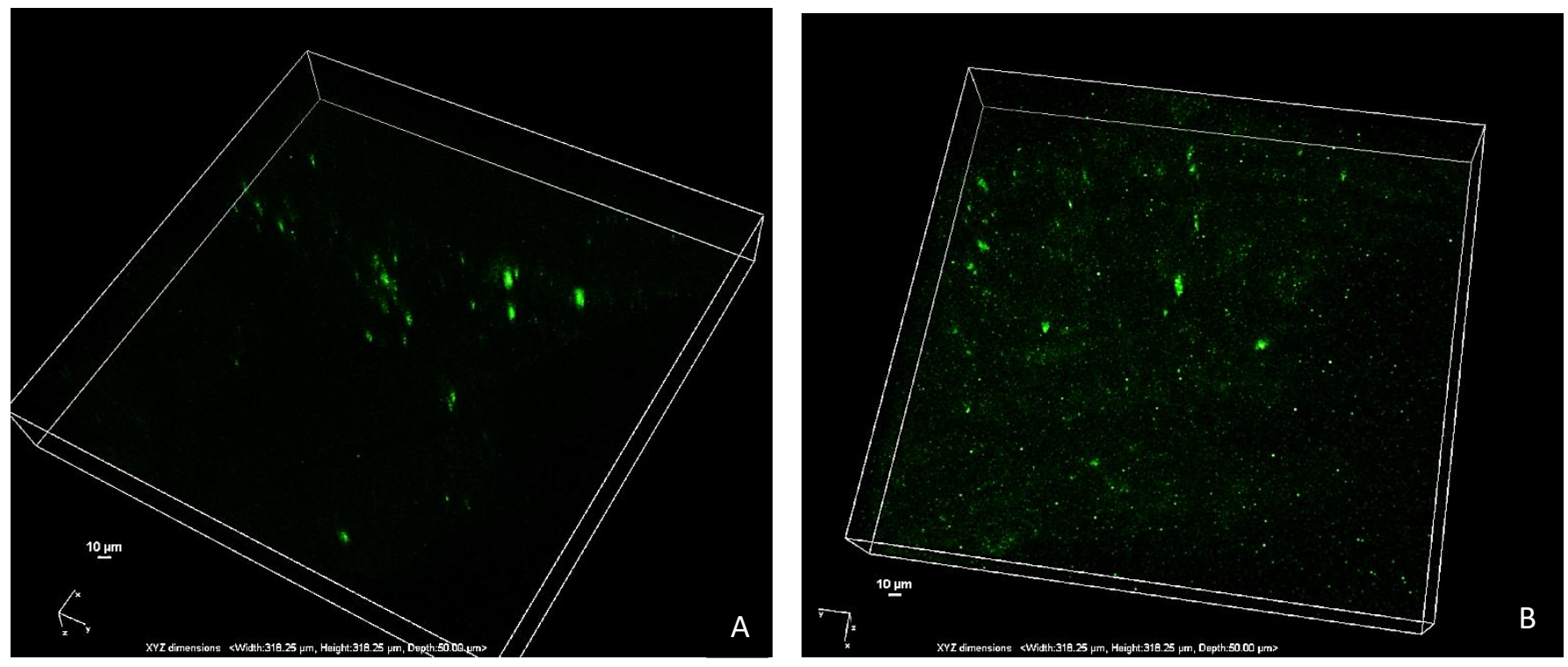

Figure 4.9a \& 4.9b: CLSM image of granule media sample during summer 2015 of anthracite after backwash using $40 \mathrm{X}$ objective and excitation of $488 \mathrm{~nm}$ laser

Figure 4.9a virtually had no EPS in the area imaged. Biofilm surface coverage also can be noticed to have dramatically dropped with the majority of the region registering with little to no biomass. Qualitative observations showed a similar level of biomass remaining on both GAC and anthracite post backwash during the summer season (Figures 4.11a and 4.11b). Few microorganisms visible had a distinct coccid shape with no "fluffy" texture observed. A total of 10 different image stacks were taken for this sample in 2015.

Figure 4.10 are images stacks of biofilm taken from GAC filter media before a backwash, during the summer season. Figures $4.10 \mathrm{a}$ and $4.10 \mathrm{~b}$ are of the same type of sample (summer GAC before backwash), however they were taken from different granules. 

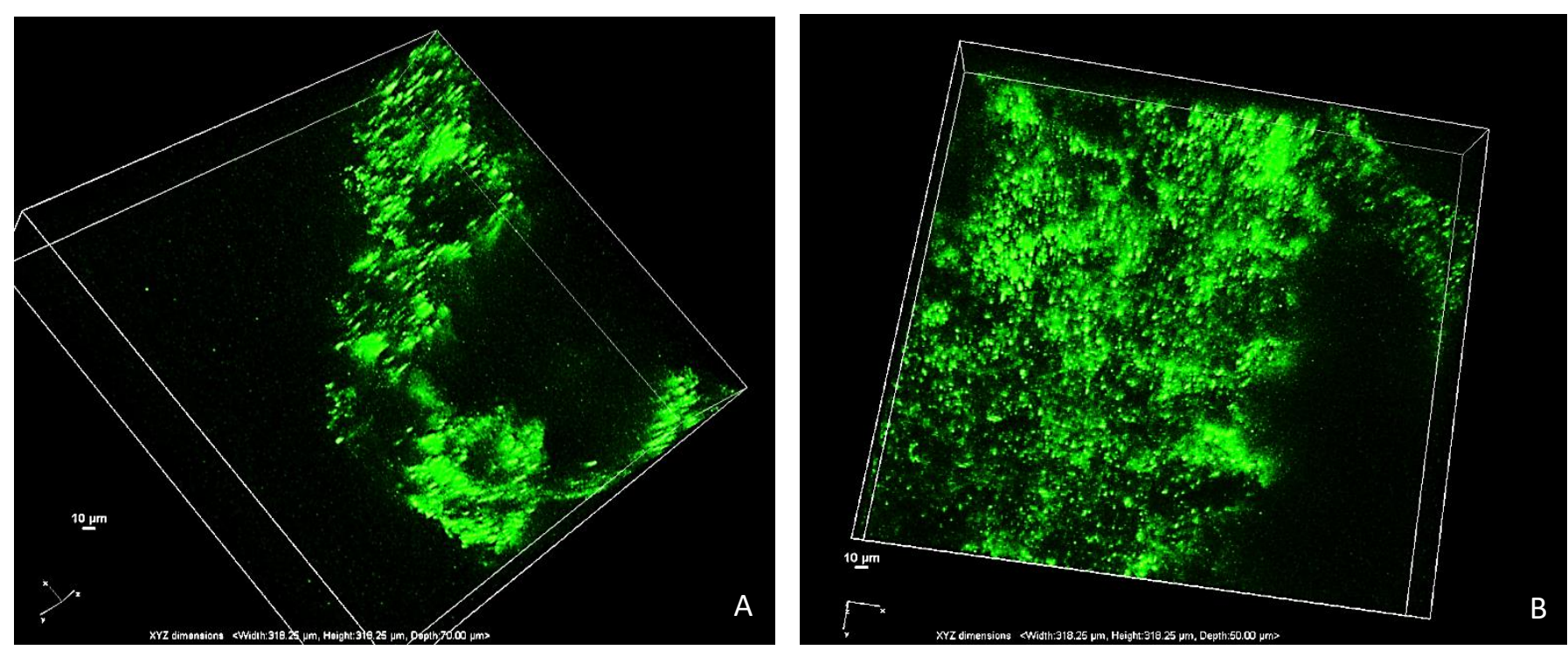

Figure 4.10a \& 4.10b: CLSM image of granule media sample during summer 2015 of GAC before backwash using 40X objective and excitation of 488nm laser

Three dimensional representation of the biofilm can be observed in Figure 4.10a, by how it is shaped to the topography of the granule, following the rugged terrain. Brightness and intensity of the pixilation confirm extensive biomass levels. Qualitatively, biomass levels were relatively high compared to summer season anthracite images (Figure 4.8a and 4.8b) or winter season GAC images (Figure 4.6a and 4.6b). A very "fluffy" texture possibly denotes high EPS levels as well. Coverage of biofilm is widespread in the captured image area. A total of 9 different image stacks were taken for this sample in 2015.

Figures 4.11a and 4.11b show remnants of a biofilm after a backwash on GAC media, from two separate granules, during the summer season. Figures $4.11 \mathrm{a}$ and $4.11 \mathrm{~b}$ are of the same type of sample (summer GAC post backwash), however they were taken from different granules. 

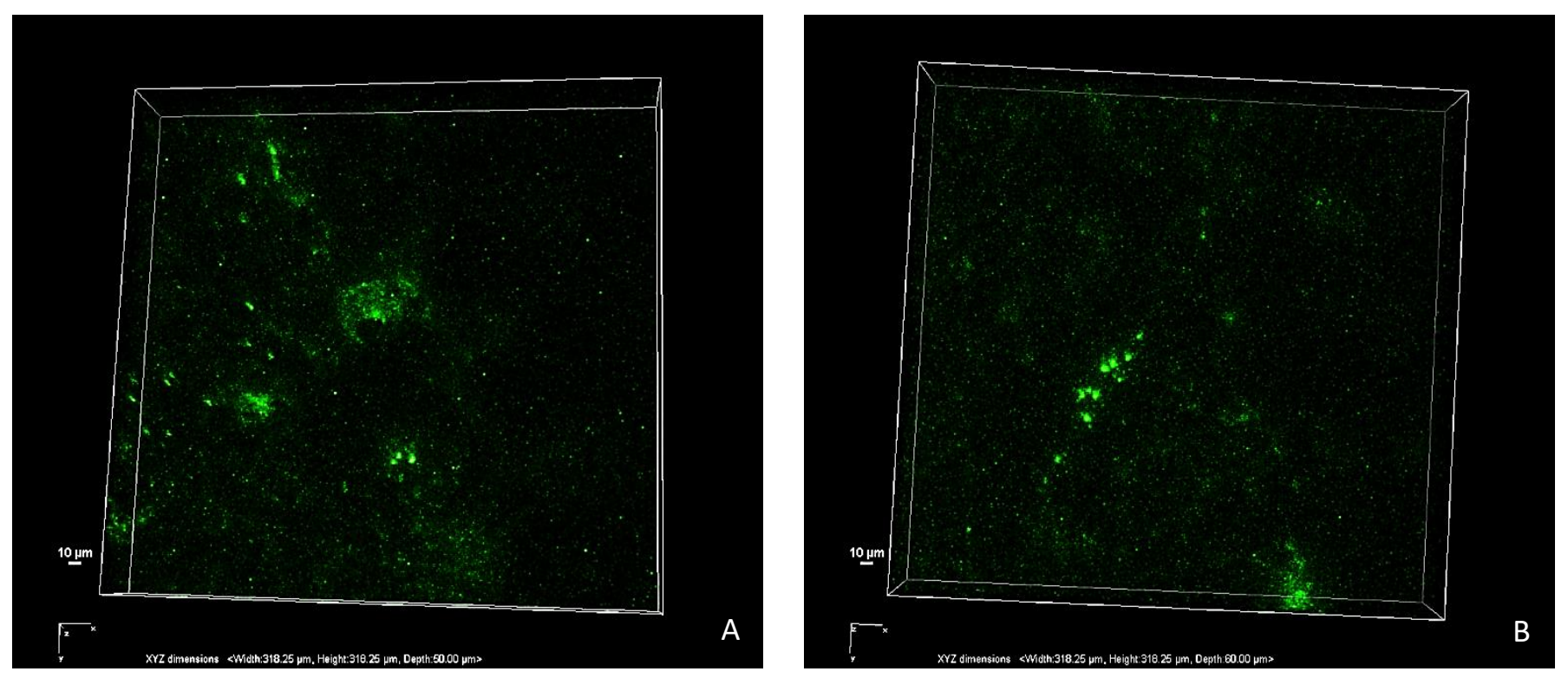

Figure 4.11a \& 4.11b: CLSM image of granule media sample during summer 2015 of GAC after backwash using 40X objective and excitation of $488 \mathrm{~nm}$ laser

Heavy reduction in both EPS and microbial cells can be observed based on colouration intensity of the pixels. Biomass levels show similar reduction to Figure 4.9a and Figure 4.9b indicating similar effect of a backwash on both filter media types. A total of 9 different image stacks were taken for this sample in 2015.

\subsection{Image Quantification}

Image analysis through the application COMSTAT assisted in revealing properties and changes of a biofilm's architecture and topography in the bioflter based on seasonality and filter media type. Quantification of images produced by microscopy constructed a greater understanding of why biofilters function the way they do. Converting qualitative information into numerical data established trends and patterns in biofilter performance.

A biofilm's structural components and variables of the biofilm architecture including the thickness, heterogeneity, and surface coverage, can be calculated using COMSTAT with the MatLab software. COMSTAT enabled a cross comparison which revealed where the majority of 
the biomass accumulates, based on media type. Finally a comparative analysis on a seasonal basis for winter and summer, supported qualitative evidence on biomass levels. Qualitative and quantitative information was then used to compliment pilot plant data on nutrient removal which bridged the functional gap of performance between the two types of media. Therefore, since nutrient removal was a function of biological activity and thus biomass concentration, these two variables are directly correlated. Figure 4.12 illustrates the biomass for both GAC and anthracite filter media before and after a backwash event.

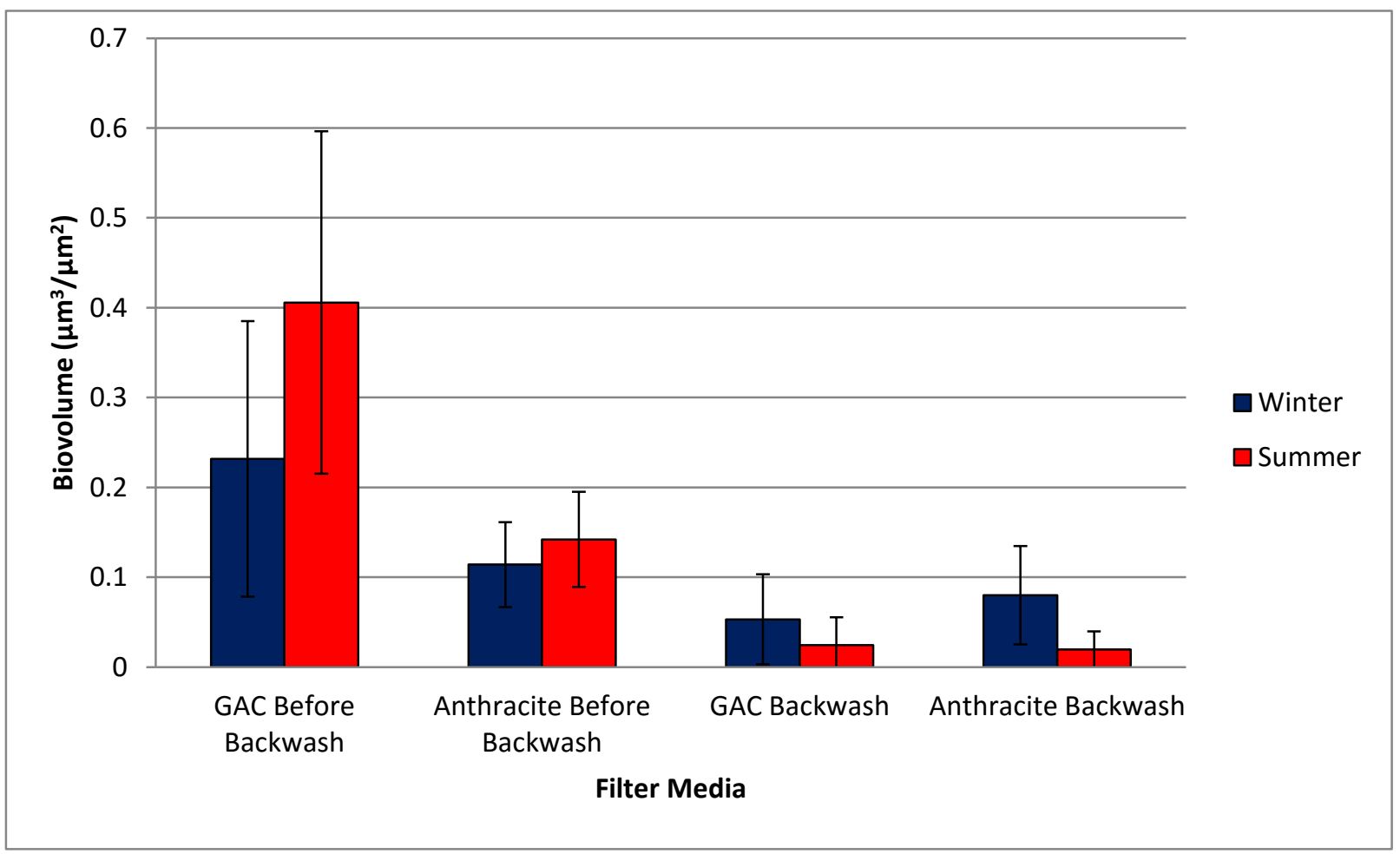

Figure 4.12: COMSTAT analysis comparing of seasonal changes for biovolume, for respective biofilter media before and after a backwash event

As can be seen from Figure 4.12, the GAC filter media harboured a higher degree of biomass than the anthracite prior to a backwash for the summer however it was statistically significant for the summer samples (p-value 0.0001) but not for the winter samples (p-value 0.32). The figure also shows the biomass reduction post backwash for both seasons. 
Backwashing of the filter media had a similar effect on both GAC and anthracite, leaving behind relatively similar amounts of biomass.

Thickness of a biofilm is an important parameter of biomass growth and is correlated to biofilm structure. This serves as a function for its primary role of nutrient and dissolved oxygen uptake and removal. A biofilm's average thickness takes into consideration biofilm structure at its highest and lowest points both on the granule's surface and within the granule's pores. Figure 4.13 illustrates how average biofilm thickness is influenced as a function of seasonal temperatures, backwashing, and filter type of filter media.

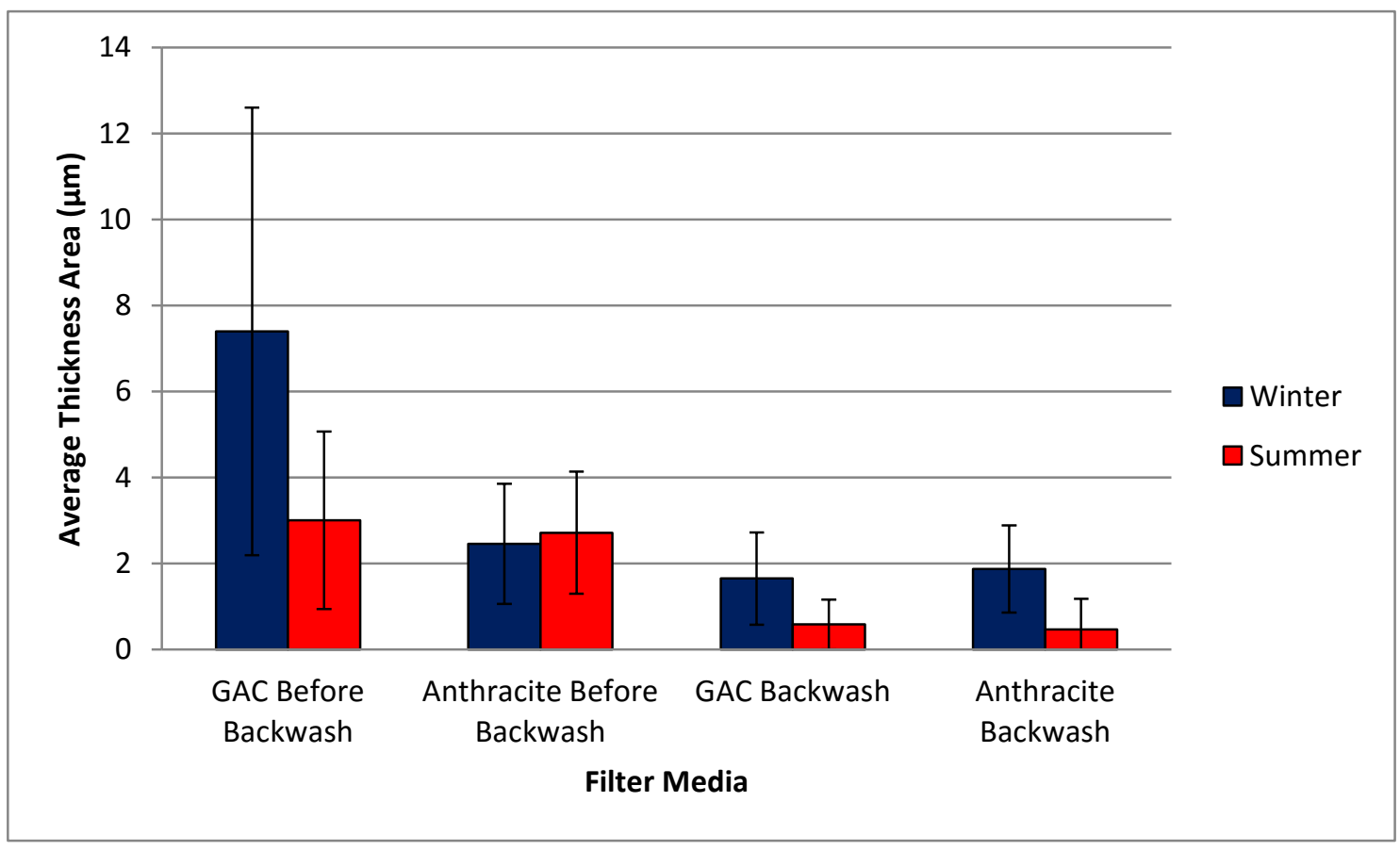

Figure 4.13: COMSTAT analysis comparing average biofilm thickness before and after a backwash event on GAC and anthracite filter media seasonally.

A backwash affected average thickness by reducing the biofilm's size, more specifically its height (with the units being measured in $\mu \mathrm{m}$ ). With the exception of GAC's winter average thickness, it is seen that both GAC and anthracite have similar thickness averages. Furthermore, winter GAC biofilms experienced statistically significant (p-value 0.0024) thickness reduction 
due to the shear forces of a backwash. Summer anthracite and GAC also experienced statically significant reduction post backwash (p-values 0.0005 and 0.0020 respectively). Winter GAC before a backwash shows a statistically significant (p-value 0.0391) larger average thickness than winter anthracite before backwash.

Biofilm roughness (Figure 4.14) compliments average thickness of a biofilm in that it gives an approximation of the biomass irregular surface. Further to this, a biofilm's roughness can also give crucial information on a biofilm's structure and architecture, which can predict its stability to withstand external forces.

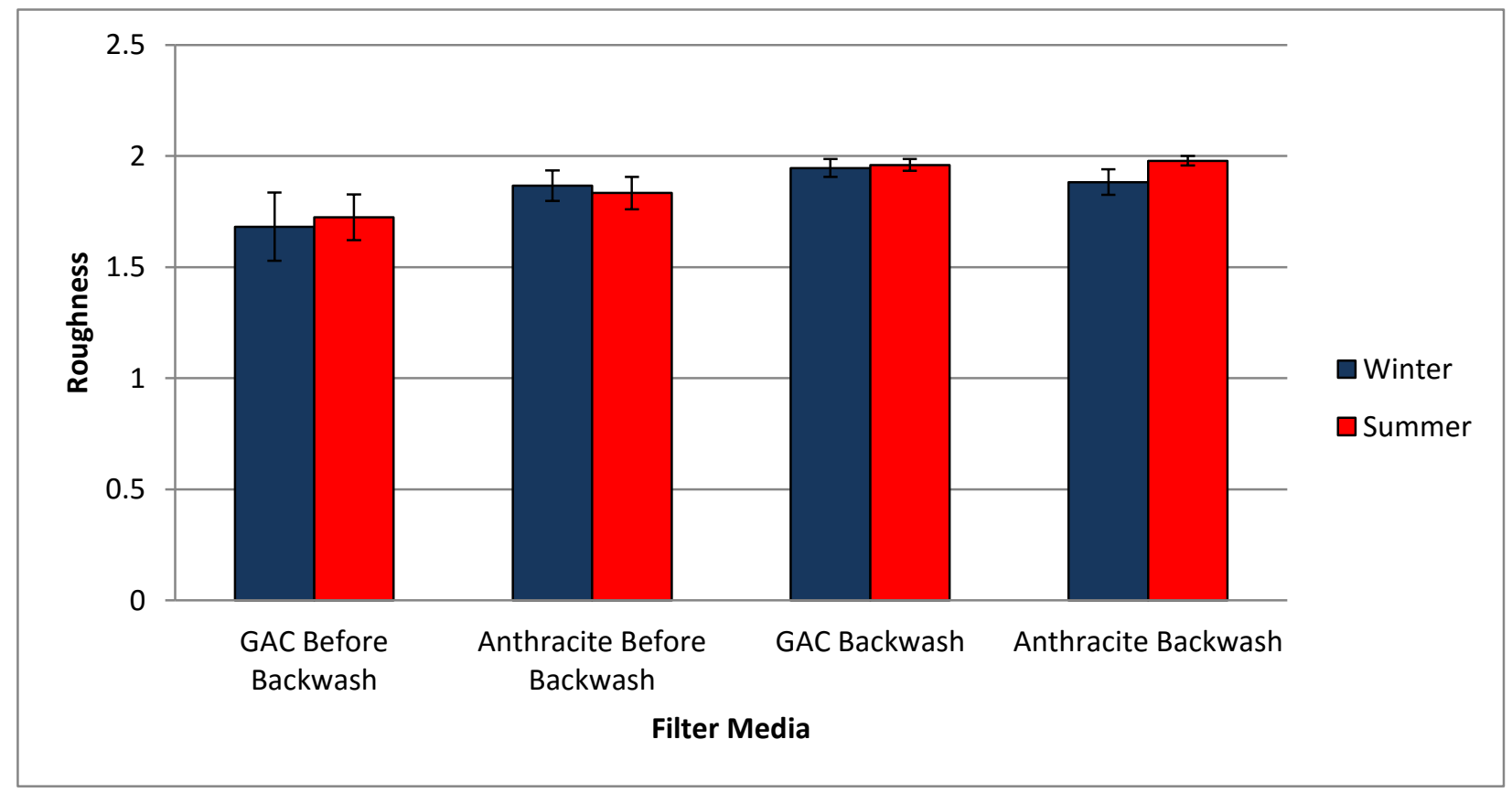

Figure 4.14: COMSTAT analysis comparing roughness of a biofilm's surface on GAC and anthracite filter media, pre and post backwash, during winter and summer seasons.

Figure 4.14 illustrates a general level of consistency for biofilm roughness among the 8 different combinations of samples using media, seasonal temperature, and backwashing. Comparison of pre backwash to post backwash samples yielded several statistically significant 
increases in heterogeneity after backwashing. Winter and summer GAC (p-values $<0.0001$ and $<0.0001$ respectively) and summer anthracite (p-value 0.0097) all reported statically significant difference in heterogeneity.

Biofilm coverage of the filter media is also an important detail. Surface coverage is intimately associated with the amount of biomass found on the filter media and although complete coverage is not likely a more extensive surface area will enhance nutrient uptake then a limited surface growth. Figure 4.15 shows surface area coverage on the two filter media before and after a backwash event.

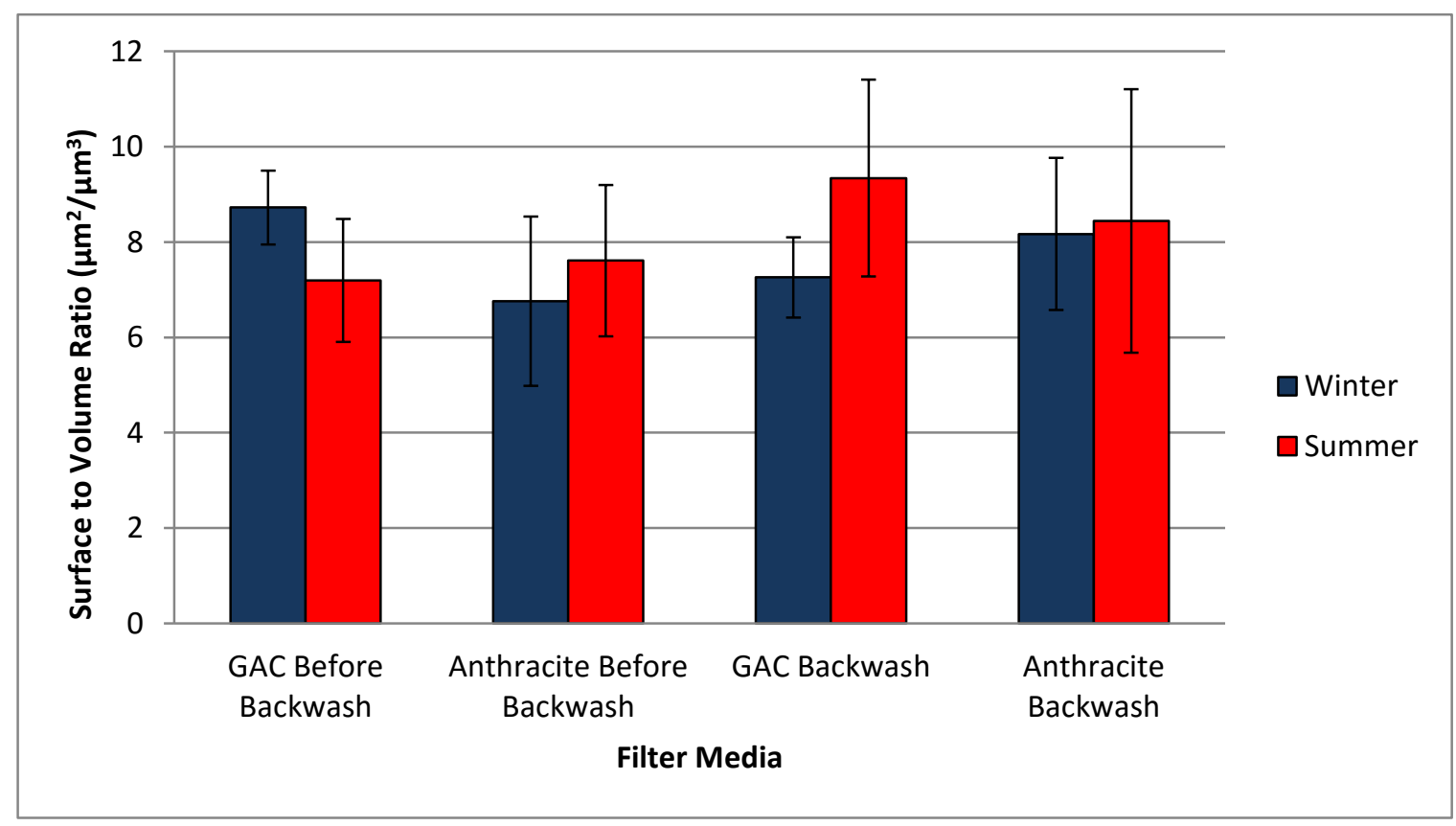

Figure 4.15: COMSTAT analysis comparing the surface to volume ratio coverage on biofilter media, before and after a backwashing event, while evaluating seasonal differences.

Figure 4.15 illustrates a highly varied biofilm structure which has formed on the filter media pre and post backwash. No significant differences were found following statistical analysis (Table 4.1) Error bars indicating high variability within the data set are larger for post backwash and summer samples. 


\subsection{Pilot Scale DOU and TOCU Data}

\section{$\underline{\text { Test } 1 \text { Conducted at Pilot Scale }}$}

Under stable conditions, there is a positive correlation between the amount oxygen up taken during cellular respiration from the microbial community and the amount of TOC biodegraded. Biofilter media removal capabilities on TOC and DO removal are shown here to be directly related and affect one another. In Figure 4.16, each biofilter with its respective media and flow rates were plotted on the scatter plot to establish a correlation between the two variables.

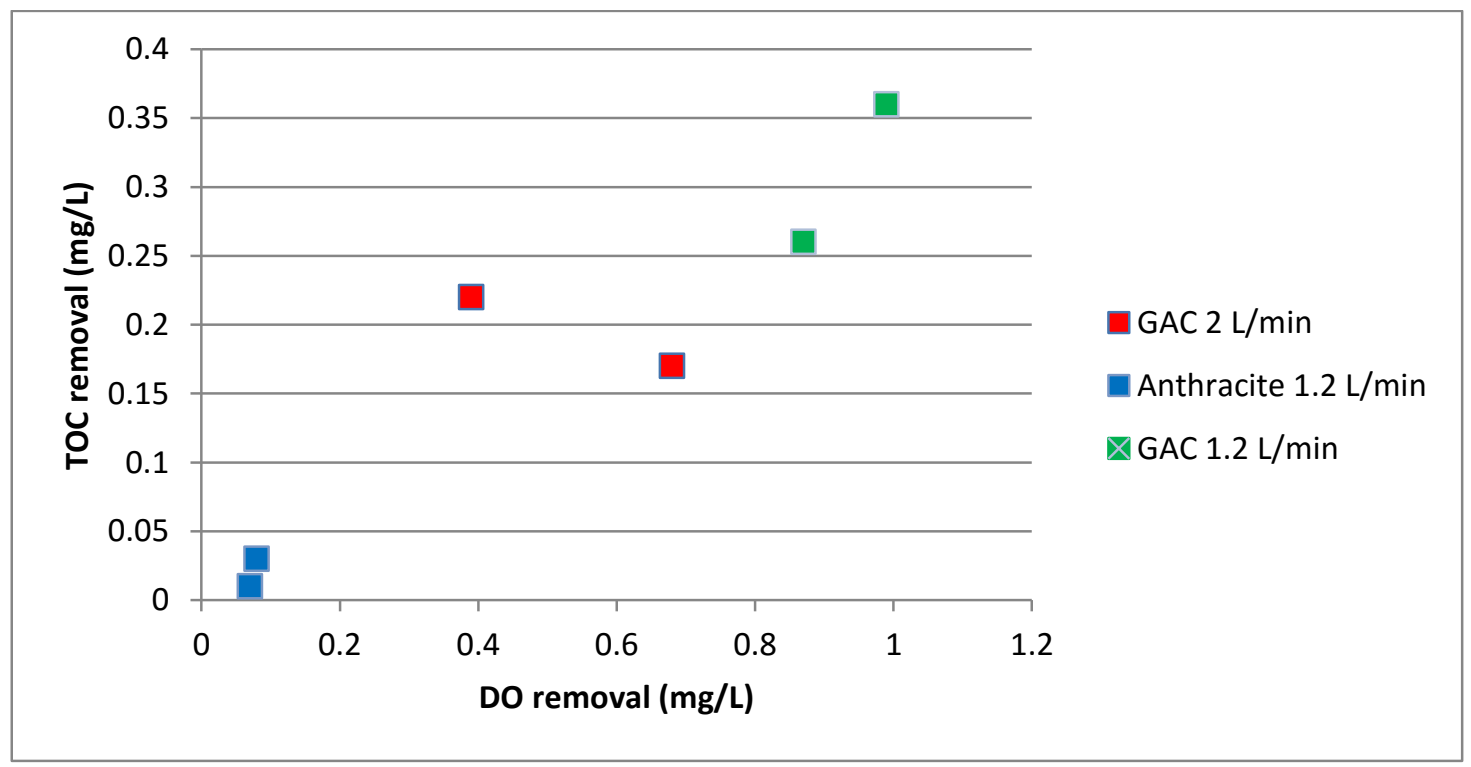

Figure 4.16: DO uptake correlated to TOC removal for GAC and Anthracite media.

From the Figure 4.16 it is seen that anthracite media has the lowest yield of TOC removed for DO consumption while GAC with a flow rate of $1.2 \mathrm{~L} / \mathrm{min}$ has the highest TOC removal for DO consumption. Based on DO removal it appears that GAC supported higher microbial activity, and thus TOC removal, than anthracite. 
Figure 4.17 shows a two series bar graph which plots the uptake and removal average of both DO (blue) and TOC (purple).

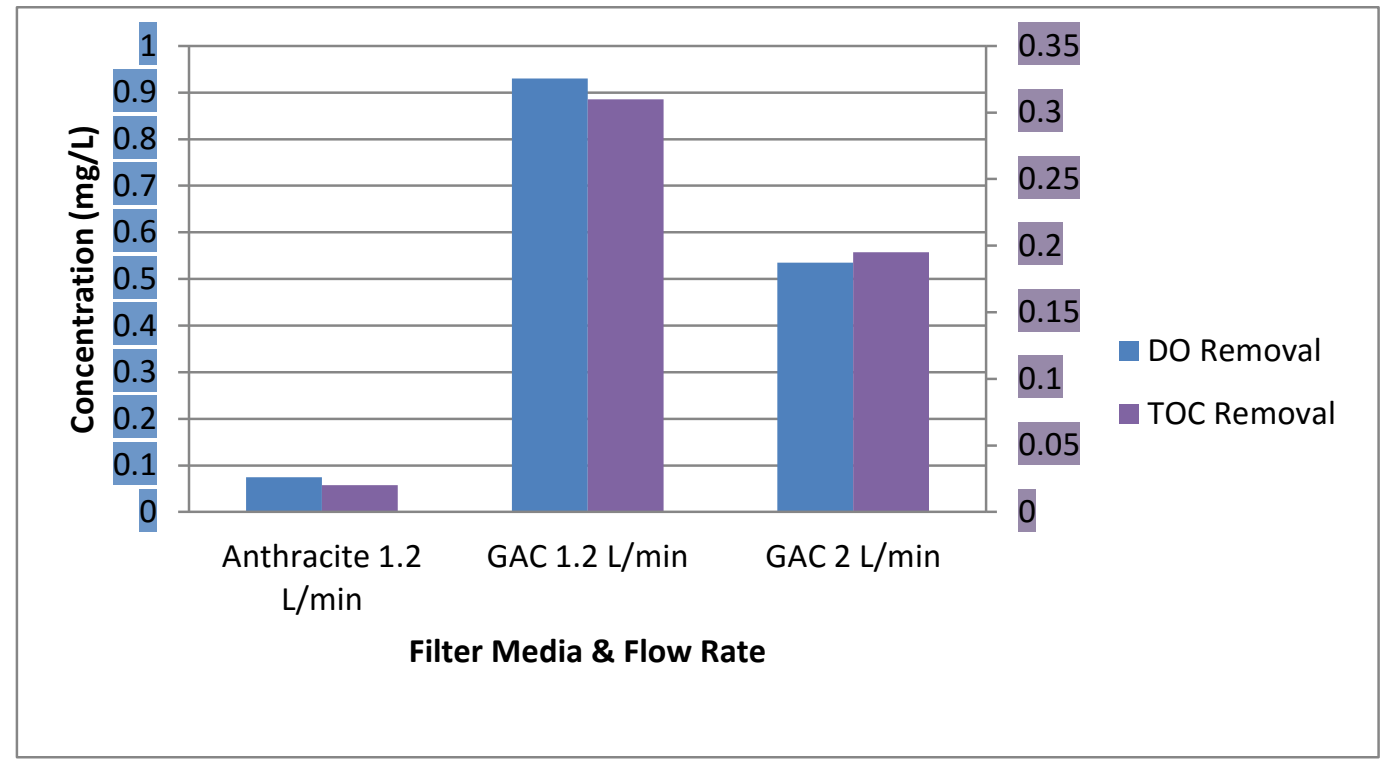

Figure 4.17: DO and TOC removal plotted for anthracite and GAC at different flow rates

Filter media with respective flow rates were compared on their DO removal ability measured in units of $\mathrm{mg} / \mathrm{L}$. GAC with a flow rate of $1.2 \mathrm{~L} / \mathrm{min}$, had the most optimal dissolved oxygen removal. Anthracite had the poorest performance of DO removal and GAC with $2 \mathrm{~L} / \mathrm{min}$ was also graphed to demonstrate how flow rate affects biofiltration performance. GAC with a higher flow rate removed considerably more than anthracite however, it still had a significantly reduced removal capability than GAC with a slower flow rate.

Biofilters with their corresponding flow rates were compared on their TOC removal capabilities and a very similar profile was seen. The anthracite filter had the smallest removal of TOC while GAC with a flow rate of $2 \mathrm{~L} / \mathrm{min}$ performed better. Finally, GAC flowing at 1.2 L/min, outperformed the other two filters. These results paralleled the DO removal results with 
respect to GAC 1.2 L/min having the highest removal followed by GAC $2 \mathrm{~L} / \mathrm{min}$ and anthracite $1.2 \mathrm{~L} / \mathrm{min}$.

\section{Test 2 Conducted at Pilot Scale}

Figure 4.18 illustrates some of the functional components of the pilot scale and how the biofilter media reacts to various activities which directly affect performance. Biofilter media is affected by external pressures such as nutrient spikes and backwashing. Performance on TOCU and DOU following a nutrient spike and a backwash, were investigated and plotted to see how these variables changed by exposing the filter to these external changes.

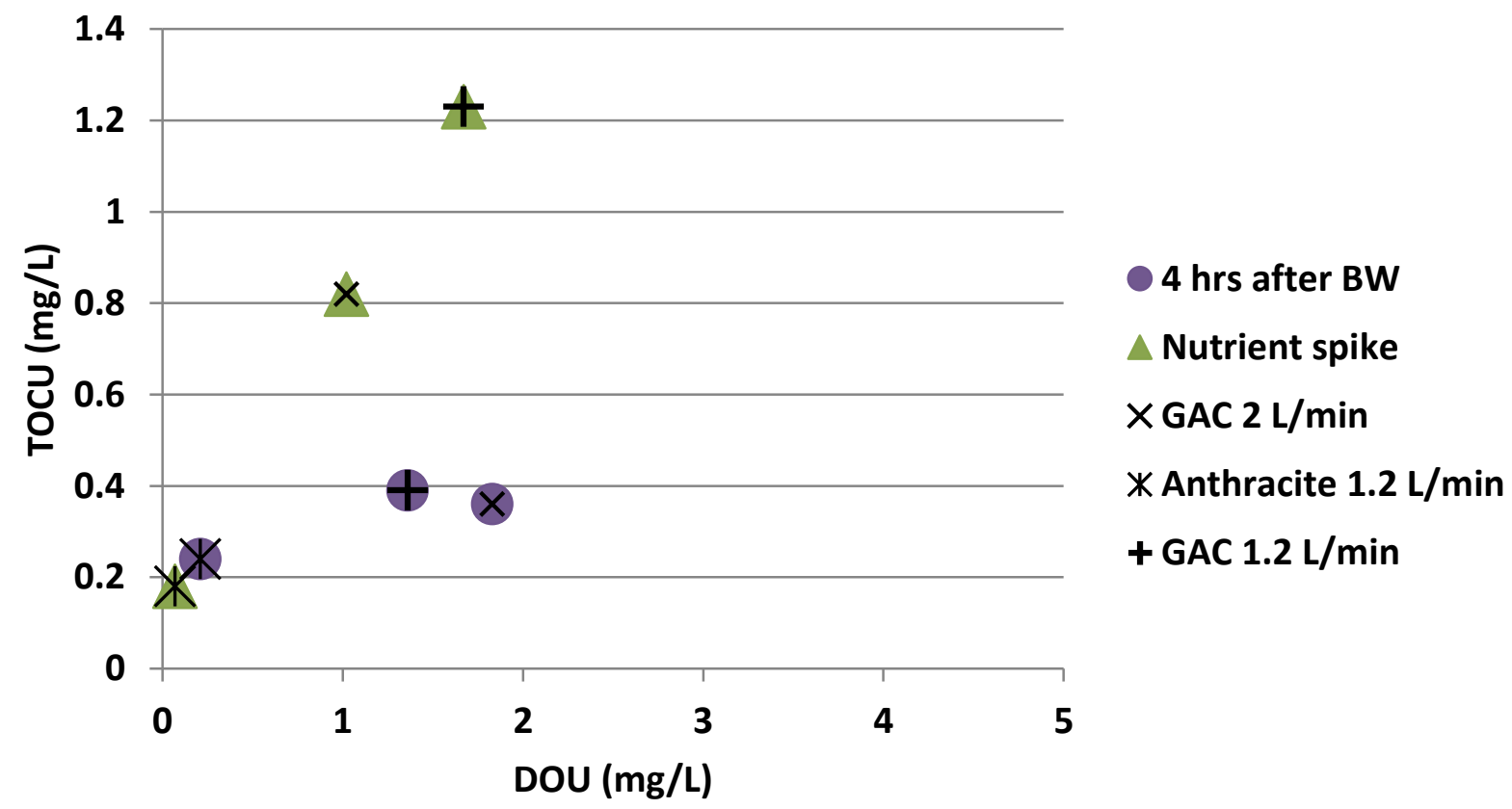

Figure 4.18: Biofilter media responding to nutrient spikes and backwashing. Anthracite and GAC filter media with their respective flow rates are plotted indicating the positive correlation of DOU and TOCU Figure 4.18 illustrated how anthracite and GAC filters at different flow rates, responded

differently to both of these operations, GAC at $1.2 \mathrm{~L} / \mathrm{min}$ had the best response to a nutrient spike, the highest removal of DO and TOC. Conversely, anthracite with a flow rate of $1.2 \mathrm{~L} / \mathrm{min}$ had the lowest response to the nutrient spike. Four hours after a backwash, the media was 
similarly examined to see how fast the media recovered and uptake recommenced. Anthracite was seen to have the slowest recovery post backwash while the GAC with flow rates of 1.2 $\mathrm{L} / \mathrm{min}$ and $2 \mathrm{~L} / \mathrm{min}$ shown similar recovery rates for TOC and DO removal.

Microbial communities are affected by filter media as well as seasonal temperatures and the anthropogenic practices that come with seasonal changes. Figure 4.19 below examined DOU dependence on temperature and filter media type. Figure 4.19 shows a positive correlation between DOU and higher temperatures. In addition DOU registered higher in GAC filter columns compared to anthracite across all temperature ranges and therefore showed better performance year round.

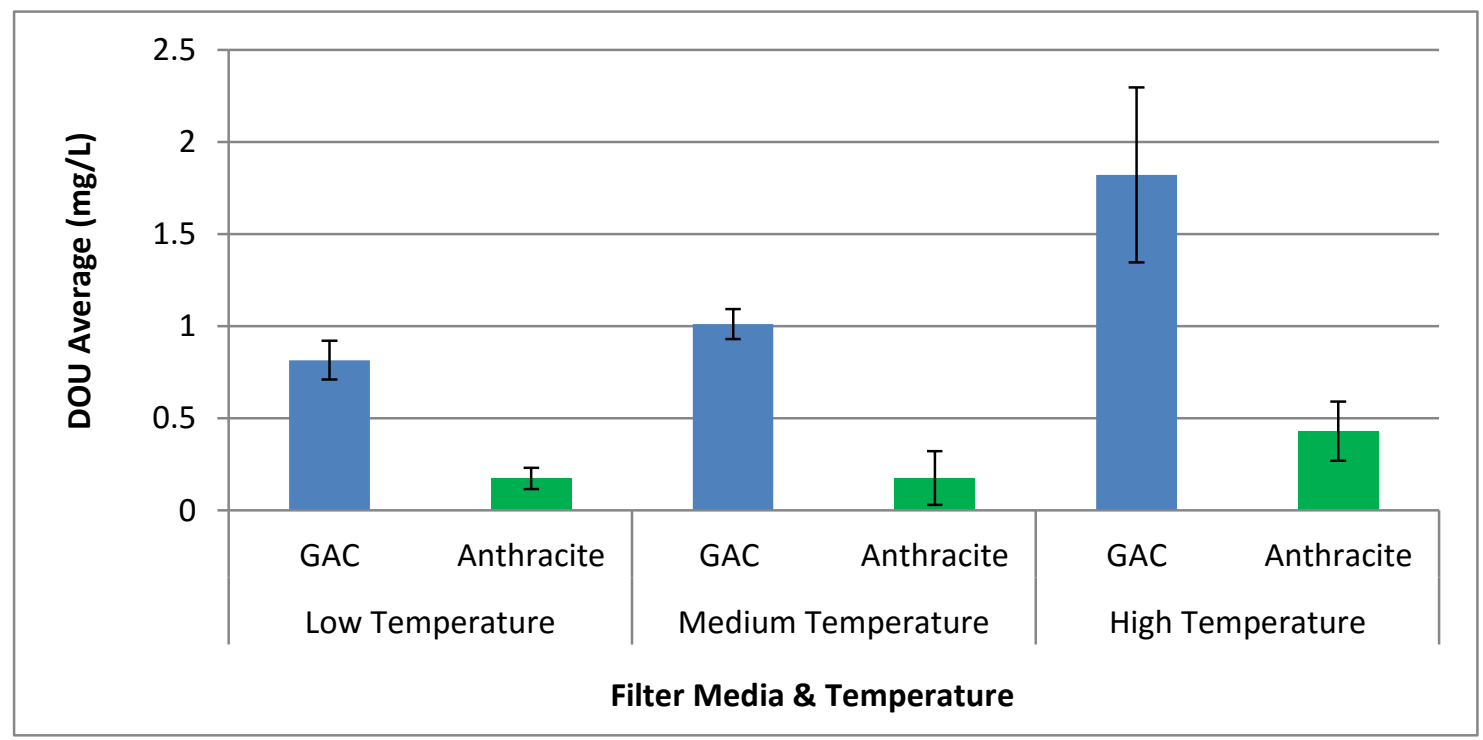

Figure 4.19: Summary of data for DOU average; comparison between GAC and anthracite during low, medium, and high water temperatures

The data set obtained from the pilot scale was a record keeping of sampling times and dates during a period of 2 years. This data was taken from log sheets monitoring the pilot's conditions and performance and was subsequently summarized into Tables A4.1 - A4.3 (Appendix 4) showing the DOU measurements during high, medium, and low water temperatures. Data was standardized to include only filters running under similar conditions (i.e. 
temperature range and flow rate). The two filter systems; anthracite filters with a flow rate of 1.2 L/min (Filters 2 and 5) and GAC filters with a flow rate of $1.2 \mathrm{~L} / \mathrm{min}$ (Filters 3 and 6). Filters 1 and 4 were also shown in the tables however their values were not incorporated into the graph. The data points between GAC filters ( 3 and 6) and anthracite filters ( 2 and 5) were averaged in order to deduce the effect of temperature ranges and filter media on dissolved oxygen uptake.

TOC uptake and DO uptake averages were taken from Figure 4.16 and readjusted to illustrate respective removal capabilities of the biofilter columns. By looking at removal concentrations of the TOC and DO variables individually, a clearer understanding of biofiltration performance can be obtained, as well as how these variables are affected by filter media type and temperature.

As done with Figure 4.19, data was similarly taken from log sheets monitoring for TOCU which were compiled into three tables A5.1 - A5.3 (Appendix 5). Once again, the data was standardized to only include filter columns running at the same flow rate (in this case $1.2 \mathrm{~L} / \mathrm{min}$ ). Figure 4.20 has taken data from for GAC and anthracite (filters 3 and 6 and filters 2 and 5 respectively) and plotted them to show a correlation between warmer temperatures and higher uptake of TOC as well as higher performance in GAC. As can be seen in Figures 4.19 and 4.20, the same trend of elevated DOU and TOCU is exhibited during warmer temperatures and on the GAC filter medium. 


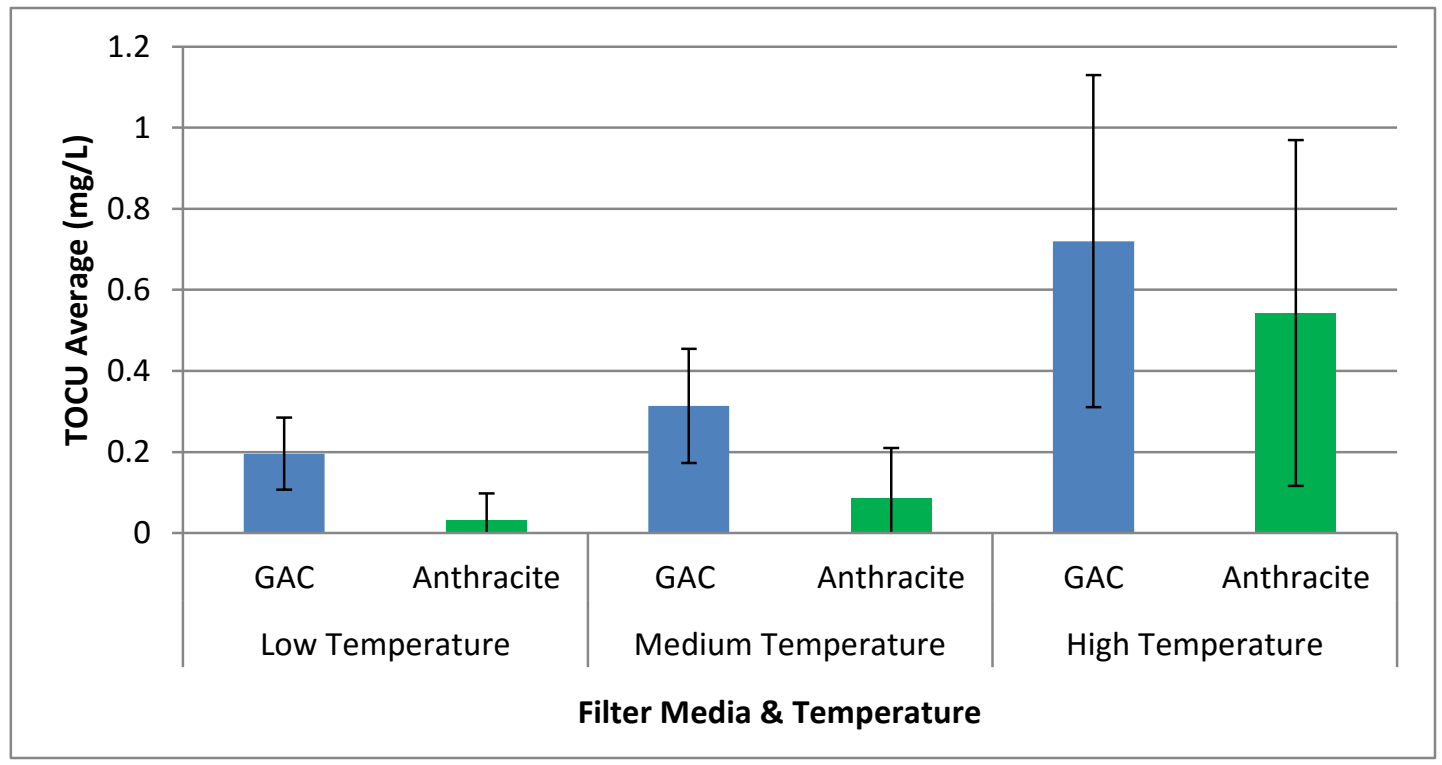

Figure 4.20: Summary of data for TOCU average; comparison between GAC and anthracite during low, medium, and high water temperatures

Figure 4.12 and Figure 4.20 were combined to observe the direct correlation that biomass and temperatures had on TOCU. Figure 4.21 shows how warmer temperatures elicit increased TOC uptake and biodegradation, as both media in the summer have a higher uptake.

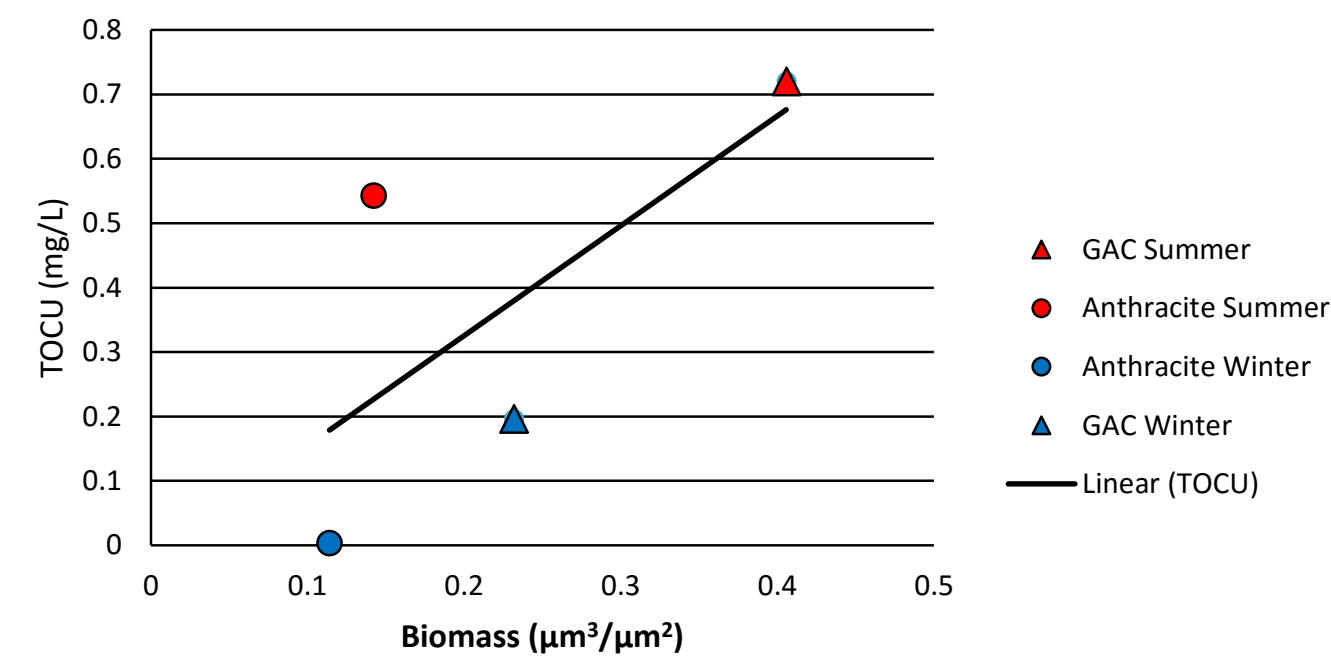

Figure 4.21: Representation of TOCU as a function of biomass levels and temperature dependence 
Figure 4.21 shows TOCU is both dependent on biomass levels as well as temperature.

This figure depicts a positive correlation with warmer temperatures and increased biomass and rising TOCU. The trend line establishes this upturn in TOCU as biomass levels shift to the right.

Comparative analyses were carried out using ANOVA tests. These statistical tests were conducted on the HPCs and quantitative data on biofilm parameters, in order to assess if the changes created either by backwashing, filter media, or seasonal were in fact significant. Table 4.1 shows the parameter that was examined, the two constituents being compared, the P-value, and if the difference is statically significant or not.

Table 4.1: Statistical Analysis of Data Determining Statistical Significance

\begin{tabular}{|c|c|c|c|}
\hline $\begin{array}{c}\text { Test } \\
\text { Parameter }\end{array}$ & Samples Tested & P-value & $\begin{array}{r}\text { Statistically } \\
\text { Significant }\end{array}$ \\
\hline HPC & $\begin{array}{l}\text { GAC Before Backwash Winter / } \\
\text { GAC Before Backwash Summer }\end{array}$ & 0.38 & Insignificant \\
\hline HPC & $\begin{array}{l}\text { Anthracite Before Backwash Winter / } \\
\text { Anthracite Before Backwash Summer }\end{array}$ & 0.99 & Insignificant \\
\hline HPC & Raw Water Winter / Raw Water Summer & 0.96 & Insignificant \\
\hline HPC & $\begin{array}{c}\text { Anthracite Before Backwash Winter/ } \\
\text { GAC Before Backwash Winter }\end{array}$ & 0.96 & Insignificant \\
\hline Biomass & GAC Before Backwash Winter/GAC Backwash Winter & 0.013 & Significant \\
\hline Biomass & $\begin{array}{c}\text { Anthracite Before Backwash Winter/ } \\
\text { Anthracite Backwash Winter }\end{array}$ & 0.99 & Insignificant \\
\hline Biomass & GAC Before Backwash Summer/GAC Backwash Summer & 0.00010 & Significant \\
\hline Biomass & $\begin{array}{c}\text { Anthracite Before Backwash Summer/ } \\
\text { Anthracite Backwash Summer }\end{array}$ & 0.0312 & Significant \\
\hline Biomass & $\begin{array}{l}\text { GAC Before Backwash Winter/ } \\
\text { GAC Before Backwash Summer }\end{array}$ & 0.0299 & Significant \\
\hline Biomass & $\begin{array}{l}\text { Anthracite Before Backwash Winter/ } \\
\text { Anthracite Before Backwash Summer }\end{array}$ & 0.99 & Insignificant \\
\hline Biomass & $\begin{array}{c}\text { GAC Before Backwash Winter/ } \\
\text { Anthracite Before Backwash Winter }\end{array}$ & 0.32 & Insignificant \\
\hline Biomass & $\begin{array}{c}\text { GAC Before Backwash Summer/ } \\
\text { Anthracite Before Backwash Summer }\end{array}$ & 0.0001 & Significant \\
\hline $\begin{array}{l}\text { Average } \\
\text { Thickness }\end{array}$ & GAC Before Backwash Winter/GAC Backwash Winter & 0.0024 & Significant \\
\hline $\begin{array}{l}\text { Average } \\
\text { Thickness }\end{array}$ & GAC Before Backwash Summer/GAC Backwash Summer & 0.0020 & Significant \\
\hline $\begin{array}{l}\text { Average } \\
\text { Thickness }\end{array}$ & $\begin{array}{l}\text { Anthracite Before Backwash Summer/ } \\
\text { Anthracite Backwash Summer }\end{array}$ & 0.00050 & Significant \\
\hline
\end{tabular}




\begin{tabular}{|c|c|c|c|}
\hline $\begin{array}{c}\text { Average } \\
\text { Thickness }\end{array}$ & $\begin{array}{c}\text { GAC Before Backwash Winter/ } \\
\text { Anthracite Before Backwash Winter }\end{array}$ & 0.039 & Significant \\
\hline $\begin{array}{c}\text { Average } \\
\text { Thickness }\end{array}$ & $\begin{array}{c}\text { GAC Before Backwash Summer/ } \\
\text { Anthracite Before Backwash Summer }\end{array}$ & 0.37 & Insignificant \\
\hline Roughness & GAC Before Backwash Winter/GAC Backwash Winter & 0.0001 & Significant \\
\hline Roughness & GAC Before Backwash Summer/GAC Backwash Summer & 0.0001 & Significant \\
\hline Roughness & $\begin{array}{c}\text { Anthracite Before Backwash Summer/ } \\
\text { Anthracite Backwash Summer }\end{array}$ & 0.0097 & Significant \\
\hline $\begin{array}{c}\text { Surface to } \\
\text { Volume }\end{array}$ & GAC Before Backwash Winter/GAC Backwash Winter & 0.81 & Insignificant \\
\hline $\begin{array}{c}\text { Surface to } \\
\text { Volume }\end{array}$ & $\begin{array}{c}\text { Anthracite Before Backwash Winter/ } \\
\text { Anthracite Backwash Winter }\end{array}$ & 0.84 & Insignificant \\
\hline $\begin{array}{c}\text { Surface to } \\
\text { Volume }\end{array}$ & GAC Before Backwash Summer/GAC Backwash Summer \\
\hline $\begin{array}{c}\text { Surface to } \\
\text { Volume }\end{array}$ & $\begin{array}{c}\text { Anthracite Before Backwash Summer/ } \\
\text { Anthracite Backwash Summer }\end{array}$ & 0.20 & Insignificant \\
\hline
\end{tabular}




\section{Chapter Five: Discussion}

Characterization of the filter media's ability to house a large and diverse microbial populations while lowering DO and TOC concentrations would grant workers at a DWTP a thorough review of this treatment process. This study provided a glimpse into why the filter media and filtration units function the way they do based on the biofilms within them, in the hope of delivering the highest quality and standard of drinking water to consumers. There are certain perceptions among the public, that using bacteria to clean the water is dangerous. Like many uninformed opinions however, skeptics are overwhelmed with concern but have little scientific backing. Nevertheless, government agencies like the EPA are reluctant to implement biofiltration out of fear of the public backlash.

The primary fear for the usage of microorganisms is that they can get back into the water. It is good for biofilm to adhere tightly to the media in order to maximize nutrient uptake. However a compromise must exist because bacteria that are too tightly associated, are not easily removed and the media will saturate faster. It is therefore most desirable for a backwash to have the optimal effect on the media re-suspending all organic components but also for minimal bacteria to be in the effluent when the filter is at rest and no shear force is applied. In addition, traditional treatment methods, with chlorination, will see to it that any microbial presence in the effluent post biofiltration will be removed. 


\subsection{Heterotrophic Plate Counts}

HPC experiments in this study provide a supplementary understanding of how microbial abundance is affected in the pilot plant. This includes, but is not limited to biofiltration operations by observing planktonic microbial concentrations released from the biofilter which can help regulate downstream treatment methods such as adjusting dosage levels of chlorine. Moreover, this experiment utilized cultivable microbial abundance which is only $1-10 \%$ (Nicholson and Hirsch, 1998) of the total population and should therefore be used as a proof of concept and a trend rather than for statistical significance. It was hypothesized that GAC would have higher colony counts than the anthracite filter media based on the literature that it harbours more microbial biomass (Symons et al., 1981). However, inspection of Figure 4.1 shows no evidence to support this claim. ANOVA analysis shows that there was no statistically significant differences between HPC counts (Table 4.1). It was expected that GAC would release a greater number of organisms into effluents due to its greater capability to support microbial growth. Anthracite has limited adsorptive capabilities making it only able to physically sieve organic materials that are not solubilised (Cochran, 2008). This is important because anthracite lacks activated sites which attract and hold bacteria for biodegredation (Chaudhary et al., 2003). Furthermore, anthracite's pores are too small to allow for bacteria to penetrate deep into the granule and therefore they are left unprotected making them slough off easier resulting in the higher HPC observed (Chaudhary et al., 2003). Desirable filter media should be characterized as one that captures organic compounds while holding onto its bacteria.

GAC has superior filtration capabilities based on its highly adsorptive nature, its overall positive charge, and catchment ability due to its macroporous structure, that anchors firmly its attached microorganisms (Cochran, 2008). This macroporous structure is the predominant reason 
why GAC has less HPCs in the effluent before a backwash event (Chaudhary, 2003). Attachment sites on GAC granules prevent loosely formed connections and reduce the chances of microbes reverting to their planktonic forms after being sloughed off. However, GAC cannot keep up adsorption indefinitely, the media becomes saturated and the adsorptive phase ends. Therefore, giving GAC biological activity not only increases the life span of the filter, but also improves water quality. As a result, when virgin GAC is fixed with a bacterial community in the biological phase, bed life expectancy is prolonged (Cochran, 2008).

In summary, no statistically significant differences were found for HPC. The experimental results garnered by Cochran et al., offer similar and consistent findings with the current study, in terms of HPC after a backwash, having comparable colony counts for both filter media. This demonstrates that a backwash has the same effect on the biomass of both GAC and anthracite.

Higher colony counts were found in the effluent of summer samples than winter samples, though these were not of a statistical significant difference. This seasonal variation between winter and summer sampling sessions denotes a change in the metabolic activity of the bacteria according to Schindlbacher et al., 2011.

Summer samples on average, had 1.3 times more cells than winter samples after a backwash event. On the other hand, summer samples had an average of 4.3 times more cells than winter samples before a backwash event. After a backwash, summer samples had an average of 273,800 cells per $\mathrm{mL}$ and winter had 207,583 cells per $\mathrm{mL}$. Before a backwash, summer samples yielded an average of 130,917 whereas winter samples only had 30,454. Raw water samples were also significantly higher for summer than for winter by a factor of 3.4 times as high 
yielding 21,529 in the summer and only 6,416 in the winter. ANOVA tests done on the data however, revealed no statistical significance on HPCs between seasons or presence and absence of a backwash. Comparing winter and summer seasons for GAC, before a backwash, yielded a pvalue of 0.38. Similarly, comparison of winter and summer seasons for anthracite, before a backwash, gave a p-value of 0.99. An interesting note however was neither the GAC nor the anthracite had a statistically significant difference seasonally when looking at the post backwash samples. This shows that the force of a backwash has the same effect on both GAC and anthracite. Raw water also did not register a statically significant increase in CFU/mL when comparing winter with summer, scoring a p-value of 0.96 .

External factors brought on by seasonal change can also affect colony counts in biofilter effluent. For example, warmer temperatures in the summer and increased precipitation exhibited by the months in late spring and summer (Henne et al. 2013) may lead to higher cell counts. Warmer ambient temperatures are correlated with higher net primary production due to raising organic and nutrient levels in the water. Consequently, this gives rise to bacterial growth which can be representative within the biofilters.

Autogenic detachment (Graba et al., 2014) may also contribute to higher number of colony forming units in the summer. Autogenic detachment can be described as a substantial and sudden detachment of biofilm brought on by less resistance of the biofilm mat to floating or drifting away. When a biofilm loses its cohesiveness and becomes thicker, it is more prone to this self-generated detachment. This behaviour is elicited under higher temperatures which is another possible reason why the summer sampling set showed much higher HPC numbers. During the summer months, a higher volume of protists, amoebae, and ciliates will inhabit the 
biofiltration units. These grazers will further induce a heightened behavioural response towards autogenic detachment (Graba et al., 2014).

\subsection{Microbial Diversity}

Bacteria have a critical role in fresh water ecosystems. Fresh water microbiota are responsible for regenerating and mobilizing nutrients within the food chain. Microorganisms are key in driving biogeochemical cycles as the primary degraders of organic compounds and mineralizers of inorganic molecules. Furthermore, microbial biomass production supports eutrophic predators and other higher order consumers fueling the food web.

Seasonal comparison of the microbial consortium residing on the media based on their 16S rRNA sequences, established some key findings. The first was that a higher microbial diversity was present in the winter. The second was that GAC had higher biodiversity than anthracite. Descriptions of the microorganisms belonging to a respective phylogenetic class would help to understand how they were found within the biofilter at the particular time of sampling. It is also good to know the characteristics of the microbes residing in the biofilter as well as their primary source of energy, to better promote balanced and regulated growth of the microcosm in the filter.

Proteobacteria encompass a large majority of agriculturally, industrially, and medically relevant microroganisms and thus is the most studied phylum. This phylum is comprised of six classes; Alphaproteobacteria, Betaproteobacteria, Deltaproteobacteria, Epsilonproteobacteria, Gammaproteobacteria, and Zetaproteobacteria (Newton et al., 2011). Proteobacteria shown to be a majority in the samples cultured. Proteobacteria occupied $40 \%$ of the total population of the summer samples and $100 \%$ of all bacteria from the winter sample set. 
Alphaproteobacteria are a class of microorganisms which belong to the phylum of Proteobacteria and are a very diverse group of microorganisms that have very different characteristics with large plasticity in their genomes. Most of them are Gram negatives although some are Gram variable due to some members in the group entirely lacking peptidoglycan (Brenner et al., 2005). A substantial amount of members from this group are phototrophic and symbionts of plants from the Rhizobium genus (Sawada et al., 2003). This is significant as the Alphaproteobacteria was identified in the summer sampling set, when higher levels of sunlight and more plant abundance are prevalent. The strain identified was indeed from the Rhizobium genus (Appendix 2). Rhizobium tropici, resides in the soil and is involved with nitrogen fixing within the roots nodules of plants. Once inside the plant cells of the root, $R$. tropici convert the atmospheric nitrogen into ammonia, which are utilized by the plant to make nitrogen containing compounds such as glutamine. In exchange, the bacteria are provided with organic molecules to use as a source of energy (Sawada et al., 2003). Alphaproteobacteria are highly resistant to predation and grazing. Substrate acquisition in some members of Alphaproteobacteria are known to degrade recalcitrant organic compounds including humic substances (Newton et al., 2011).

Betaproteobacteria are a class of microorganisms which belong to the phylum of Proteobacteria and are thus also Gram negative (Gyaneshwar, et al., 2011). Betaproteobacteria are aerobic or facultative anaerobic and are highly flexible with what they can biodegrade and use as a source of nutrition. Like Alphaproteobacteria, many Betaproteobacteria are also phototrophic as well as have nitrogen fixing capabilities by oxidizing ammonium to produce nitrite (Gyaneshwar et al., 2011). Betaproteobacteria were also only found in the summer sampling set (Appendix 2) showing that longer day time hours and brighter light conditions create favorable conditions motivating their proliferation. Betaproteobacteria are readily 
culturable and the best studied class in the Proteobacteria phylum. This is also why so many of them were isolated and sequenced. Betaproteobacteria in many instances tend to be the numerically dominant class of microorganism present (Newton et al., 2011). Betaproteobacteria are stratified throughout the lake and therefore found in different concentrations depending on the depth sampled, with their highest abundance near the surface. Many microorganisms from this class are often found in close association with algae (Newton et al., 2011).

Betaproteobacteria have been seen to inhabit many kinds of freshwater ecosystems including temperate, stratified, oligotrophic, and eutrophic locations. These microbes are also competitive in photosynthetically active planktonic systems, and have a particularly fast growth rate in the presence of a nutrient surplus (Newton et al., 2011).

Gammaproteobacteria are Gram negative and belong to the phylum Proteobacteria. This class is comprised of important groups such as Enterobacteriaceae and Pseudomonadaceae (Williams et al., 2010). These groups of microorganisms have a huge influence on both science and medical fields due to their impact on research and human health as a number of bacterial pathogens occupy this class. Some of the most significant ones include; Salmonella spp., Yersinia pestis, Vibrio cholera, Pseudomonas aeruginosa, and Escherichia coli (Williams et al., 2010). However, none of these virulent and pathogenic microbes were detected from the filter media during community characterization. Gammaproetobacteria tend to be very metabolically versatile and so they would help degrade many various organic substrates (Williams et al., 2010). Many Gammaproteobacteria come from anthropogenic or zoonotic excrement sources and are therefore regarded as transient in nature. A majority of Gammaproteobacteria are copiotrophs, favoring environments rich in nutrients and therefore 
show higher presence near influent of waste water treatment plants. They have fast growth rates especially in the presence of nitrogen and phosphorus (Newton et al., 2011).

Microorganisms belonging to the class Flavobacteriia can be described as Gram negative, aerobic, rod shaped bacteria that are commensal or opportunistic in nature (Bernardet and Bowman, 2013). These microorganisms belong to the phylum Bacteriodetes and are known for being motile due to their ability to glide. Flavobacteriia can be found in almost all soil and freshwater environments and degrade a wide variety of polysaccharides but not cellulose (Bernardet and Bowman, 2013). Sphingobacteriia are a class of species also belonging to the phylum Bacteriodetes. Sphingobacteriia have the distinctive property of being able to synthesize sphingolipids and incorporate them into their cell walls. The particular bacterium isolated is of the genus Pedobacter (Muurholm et al., 2007). This microorganism is Gram negative and rod shaped. Pedobacter steynii are chemoheterotrophic, meaning they obtain their energy from the oxidation from electron donors of organic molecules. These can include proteins, carbohydrates, and lipids which are all prevalent in biofilms.

Cytophagia are a class also belonging to the phylum of Bacteriodetes. The bacteria isolated from the samples was shown to be Sporocytophaga cauliformis. There is very little information on this particular microorganism however most species within its class are known to be Gram negative and aerobic. Many microorganisms in this class are motile through means of gliding and tend to favor psychrophilic environments which explains why it was an isolate in the winter sample set (Reichenbach, 1974). This class is often in close relation to Flavobacteriia and they are both known for their low GC content. All microorganisms with the class Cytophagia are chemoorganoheterotrophs meaning they derive energy off of consuming pre-formed organic molecules. Most of them prefer to oxidize proteins such as casein or gelatin although many are 
also capable of undergoing the process of glucose fermentation. Many of these microorganisms also live in the soil and readily decompose cellulose so they play a key role in the recycling of nutrients in the ecosystem (Reichenbach, 1974).

This collection of classes all under the phylum of Bacteriodetes exhibits a large phenotypic and metabolic diversity (Newton et al., 2011). Baceteriodetes are commonly found in soil and fresh water environments but also as symbionts of plants, animals, and humans. Bacteriodetes nutritionally are chemoorganotrophs and play an important role in degrading many biopolymers (Newton et al., 2011). Interestingly, Bacteriodetes occurrence cannot be patterned to any seasonal or lake specific occurrence however, their abundance is seen to follow after cyanobacterial blooms (Eiler and Bertillson, 2004).

Bacilli were the only class of microorganism belonging to the phylum Firmicutes while all the rest either belonged to the phyla Bacteriodetes or Proteobacteria. Bacteria in the class Firmicutes are largely Gram positive (Vilain et al., 2006). These microorganisms tend to be aerobic, meaning that they use oxygen as a terminal electron acceptor, but can also be facultative anaerobes (Vilain et al., 2006). This is a group that has high genetic heterogeneity with GC content ranging from 32 to $69 \%$. This indicates that this is a complex and well diverse group of microorganisms (Bergey's Manual of Systematic Bacteriology, 1st ed. 1986). The isolate discovered in the winter sample set was identified as Bacillus cereus. Several strains of B. cereus are known to be common pathogens causing food poisoning. It all of the aforementioned features described above common to the majority of microbes in its class and is rod shaped. B. cereus is also very motile through its flagella and exhibits both swimming and swarming types of motility. Furthermore, it is most comfortable between $20^{\circ} \mathrm{C}-30^{\circ} \mathrm{C}$ making it mesophilic however it is known to be highly resistant and very adaptable to different environments in part due its ability 
to form endospores. B. cereus is very metabolically versatile and can use a variety of compounds such as carbohydrates, proteins, peptides, and amino acids (Mols, et al., 2007). The most common carbohydrates it can break down include glucose and sucrose but it can also biodegrade nitrate using its metabolic enzyme nitrate reductase (Mols, et al., 2007). This microbe can be found in soil interacting within the rhizosphere acting as a saprophyte and decomposing dead matter as well as parasitizing fungi and therefore being beneficial to plants (Jensen et al., 2003).

Though not identified within the samples, Actinobacteria are also very common microbes prevalent in freshwater ecosystems. In fact, they are often the numerically dominant phylum contributing $>50 \%$ of the bacteria in the epilimnion (Newton et al., 2011). They are also present in the hypoliminon but reduced oxygen diminishes their abundance at this depth. Isolation of these microbes was proven to be difficult providing reason to why they were not present on the plates. Actinobacteria have been seen in both oligotrophic as well as hypereutrophic lakes indicating their persistence in a range of nutrient levels (Newton et al., 2011). Actinobacteria are small in size, have thin cell walls, and are Gram positive. They have average to below average growth rates compared to other phyla of fresh water bactrioplankton communities. Examination of their nutrition and metabolic pathways revealed a preference in nucleic and amino acid metabolism as well as harboring rhodopsins, supplementary machinery for energy via light harvesting (Newton et al., 2011).

\subsection{Seasonal Changes}

Microbial diversity results parallel the findings from Henne et al. where warmer water temperatures yielded significantly less biodiversity than colder water temperatures (Figures 4.2 and 4.3). Their study observed a more than 50\% reduction in phylotypes in hot drinking water 
than from cold drinking water (Henne et al., 2013). Additionally, community finger prints indicated that both Alphaproteobacteria and Betaproteobacteria were the most dominant taxonomic groups in hot drinking water as they were best adapted to higher temperatures. Both of these findings are consistent with the current experimental results for characterization of the summer sampling set (Figure 4.3).

Phylogenetic identification revealed a markedly different bacterial community structure between winter and summer sampling sets indicating a high turnover of the microflora. This highly seasonal variation in the microbial population may also be a product of extrinsic factors including precipitation as well as mixing periods within the lake. According to Henne et al, increased precipitation levels in warmer temperatures seen in spring and summer introduce a lot of nutrients into the water through elevated run off. Higher concentrations of organic and inorganic nutrients, such as carbon compounds and nitrates, enter the water system resulting in the subsequent growth of microorganisms (Henne et al., 2013).

Bodies of water found in Canada are classified as temperate lakes. Many of these freshwater sources are either dimictic or monomictic depending on temperature conditions. Lake Ontario is a cold monomictic lake meaning that water circulation occurs once a year during the summer. This dramatic shift in nutrients, oxygen levels, and temperatures opens a gap for other bacteria to establish dominance better suited to the new conditions (Henne et al., 2013). Typically, due to the higher levels of resources in the summer, the now dominant mesophilic community will out compete and drive out most of the psychrophilic bacteria.

Phylotypic identification shows differences throughout the year however this is not to say that these same microbes are not found year round (Henne et al., 2013). Rather, their abundance 
at certain points under unfavorable environmental conditions reaches very low, beyond detectable limits. Based on the model of abundant rare numbers, the biofilm is comprised of a few core members which flourish, while a multitude of many other microorganisms belonging to a variety of taxa forming what is known as a "seed bank", exist but do not proliferate enough to outcompete the better adapted microbes (Henne et al., 2013). These other bacteria are present in very low abundance and may go undetected however will dominate once favorable conditions promote their growth.

\subsection{CLSM \& Image Quantification of Biofilm Parameters}

One of the factors contributing to the novelty of this study concerns with confocal microscopy being used to image biofilms on biofilter media from a biofiltration system. The images produced, together with the quantitative data garnered through COMSTAT on the biofilm parameters and the nutrient removal data provided by the pilot scale, will complete the study. Jointly this data and information will provide an all-encompassing understanding of the operation of biofiltration systems on a seasonal basis, specifically in and around Lake Ontario under current conditions and anthropogenic practices. Qualitative observations will be linked with quantitative data to show similar findings and consistency.

A qualitative assessment shows winter CLSM images to have concise colonies that are densely packed and a few definitive trends are established very quickly. The first trend observed, relates to the backwashing effect on biomass, which is significantly reduced for both GAC and anthracite media. A cross comparison between Figure 4.4a and Figure 4.4b with Figure 4.5a and Figure $4.5 b$, indicates that anthracite is losing considerable amounts of biofilm. Similarly, a cross comparison between Figure 4.6a and Figure 4.6b with Figure 4.7a and Figure 4.7b illustrates 
how GAC also loses a significant portion of its biofilm to a backwash. Although much of the biomass may have been sheared off, the media may still be overloaded on the molecular level due to its highly adsorptive nature. Therefore, GAC's adsorbent phase may still be at capacity even after a backwash, still rendering it saturated. The saturation however is not visible qualitatively through CLSM because the adsorbed particulate matter, is not entirely from microbes or constituents of biofilm, but also includes small inorganic molecules (Janerotech Inc., n.d.).

The next noteworthy pattern stemming purely from a qualitative interpretation of the winter sample set relates to biomass. GAC has a higher level of biomass than the anthracite media before backwashing. When evaluating brightness intensity and pixilation which are indicators of biomass, Figure 4.6a and 4.6b (GAC before a backwash) had more microbial biomass than Figure 4.4a and 4.4b (anthracite before a backwash). This observation goes hand in hand with the literature as well as the quantitative analysis through COMSTAT in Figure 4.12, which showed biomass concentration is double for GAC than it is for anthracite. This can be attributed to GAC's much more rough and heterogeneous physical nature. The increased surface area allows for more sites for bioattachment which inevitably contributes to higher levels of biomass. The experimental data retrieved, supports the literature which states that GAC has biomass levels that are many orders of magnitude higher than anthracite. Studies have seen that GAC can harbour anywhere between three to eight times more biomass than anthracite (Chaudhary et al., 2003). This would allow for a much higher rate of nutrient uptake and biodegradation of organic molecules, leaving the effluent with a reduced nutrient load. The random acquisition of images in order to reduce bias, has created the graphs with highly variable data and large error bars which can be seen above. Biofilms do not have consistency or order due 
to high fluctuations in cellular biomass and organic material entrenched in the biofilter matrix. Examination of Figure 4.8 shows that the error bars for the GAC media are much larger than for the anthracite indicating a large degree of variation in biomass for GAC but still harbouring a higher concentration of microbes.

According to a recent study conducted by Passarelli et al., 2014, which investigated the composition of EPS based on seasonal changes, it was seen that there is a greater amount of polysaccharides during the summer season. In addition, it was discovered that a large amount of the EPS is comprised of carbohydrates, predominantly glucose but also consisting of a high proportion of galactose and mannose (Passarelli et al., 2014). This not only shows the importance on having a large biodiversity of microorgansisms that can break down sugars but also gives some insight and reason behind the biofilm structure in the images obtained. Qualitative assessment of the images in figures 4.10a and 4.10b show a much fluffier composition. The highly branched polysaccharides are responsible for this fluffy texture (Reese and Guggenheim, 2007). This provides one possible explanation, linking a higher concentration of polysaccharides to the "fluffy" biofilm images of the summer season. This "fluffier" or confluent appearance is in comparison to the winter images which are more diffuse in terms of cellular distribution across an imaged area and compact in biofilm structure.

Microscopy and subsequent quantitative analysis on the summer sample set revealed that biomass did in fact change post backwash showing a reduction in both filter media types. Statistical analysis conducted on the data comparing biomass levels before and after a backwash was carried out by performing the ANOVA test. The four tests were done in order to see if the reduction in biomass after a backwash was indeed significant. The ANOVA comparing biomass for GAC before and after backwash in the winter gave a p-value of 0.013 while the summer gave 
a p-value of 0.00010 (Table 4.1). Both of these values are below 0.05, and therefore GAC biomass reduction is statistically significant. Moving on to the anthracite, the summer sample gave a p-value of 0.031 while the winter value was 0.99 (Table 4.1). Therefore, the two tests for anthracite show biomass reduction by backwashing in the summer, to be statistically significant, however biomass reduction in the winter was not statistically significant.

Biomass was considerably higher for GAC than for anthracite before a backwash. This was also similarly tested using the data to see if it was a significant difference between the two filter types. The ANOVA comparing GAC before a backwash with anthracite before a backwash in the winter months, gave a p-value of 0.32 which shows that GAC did not significantly have more biomass than anthracite in the winter sample set. The summer comparison before a backwash between the two filter media however yielded a p-value of 0.0001 . Therefore, only the summer comparison pre-backwash gave a p-value below the 5\% significance level. A trend can be seen here; ANOVA tests show that when comparing between samples that are both anthracite media or both within the winter season, the differences are not statistically significant. Overall, GAC had a statistically significant higher volume of biomass than anthracite during summer months and before a backwash.

There was a tendency for summer season samples to report a higher level of biomass than winter samples. One reason for this is due to the larger amount of EPS observed in summer samples (outlined above by Passarelli et al 2014) which was stained by Syto 9. In addition, microbial concentration was also higher. A microbial concentration increase is brought on in summer months due to warmer ambient temperatures which have a positive influence on growth rates of many mesophilic bacteria (Kelly et al., 2014). Bacterial abundance is also boosted in summer months due to increased presence of inorganic nutrients such as nitrogen and 
phosphorus (Kelly et al., 2014). When statistical analysis was performed to see if this seasonal trend was significant, the ANOVA comparing GAC before backwash in the winter with GAC before backwash in the summer yielded a p-value of 0.0299. Likewise, anthracite before a backwash was also compared between winter and summer and the p-value was 0.99 . This therefore shows that GAC was able to keep up biological activity higher than anthracite for both seasons, although there wasn't a statistical significance between the two media during the winter (p-value 0.32). To summarize, ANOVA tests indicated seasonal changes brought on significant increases in biomass between winter and summer seasons for GAC filter media. While the biomass levels did increase for anthracite, it was not a statistically significant difference.

The next important trend observed, was relevant for both winter and summer sample sets. GAC's biofilm consisted of a more "fluffy" or clumped nature than the biofilm residing on anthracite. It would seem that the microbes on the GAC have produced a structurally unique and distinctly different biofilm from the microbes living on the anthracite, this can be attributed to the presence of the activated sites on the GAC (D. Scott, personal communication, August $31^{\text {st }}$, 2015). The dense and "lumpy" biofilm on the GAC for both seasons (Figures 4.6a \& 4.6b and 4.10a \& 4.10b) is very unlike the dispersed and "clear" biofilm on the anthracite.

The biofilm is a meshwork of compact and interlocked organic structures which is not easily disrupted. As stated before, the cells are embedded into the EPS anchoring them to a surface. Removal of the EPS will consequently remove the microorganisms embedded in it, leaving behind only the cells loosely associated with the biofilm or well protected microbes, entrenched deep in the pores. Judging by the images from before a backwash (Figure 4.6a and Figure $4.6 \mathrm{~b}$ or Figure 4.10a and Figure 4.10b), the biofilm on the GAC had a thicker EPS layer that rooted them in place. On the other hand, the biofilm on the anthracite was not as thick or 
extensive as can be seen by the singular cells and dark spaces between them (Figure 4.4a \& Figure $4.4 \mathrm{~b}$ and $4.8 \mathrm{a} \& 4.8 \mathrm{~b})$. The biofilm, and specifically the EPS layer, is in closer association with the microbes on the GAC than with the anthracite. Hence explaining why much of the biomass (and therefore a majority of the bacteria) was removed after a backwash within the GAC (see Figure 4.12). In conclusion, a thicker and more encapsulating biofilm is seen to reside in GAC over anthracite and in summer samples more than winter samples and therefore contributes to the greater reduction of microbes after a backwash for both biomass (Figure 4.12) and average thickness (Figure 4.13).

Both summer and winter samples reported GAC before a backwash, with a higher average thickness than anthracite before a backwash. An ANOVA test comparing GAC and anthracite prior to backwashing in the winter season yielded a p-value of 0.039 , scoring below the 5\% level and thus showing that GAC did have a higher average thickness than anthracite. The same ANOVA test carried out for the summer season yielded a p-value of 1.00, indicating that although there was a slight trend for GAC's average thickness to be more, it was not a statistically significant difference. The reasoning behind this is due to the macroporous structure of the GAC, which seems to provide a more all-encompassing protection of the biofilm than the mesoporous and microporous structure does in the anthracite. This can be seen in Figure 4.13 which is a graphical representation of average thickness. GAC's macroporous structure allows for a larger buildup of biofilm in the trenches of the media's surface. This bioaccumulation between the "large peaks and valleys" are granted heightened stability allowing the biofilm to pile up higher and get up to 50 microns thick in some cases (D. Scott, personal communication, August $31^{\text {st }}$, 2015). The protection granted by the internal structure of the GAC granules serves to keep the biofilm intact for small scale disturbances such as draining of the filter, which is not 
significantly turbulent enough to cause sloughing off. However, the macroporus structure cannot protect against the more abrasive backwash that has enough shear force which removes the majority of the biofilm to the same extent or more than with anthracite.

Moving forward, addressing the difference between the filter media's average thickness before and after a backwash is also necessary, to better conceptualize biofilm structure within the granules. Figure 4.13, shows that the average biofilm thickness of both GAC and anthracite has been cut down considerably after a backwash. Analysis of the data shows a statistically significant decline in average thickness after a backwash for GAC in both winter and summer seasons as well as anthracite in the summer producing p-values $0.0024,0.0020$, and 0.00050 respectively (Table 4.1). However, it is important to note that there are also many regions within the carbon based granules that are unreachable to the forces of a backwash hence retaining some biofilm. The biofilm remained intact along the length of the pore which runs very deep especially in the GAC due to the macroporous structure. Although biofilm on the surface and near the mouth of the pore was scrubbed off in many places, the "arteries" and "channels" running through the granules are still filled with the solidly entrenched biomass (Figure 5.1).

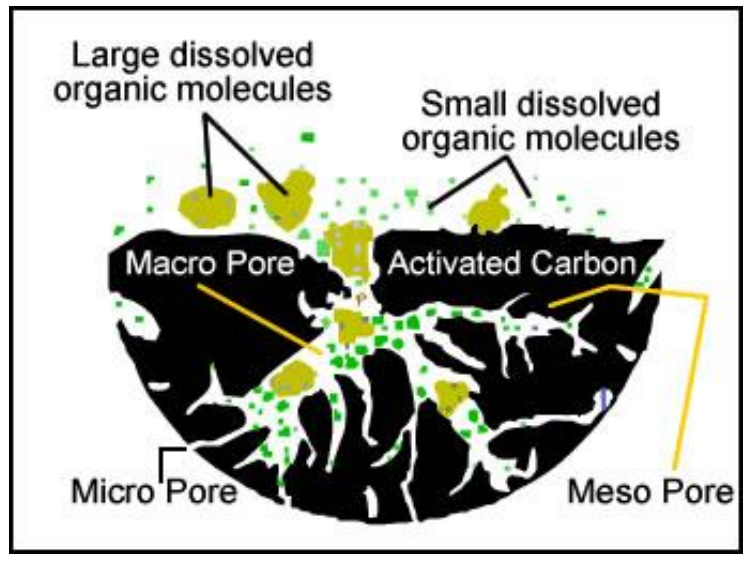

Figure 5.1: Biomass and organic content entrenched in pores of activated carbon granules. The biomass deep inside is not exposed to shear forces exerted by backwash preventing complete removal. Image adopted from Abdulqadir, 2014. 
Upon examination of the roughness variable (Figure 4.14) both winter and summer sample sets reveal a similar trend. An increase in the roughness coefficient of a biofilm's surface after a backwashing event can be seen for both GAC and anthracite filter media. This phenomenon can be attributed to the backwashing which leaves behind a more heterogeneous layer. ANOVA tests revealed a statistically significant increase in the roughness coefficient post backwash for GAC in both winter and summer seasons as well as for anthracite during the summer, yielding p-values of 0.0001, 0.0001, and 0.0097 respectively (Table 4.1).

The abrasive power of the backwash exerts a ripping or shearing type of force on the biofilm (Bai et al., 2004). When a backwash occurs water at a high pressure is released from the bottom of the filter column and rushes upwards getting beneath the biofilm's weakest layers and detaching the loosely associated parts. Detachment rate is a significant cause behind biofilm roughness. This detachment frequency is based on a series of variables that incorporate substratum roughness, biofilm thickness, EPS composition; i.e. its density (Stewart, 1992) (Figure 5.2). This was done to try to model biofilm detachment due to the many categories of detachment; erosion, sloughing, human intervention, predator grazing, and abrasion (Bryers, 1988). Due to the branched and interwoven nature of the polysaccharides (Vu et al., 2009), this detachment does not result in a smooth layer but rather a rough and uneven one. The distorted meshwork of cellular components and organic compounds left behind in the torn remnants of the EPS will form irregular protrusions along the new surface. A biofilm's surface, which has not been disturbed (before a backwash), would be prone to leveling events resulting in a more horizontally even plane. Over time, the biofilm would be eroded and "filed" down by biofilm grazers and the downwards current at unstable points (Picioreanu et al., 2000). Once a backwash 
occurs however, this new surface has not been exposed to those same elements and therefore has the slightly coarser exterior.

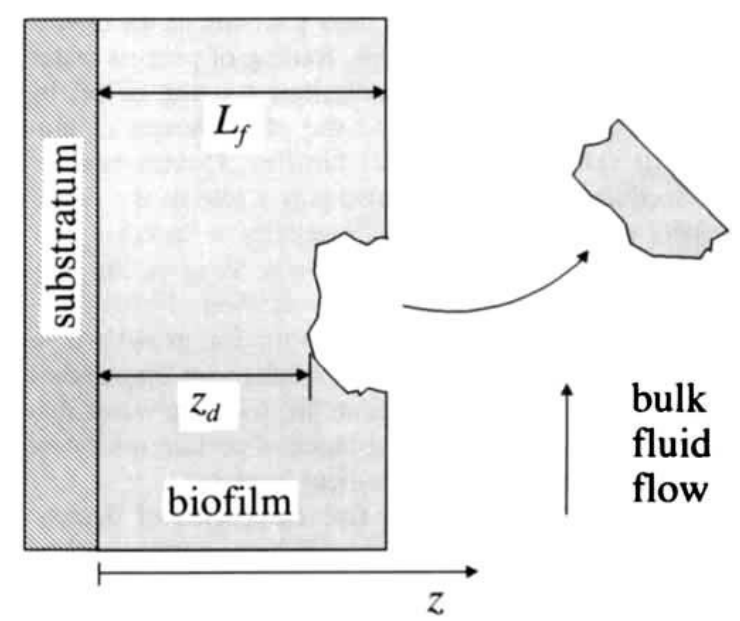

Figure 5.2: Schematic of biomass detachment from a biofilm during a backwash event. Where $L_{f}$ denotes biofilm thickness. $\mathrm{z}$ represents the local detachment frequency, and $\mathrm{z}_{\mathrm{d}}$ equals the thickness after detachment at $\mathrm{z}=\mathrm{z}_{\mathrm{d}}$. The substratum begins at $\mathrm{z}=0$. These variables were all constructed on the mathematical model and coordinate system adopted by Stewart, 1992.

Figure 4.15 depicts surface coverage for the two filter media during winter and summer seasons, as well as the state of the biofilm before and after a backwash. An interesting observation can be drawn; just as with roughness coefficient, the surface coverage for most of the samples (excluding GAC before backwash in the winter which shows a decrease), also increase post backwash. These slight increases however, are not statistically significant for any of the comparative analyses. Each test conducted compared pre-backwash with post backwash within the same season, to observe for any significant difference on the biofilm structure. ANOVA tests comparing GAC in the summer and winter and anthracite in the summer and winter yielded p-values of $0.20,0.82,0.97$, and 0.84 respectively (Table 4.1 ). Limited literature is currently offered, however the similar trend can lead to a plausible explanation. What is seen in the data, is the distortion of the biofilm caused by the external force of the backwash, consequently shaping the biofilm differently. Upwards pressure of a backwash may also cause a 
partial flattening of the biofilm causing it to spread out and disperse. This dispersal and flattening to some extent, explains why the biofilm thickness was also reduced.

\subsection{Pilot Scale DOU and TOCU Data}

A series of diagnostic tests were conducted at the pilot scale in order to determine the efficiency of the filers with regards to removal of organics as well as biological activity. Both of these factors were tested by measuring the two variables, TOCU and DOU. The first test that was run (Figure 4.16) looked at the two variables and how their uptake and consumption within the filter are influenced. Figure 4.16 depicted the important role which EBCT plays in nutrient removal. It is seen that GAC filters with a flow rate of $1.2 \mathrm{~L} / \mathrm{min}$ have the highest removal rates for DO and TOC, with $0.93 \mathrm{mg} / \mathrm{L}$ and $0.31 \mathrm{mg} / \mathrm{L}$ respectively. GAC with a flow rate of $2 \mathrm{~L} / \mathrm{min}$ has less uptake capabilities with DO and TOC removal being recorded at $0.535 \mathrm{mg} / \mathrm{L}$ and 0.195 $\mathrm{mg} / \mathrm{L}$ respectively. Finally anthracite which was flowing at $1.2 \mathrm{~L} / \mathrm{min}$ had a DO and TOC removal of $0.075 \mathrm{mg} / \mathrm{L}$ and $0.02 \mathrm{mg} / \mathrm{L}$ respectively. Comparison of the numerical data for the two GAC filter systems (at different flow rates) show an inversely proportional relationship between the flow rate and nutrient removal. That is, the higher the flow rate, the lower the uptake and consumption. Removal rates are seen to influence uptake of nutrients based on their residence time within the filter system.

TOCU and DOU have an indirect effect on each other because both variables are on opposite ends of the same process. Carbon, found in carbon containing compounds which are generally grouped as TOC, is the initial constituent which is up taken and broken down by microorganisms. Most of the microbes biodegrading these organics are aerobes and thus require oxygen when undergoing cellular respiration to derive energy. This oxygen, which is already 
dissolved in the water is taken up by the bacteria. Thus, DOU can be established as the independent variable because it reflects the microbes' metabolism, which dictates the rate at which organics are broken down and removed from the effluent. DO consumption and thus biofilm respiratory activity, is an indication of TOC removal. Figure 4.16, depicts there is a correlation between the concentration of dissolved oxygen that is taken up and the amount of organics that are utilized. Figure 4.17 supports this linear relationship by illustrating the proportionately equivalent profile of the bars for both DOU and TOCU.

The second experiment carried out was to observe how the biofilm would react when adding extra nutrients which normally are not present in such abundant quantities. Phosphate is a very good indicator for such tests because it is the limiting reagent for metabolic processes and essential for life.

Phosphate, is a limiting nutrient which enhances metabolic potential by keeping the biological community active (Li et al., 2010). An elevated level of metabolic activity ensures a biofilm is proliferating and has a heightened level of cellular respiration. The higher this rate of cellular respiration means the largely aerobic communities require a higher level of oxygen consumption. Consequently, the dissolved oxygen removal will increase. Higher cellular respiration indirectly correlates to more organics biodegraded which will help sustain the active microbial community; thus with an increased metabolic activity, the level of organic molecules biodegraded also amplified. Therefore, the level of TOC removal is increased.

Nutrient spikes comprised of glucose, phosphate and ammonia were added in a concentration of $1 \mathrm{mg} / \mathrm{L}$. What was observed was that all the sugar was removed and biodegraded because it was not detected in the effluent. However, there was not a proportionate reduction in DO which should have also decreased due to cellular respiration taking place 
(Figure 4.19). The green data shows a very steep slope of TOC removal, interestingly, this trend doesn't apply to the DO removal.

From the data received, GAC biofilters with a flow rate of $1.2 \mathrm{~L} / \mathrm{min}$, detected an average TOC concentration of $1.52 \mathrm{mg} / \mathrm{L}$. TOCU from GAC at $1.2 \mathrm{~L} / \mathrm{min}$ however read an average of $0.31 \mathrm{mg} / \mathrm{L}$. Therefore, the observable removal of TOC from the GAC biofilters with a flow rate of $1.2 \mathrm{~L} / \mathrm{min}$ was $20.4 \%$. This was calculated by dividing the removed concentration from the total concentration. For the same filters, DO was detected to have an average concentration of 13 $\mathrm{mg} / \mathrm{L}$ and DOU was recorded at $0.93 \mathrm{mg} / \mathrm{L}$. As a result, the removal of DO was calculated at $7.15 \%$.

GAC biofilters with a flow rate of $2 \mathrm{~L} / \mathrm{min}$ observed an average TOC concentration of $1.64 \mathrm{mg} / \mathrm{L}$. TOCU from these biofilter columns was an average of $0.1 \mathrm{mg} / \mathrm{L}$. This resulted in an overall uptake and removal of $6.1 \%$ of TOC. These same biofilters had a DO concentration reading of $13.52 \mathrm{mg} / \mathrm{L}$ and DOU of $0.38 \mathrm{mg} / \mathrm{L}$. Consequently, this means there was an average of $2.8 \%$ reduction in DO from these filters.

Anthracite biofilters with a flow rate of $1.2 \mathrm{~L} / \mathrm{min}$ detected an average TOC concentration of $1.81 \mathrm{mg} / \mathrm{L}$. TOC removal was determined to be an average of $0.02 \mathrm{mg} / \mathrm{L}$. Therefore the anthracite filter columns had an overall net reduction of $1.1 \%$ for TOC. The DO concentration in the anthracite filters was measured to have an average of $13.88 \mathrm{mg} / \mathrm{L}$. DOU was shown to be $0.075 \mathrm{mg} / \mathrm{L}$ which as a result shows an average DO reduction of $0.5 \%$.

Upon comparison of these percentages it can be seen that conversely to Figures 4.17 and 4.18, the respective proportions of DO and TOC removal have reversed. This deviation from the standard conditions creates speculations as to why this occurs. One popular explanation lies with 
the inherent nature and behaviour of the microbial community which is dependent on their external surroundings (D. Scott, personal communication, August $31^{\text {st }}, 2015$ ). The higher reduction in nutrients without similar reduction levels of DO shows that these nutrients are being taken up and removed from the water, however the lack of increased metabolic activity measured indirectly through the DO measurements show that it is being held on to rather than being biodegraded. Therefore, this finding indicates that the sugar is not being consumed by the microorganisms, it is being stored in the biofilm and saved for a period of resource scarcity (D. Scott, personal communication, August $\left.31^{\text {st }}, 2015\right)$. The purple data point at $(0.21,0.24)$ is the anthracite 4 hours after a backwash. The low removal rate of DO suggests that the anthracite biofilm has a hard time recovering to its original state. The other two points from the purple data set located at $(1.36,0.39)$ and $(1.83,0.36)$, are how the GAC responded 4 hours after a backwash. It is clearly visible that although GAC has not recovered to the original state at the time of the nutrient spike, pre-backwash, it still managing better than the anthracite, with DO and TOC removal markedly higher.

Combining data of DOU based on filter media with the added parameter of seasonal influence on biofiltration systems, a better understanding of biofiltration systems can be acquired. A comparative analysis using the external conditions of temperature will also help future operations with regards to flow rate, nutrient spikes, regulation, and monitoring.

Data was collected and standardized appropriately, considering only filtration systems with the same flow rate. This was done in order to keep the study's results consistent and nonbiased. Therefore, the GAC and anthracite filters with a flow rate of $1.2 \mathrm{~L} / \mathrm{min}$ were the only ones incorporated into the calculations. Flow rate has a direct correlation to nutrient removal 
because it influences the EBCT, hence affecting the amount of time these nutrients spend in the filter columns.

From Figure 4.19 it is visible that GAC's removal capabilities on dissolved oxygen are far beyond that of anthracites throughout different seasonal temperatures. As hypothesized about nutrient removal and bacterial metabolism, DO uptake is significantly lower in cold temperatures as opposed to warm temperatures. The fluctuations in dissolved oxygen uptake is correlated with metabolism and bacterial proliferation which have evidently slowed during the winter months (Jan et al., 1996). During the summer months DOU increases, and according to Kelly et al, this is due to microbial concentrations increasing. Furthermore, metabolic activity also increases during warmer ambient temperatures (Schindlbacher et al., 2011). Therefore, with higher microbial biomass (observed in both COMSTAT data and HPC), as well as increased levels of metabolic activity and aerobic respiration, the DOU was predicted to rise. The graph in Figure 4.19 is consistent with results showing a positive correlation between higher temperature and increased DO uptake.

GACs ability to outcompete anthracite year-round is consistent with the other experiments in this study that show GAC's higher biomass both qualitatively and quantitatively as well as it encompassing a larger biodiversity during winter months (Appendix 1).

Figure 4.21 was constructed from biomass data from Figure 4.12 and pilot plant TOCU temperature dependent data from Figure 4.20. Figure 4.21 bridged two very important concepts regarding variables influencing TOCU. It is evident that GAC harbors more biomass in both seasons (Figure 4.12), despite this, summer anthracite outperforms winter GAC in TOCU. Hence this tethers a link between TOCU and metabolic activity which is boosted in warmer climates 
(Schindlbacher et al., 2011). This showed that for a given temperature, higher biomass levels support higher TOCU. Further, Figure 4.21 also depicted that for a given temperature, GAC supports a larger biomass than anthracite. What this therefore establishes is that TOCU is both dependent on biomass levels and temperature (biodegradation rate).

\subsection{Enhancing Biofilters}

Enhancing biofilter performance can be accomplished by inducing the microbial metabolic activity or strengthening the bonds that tether two distinct microorganisms which mutually benefit from each other's presence. In biofilms, microbes are constantly in close proximity to one another and use synergistic, commensalistic, and mutualistic relationships to cohabitate and proliferate. A study by Buitron and Gonzales, 1996, indicates that drinking water biofilms offer such benefits to the microbial community as a whole rather than in pure cultures. Common acclimated strains that are present in drinking water such as Aeromonas sp., Flavimonas sp., and Pseudomonas sp., (Appendix 1 and 2) all functioned faster at biodegredation of organic compounds by one to two orders of magnitude when they are used together compared to when in pure cultures (Buitron and Ganzales, 1996).

In addition specific metabolite requirements from one type of microorganism can be an opportunity for other species with different nutrition demands to also cohabitate. This would allow other microbes to take advantage of the untapped niche and abundant resources thereby allowing a multispecies consortium to coexist. When there is little overlap between two microorganisms" metabolic needs, both can live harmoniously and not be in direct competition with one another. Therefore it is desirable to create a microbial community with greater nutrient versatility by effectively broadening the spectrum of metabolites that can be up-taken and used, 
which consequently translates into a greater biomass production and consumpion rates (Tilman, 1999). An example of this can be seen with the two strains A. hydrophilia and H. defluvii which belong to the class Gammaproteobacteria and Betaproteobacteria respectively. Both of these microorganisms were isolated, sequenced and, identified in the biofilters as seen in Appendix 1 and Appendix 2.

A. hydrophilia and $H$. defluvii both utilize polysaccharides as their source of energy. However, nutrient demand and metabolite specificity cause both these microbes to biodegrade different substrates. A. hydrophilia uses the phosphoenolpyruvate (PEP) mannose phosphotransferase system (PTS) and $\mathrm{II}^{\mathrm{Glc}}$ (glucose) PTS in order to break down sugars (Binet et al., 1998). Both of these systems have sugar specificities that allow for a narrow range of metabolite activity. II ${ }^{\mathrm{Glc}}$ PTS is known for the uptake of glucose and $\alpha$-methyl-glucoside while mannose PTS is known for uptake of mannose, glucose, 2-deoxyglucose, $\mathrm{N}$-acetylglucosamine, glucosamine, and fructose.

On the other hand, $H$. defluvii undergoes oxidative metabolism and has a different list of metabolites which it can use a source of carbon; gluconate, glutarate, lactate, 3hydroxybutyrate, pyruvate, suberate, L-alanine, L-leucine, L-aspartate, L-histidine, phenylalanine, L-proline, 3-hydroxybenzoate and 4-hydroxybenzoate (Kampfer et al., 2005). A cross comparison analysis shows that, from the above lists of nutrient requirements for a carbon source, A. hydrophilia and H. defluvii are not in direct competition to each other. However allowing for these microorganisms to cohabitate would contribute to a greater volume reduction of polysaccharides in the water.

This is a prime example showing how boosting biodiversity and understanding the microbial interactions of the drinking water biofilm is crucial to the function and up-regulation of 
biofiltration. Polysaccharides are very common in freshwater ecosystems and the excess carbon present in the system can lead to some of the issues mentioned previously. Therefore it is imperative to not only harbour a diverse microbial consortium within the biofilm, but also one nutritionally biased to the compounds currently present within the water. Selecting a consortium on a seasonal basis which will target the main contaminants and macromolecules of abundance during those months can ensure maximal biodegradation.

Physical parameters can also play a role in nutrient removal. As was seen from the data in Figures 4.16 and 4.17, flow rate influenced the capabilities of a reduced nutrient load in the effluent. Therefore by increasing residence time of the water in the filtration units, the probability of nutrient uptake and biodegradability is greatly increased. Flow rate however, needs to be balanced with consumer demands. Biofiltration cannot be a rate limiting step in the treatment of water, and therefore there has to be a compromise between having a longer EBCT and delivering an ample supply of nutrient low water to the community. Increasing the residence time of the water in a biofilter can happen by decreasing the flow rate as well as increasing the length of the filter column or tank. Depth of filtration units, slope, and clogging are also parameters that need to be taken into consideration (Sileshi et al., 2010). Utilizing such parameters to adjust flow rate and therefore manipulate the quality and timing of the final product, will expose the water to biofiltration treatment for longer. 


\section{Chapter Six: Conclusion and Future Work}

The conclusions which can be drawn from this study help reveal the reasons behind GAC's better performance. The three objectives were all met with conclusions supporting GAC as the filter media of best choice for nutrient reduction. Experiments performed to fulfill objective 1, revealed that when backwashing, seasonal change and filter media did not play a role in microbial numbers. Additionally, although there was a difference in HPCs for prebackwash samples, showing summer with a higher abundance (Figure 4.1), ANOVA tests concluded that this was not a statistically significant difference. Anthracite had higher microbial counts pre backwash which indicates it is not as good at anchoring biofilm growth as GAC. Although there was a higher abundance of microbes in the effluent for the summer, it was not a statistically significant difference. Therefore, the first hypothesis regarding a larger microbial presence in the summer, was not supported by the plate counts.

The data also showed that seasonal change elicits a large turn over in the microflora causing a reduction in cultivable microbial diversity during the summer months. Characterization of the community profile displayed GAC as housing higher diversity than anthracite. Therefore, data did not support the first hypothesis, as the diversity was higher in the winter season than in the summer season as shown in Figures 4.2 and 4.3.

Experiments carried out for objective 2 showed that GAC supported double the biovolume that anthracite could support. This larger microbial presence can be attributed to activated sites which allow for adsorption of organics, followed by biodegredation, facilitating an environment for growth (Chaudhary et al., 2003). Furthermore, GAC granules have a pore structure enabling increased bioattachement. Therefore the data supported the second hypothesis which predicted that GAC having more biomass than anthracite (Figure 4.12). This larger 
biological activity will promote extended biological breakdown of TOC which leads to objective three.

With the help of pilot scale data, results for objective 3 demonstrated a correlation between external influences such as temperature, filter media type, and EBCT and nutrient removal. Once again, GAC showed a higher removal than anthracite for both DO and TOC. GAC during warmer temperatures and having a lower flow rate lead to the best nutrient uptake results. Higher TOCU and DOU are tightly correlated to temperature and seasonal changes which boost or suppress microbial metabolism (Jan et al., 1996; Schindlbacher et al., 2011). TOC and DO removal rates are higher in GAC than anthracite which complement the larger biomass concentration results observed. This larger biomass would effectively amplify the level of nutrient uptake and DO consumption. Furthermore, the larger biodiversity found in GAC would allow for a larger spectrum of metabolites to be biodegraded and removed, allowing for a more complete removal (Tilman, 1999). Therefore the second hypothesis was supported in stipulating that GAC would have a higher removal rate of TOC as seen in Figure 4.21 which verified greater TOCU with increased biomass and warmer temperatures. Figure 4.21 therefore provides a connection, linking biomass levels to nutrient removal while factoring in temperature as an influencing variable on metabolic activity and growth rate. Figure 4.17 provided further support indicating increased DOU and TOCU in GAC filter columns.

Overall, GAC provides a suitable environment for consistent growth and uptake, consequently leading to a more robust biofilm. From an extensive network of channels brought on by more surface roughness, to adsorption of the activated sites and subsequent biodegradation and bioregeneration (Chaudhary et al., 2003), GAC functions better at producing a low nutrient effluent. 
This experimental study investigated parameters of biofilter media and compared them to elucidate which would have better performance in nutrient removal. The parameters sought after, including biomass, biofilm thickness, and consortium diversity, directly correlate to a biofilter's nutrient load reduction capability. There are many other factors contributing to biofilter functionality however, and future studies can examine and analyze external parameters affecting a biofilm's proliferation in order to maximize efficiency. Such external influences include the presence of grazers and nutrient spikes.

There are many other external factors that can manipulate biofilm growth within biofilters and thus affect and alter performance. Many higher order consumers such as protozoa and other invertebrates depend on biofilms as a source of food. These heterotrophs often known as grazers also reside within the biofilters. Predation was initially not thought to extend its reach to the microbes under the protective cover of EPS (Parry et al., 2007). However, recent research shows that even these microorganisms are not exempt and are susceptible to being incorporated into the food chain. Predators originating in higher order trophic levels are able to penetrate EPS and allow the microbes to contribute to the food chain. Predation on microbial biofilms is known as grazing and a lot of it is undertaken by protists such as rotifers. Grazing allows for a consistent and constant uptake of nutrients and nutrient cycling. In contrast, with the absence of grazing, the biofilm would continue to develop into its mature state which can potentially decrease nutrient removal and thus metabolic activity (Block et al., 2007). A biofilm's growth and maturity is directly associated with the nutrient demand and resource pressure it exerts on its surrounding. Grazing allows for a biofilm to be kept in its adolescent stage and prevents maturation. Keeping biofilms in a younger stage allows them to always be in their exponential growth phase, where they exhibit a higher metabolic potential (Bruns et al., 2010). This increased metabolic activity 
leads to a higher nutrient demand and consequently a larger yield of organic substrates removed from the water.

Phosphorus is an essential nutrient for many organisms and is sometimes incorporated within nutrient spikes to boost microbial growth. It is a very tricky substance to supply to a microbial community however, because in many cases it is the limiting reagent which restricts organisms from continuing to grow and reproduce. Addition of phosphorus into an aquatic system leads to an explosion of growth. If too much of this nutrient is added, eutrophication can be a regretful outcome. However, the biofilms within the media bed of the biofilters require this element and are supplied it in predetermined doses. Phosphorus will increase microbial concentration and effectively amplify nutrient uptake and biodegradation (Miettinen et al., 1997).

The advantage of adding phosphorus is multifaceted; its addition is known to be associated with the increase in biodiversity which inadvertently increases biomass (Fang et al., 2009). This increase in biodiversity is key to greater nutrient cycling as well as enhanced uptake and subsequent breakdown of macromolecules (Li, et al. 2010). Furthermore, phosphorus addition is followed by advantageous behavioural changes within the microbial community. Research has indicated decreased EPS levels in communities which have been supplied with phosphorus. Therefore, these drinking water biofilms are less resistant and hence more susceptible to antimicrobial measures such as chlorination and antibiotics.

In addition, biodiversity results procured from the pilot plant were taken from only one day from the winter and one day from the summer. This alone is not a significant sample size to assess biodiversity. Future studies examining biodiversity derived from this pilot should include multiple sampling dates for both winter and summer seasons. Finally, cultivable biodiversity, 
which was examined in this study, constrains the range of microorganisms observed, as only $1-$ $10 \%$ are cultruable (Nicholson and Hirsch, 1998). Future studies should forgo pre-enrichment and use denaturing gradient gel electrophoresis (DGGE) to characterize microbes.

From the above examples it can be seen how imperative it is to know how to regulate and manipulate the biofilm community residing within the biofilters. This includes techniques to alter their metabolic state as well as making them less recalcitrant in the event the biofilter needs to be purged and re-inoculated. 


\section{Appendix 1}

\section{Table A1.1: DNA sequence and microbial identification of winter 2014 sampling set}

\begin{tabular}{|c|c|c|c|c|c|}
\hline Sample & Source & $\begin{array}{l}\text { Closest } \\
\text { Isolate }\end{array}$ & $\begin{array}{c}\text { Phylum/ } \\
\text { Class }\end{array}$ & $\%$ & DNA Sequence \\
\hline $1 \mathrm{CB}$ & $\begin{array}{l}\text { Anthracite } \\
\text { Before } \\
\text { Backwash }\end{array}$ & $\begin{array}{l}\text { Aeromonas } \\
\text { hydrophila } \\
\text { pc104A, } \\
\text { complete genome }\end{array}$ & $\begin{array}{c}\text { Proteobacterial } \\
\text { Gammaproteobacteria }\end{array}$ & 99 & 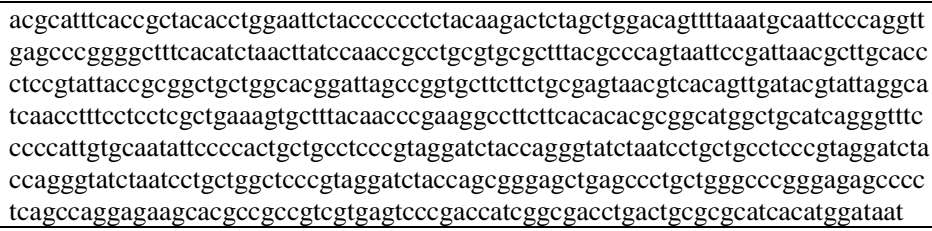 \\
\hline $2 \mathrm{WB}$ & $\begin{array}{l}\text { Anthracite } \\
\text { Backwash }\end{array}$ & $\begin{array}{l}\text { Pseudomonas } \\
\text { mandelii JR-1, } \\
\text { complete genome }\end{array}$ & $\begin{array}{c}\text { Proteobacterial } \\
\text { Gammaproteobacteria }\end{array}$ & 99 & 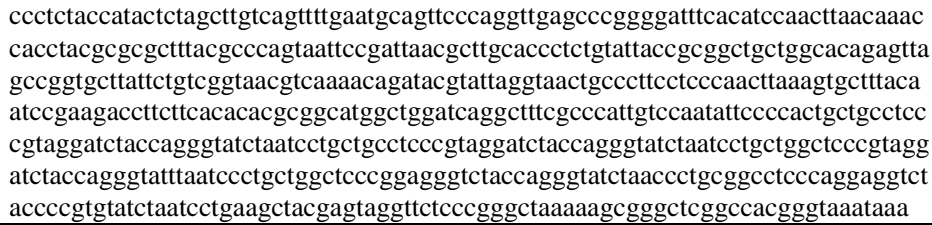 \\
\hline $3 \mathrm{YB}$ & $\begin{array}{c}\text { GAC } \\
\text { Backwash }\end{array}$ & $\begin{array}{l}\text { Flavobacterium } \\
s p . \text { UA-JF1511 } \\
\text { 16S ribosomal } \\
\text { RNA gene, } \\
\text { partial sequence }\end{array}$ & $\begin{array}{l}\text { Bacteriodetes/ } \\
\text { Flavobacteriia }\end{array}$ & 99 & 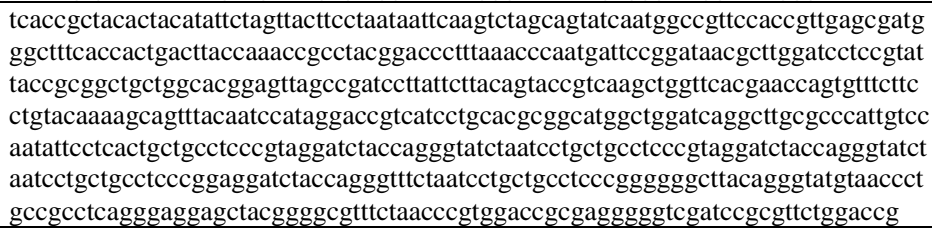 \\
\hline $4 \mathrm{WB}$ & $\begin{array}{l}\text { GAC Before } \\
\text { Backwash }\end{array}$ & $\begin{array}{l}\text { Flavobacterium } \\
\text { sp. } \\
\text { T148L.10.BKT. } \\
\text { W.Gill.N 16S } \\
\text { ribosomal RNA } \\
\text { gene, partial } \\
\text { sequence }\end{array}$ & $\begin{array}{l}\text { Bacteriodetes/ } \\
\text { Flavobacteriia }\end{array}$ & 99 & 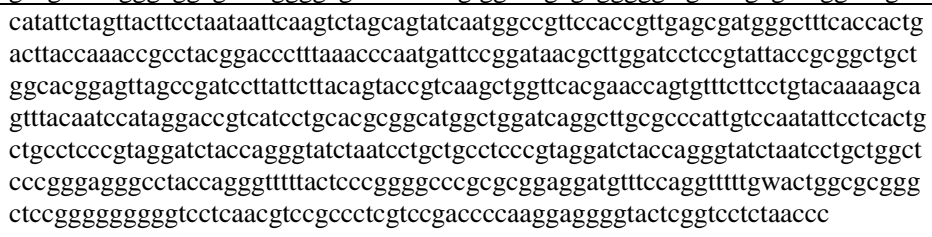 \\
\hline $5 \mathrm{WB}$ & $\begin{array}{l}\text { Anthracite } \\
\text { Before } \\
\text { Backwash }\end{array}$ & $\begin{array}{l}\text { Pseudomonas } \\
\text { koreensis partial } \\
\text { 16S rRNA gene, } \\
\text { isolate HR146 }\end{array}$ & $\begin{array}{c}\text { Proteobacterial } \\
\text { Gammaproteobacteria }\end{array}$ & 100 & 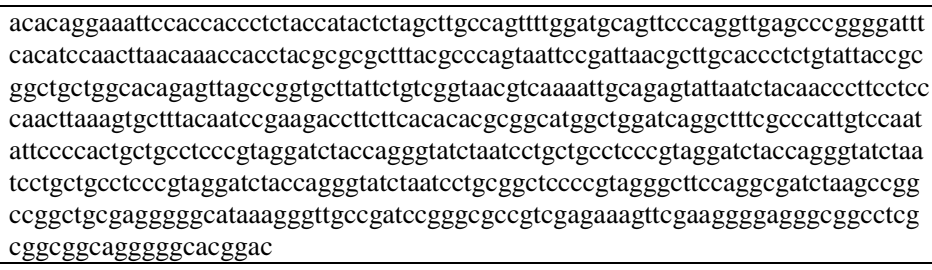 \\
\hline $6 \mathrm{WB}$ & $\begin{array}{l}\text { GAC Before } \\
\text { Backwash }\end{array}$ & $\begin{array}{l}\text { Bacillus cereus } \\
\text { strain SWFU02 } \\
\text { 16S ribosomal } \\
\text { RNA gene, } \\
\text { partial sequence }\end{array}$ & Firmicutes/Bacilli & 99 & 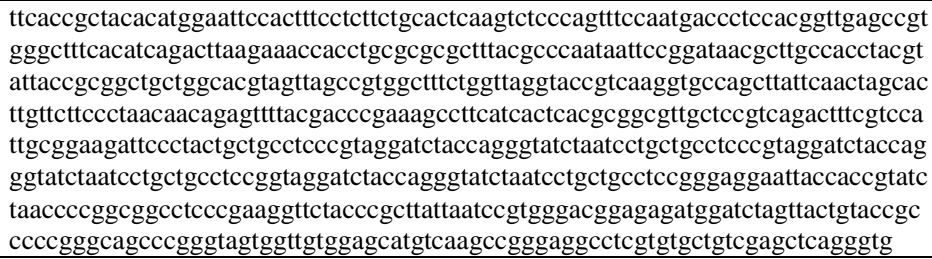 \\
\hline $7 \mathrm{SB}$ & $\begin{array}{c}\text { GAC } \\
\text { Backwash }\end{array}$ & $\begin{array}{l}\text { Pseudomonas } \\
\text { mandelii JR-1, } \\
\text { complete genome }\end{array}$ & $\begin{array}{c}\text { Proteobacteria/ } \\
\text { Gammaproteobacteria }\end{array}$ & 99 & 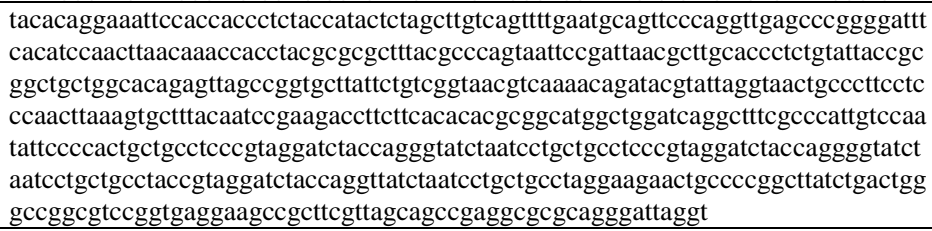 \\
\hline
\end{tabular}




\begin{tabular}{|c|c|c|c|c|c|}
\hline $8 \mathrm{SB}$ & $\begin{array}{c}\text { GAC } \\
\text { Backwash }\end{array}$ & $\begin{array}{l}\text { Pseudomonas } \\
\text { arsenicoxydans } \\
\text { strain AKB1 16S } \\
\text { ribosomal RNA }\end{array}$ & $\begin{array}{c}\text { Proteobacterial } \\
\text { Gammaproteobacteria }\end{array}$ & 99 & 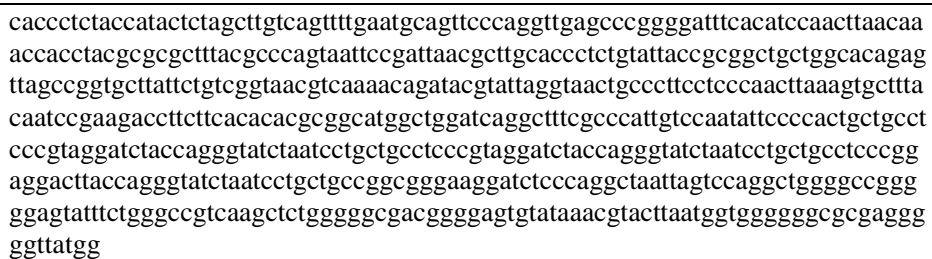 \\
\hline 9YB & Raw Water & $\begin{array}{l}\text { Sporocytophaga } \\
\text { cauliformis strain } \\
9726 \mathrm{R} 16 \mathrm{~S} \\
\text { ribosomal RNA } \\
\text { gene, partial } \\
\text { sequence }\end{array}$ & $\begin{array}{l}\text { Bacteriodetes/ } \\
\text { Cytophagia }\end{array}$ & 99 & 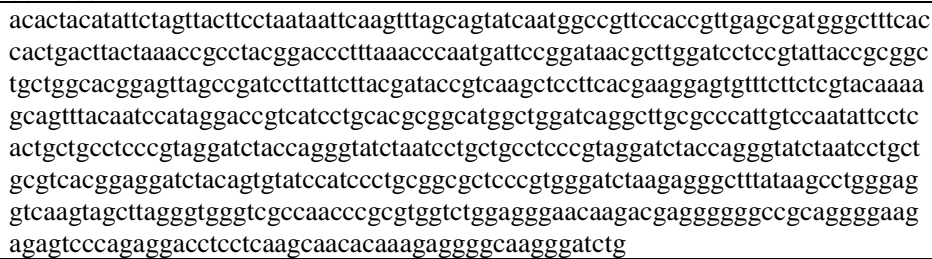 \\
\hline $10 \mathrm{CB}$ & Raw Water & $\begin{array}{l}\text { Aeromonas } \\
\text { veronii strain } \\
\text { K_G_AE-1 } 16 \mathrm{~S} \\
\text { ribosomal RNA } \\
\text { gene, partial } \\
\text { sequence }\end{array}$ & $\begin{array}{c}\text { Proteobacteria/ } \\
\text { Gammaproteobacteria }\end{array}$ & 99 & 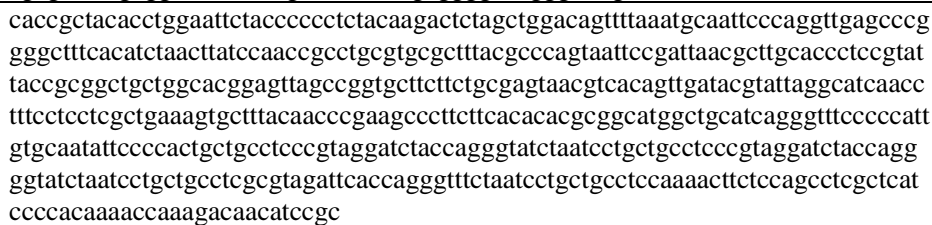 \\
\hline $11 \mathrm{YB}$ & $\begin{array}{l}\text { Anthracite } \\
\text { Backwash }\end{array}$ & $\begin{array}{l}\text { Pseudomonas } \\
\text { marginalis strain } \\
\text { PE34 } 16 \mathrm{~S} \\
\text { ribosomal RNA } \\
\text { gene, partial } \\
\text { sequence }\end{array}$ & $\begin{array}{c}\text { Proteobacterial } \\
\text { Gammaproteobacteria }\end{array}$ & 99 & 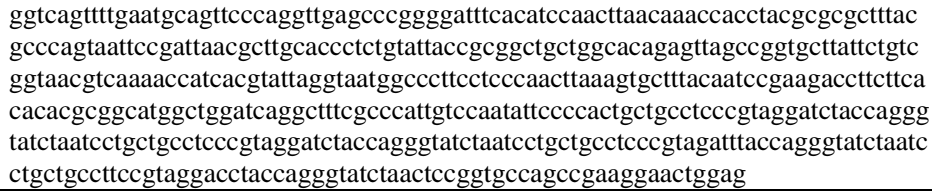 \\
\hline $12 \mathrm{CB}$ & $\begin{array}{l}\text { Anthracite } \\
\text { Before } \\
\text { Backwash }\end{array}$ & $\begin{array}{l}\text { Aeromonas } \\
\text { hydrophila } \\
\text { pc104A, } \\
\text { complete genome }\end{array}$ & $\begin{array}{c}\text { Proteobacteria/ } \\
\text { Gammaproteobacteria }\end{array}$ & 99 & 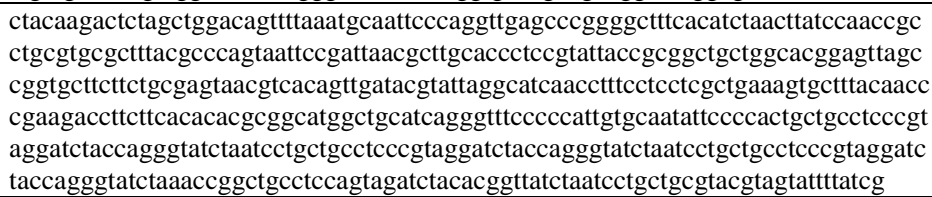 \\
\hline $13 \mathrm{~TB}$ & $\begin{array}{c}\text { GAC } \\
\text { Backwash }\end{array}$ & $\begin{array}{l}\text { Pedobacter } \\
\text { steynii strain } \\
\text { DX-4 16S } \\
\text { ribosomal RNA } \\
\text { gene, partial } \\
\text { sequence }\end{array}$ & $\begin{array}{c}\text { Bacteriodetes/ } \\
\text { Sphingobacteriia }\end{array}$ & 99 & 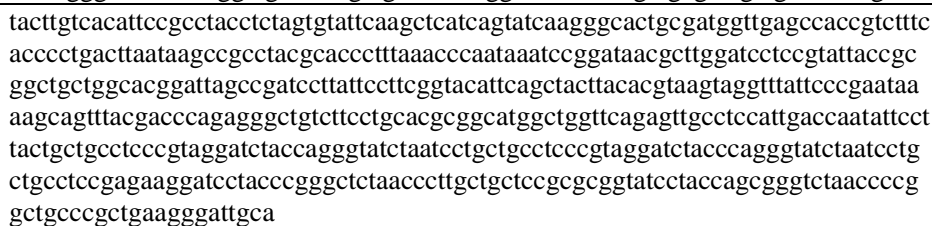 \\
\hline
\end{tabular}




\section{Appendix 2}

\section{Table A2.1: DNA sequence and microbial identification of summer 2014 sampling set}

\begin{tabular}{|c|c|c|c|c|c|}
\hline Sample & Source & $\begin{array}{l}\text { Closest } \\
\text { Isolate }\end{array}$ & $\begin{array}{c}\text { Phylum/ } \\
\text { Class }\end{array}$ & $\%$ & DNA Sequence \\
\hline 1 & $\begin{array}{c}\text { GAC } \\
\text { Backwash }\end{array}$ & $\begin{array}{l}\text { Hydrogenophaga } \\
\text { caeni strain EMB71 } \\
16 \mathrm{~S} \text { ribosomal RNA } \\
\text { gene, partial } \\
\text { sequence }\end{array}$ & $\begin{array}{c}\text { Proteobacterial } \\
\text { Betaproteobacteria }\end{array}$ & 99 & 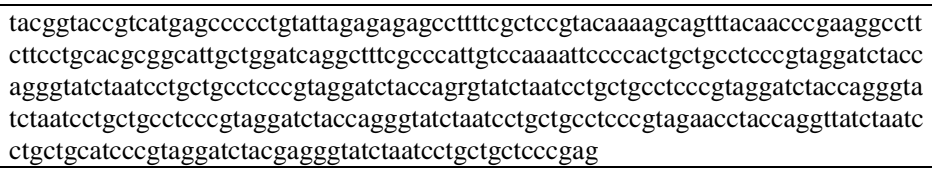 \\
\hline $3 a$ & $\begin{array}{c}\text { GAC } \\
\text { Backwash }\end{array}$ & $\begin{array}{l}\text { Albidiferax } \\
\text { ferrireducens strain } \\
\text { T118 16S ribosomal } \\
\text { RNA gene, complete } \\
\text { sequence }\end{array}$ & $\begin{array}{c}\text { Proteobacterial } \\
\text { Betaproteobacteria }\end{array}$ & 96 & 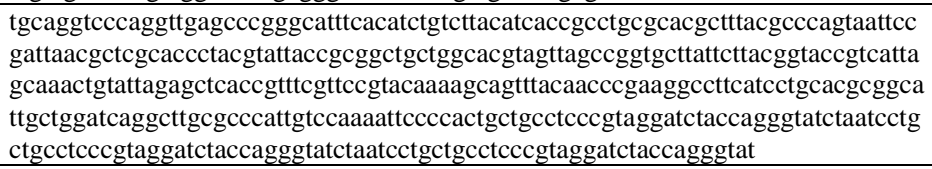 \\
\hline $3 b$ & $\begin{array}{c}\text { GAC } \\
\text { Backwash }\end{array}$ & $\begin{array}{l}\text { Polaromonas } \\
\text { aquatica } \text { strain } \\
\text { CCUG } 3940216 \mathrm{~S} \\
\text { ribosomal RNA } \\
\text { gene, complete } \\
\text { sequence }\end{array}$ & $\begin{array}{c}\text { Proteobacterial } \\
\text { Betaproteobacteria }\end{array}$ & 95 & 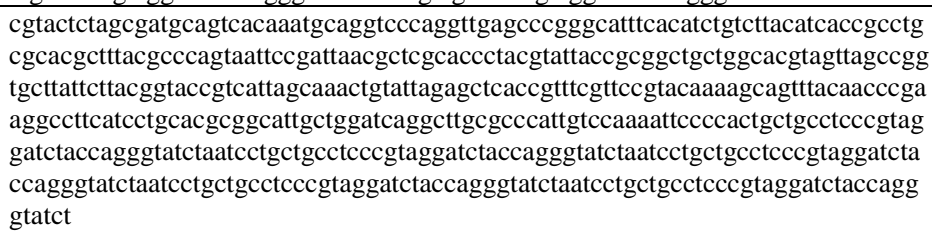 \\
\hline 4 & $\begin{array}{c}\text { GAC } \\
\text { Backwash }\end{array}$ & $\begin{array}{l}\text { Herminiimonas } \\
\text { arsenicoxydans } 16 \mathrm{~S} \\
\text { ribosomal RNA, } \\
\text { complete sequence }\end{array}$ & $\begin{array}{c}\text { Proteobacterial } \\
\text { Betaproteobacteria }\end{array}$ & 99 & 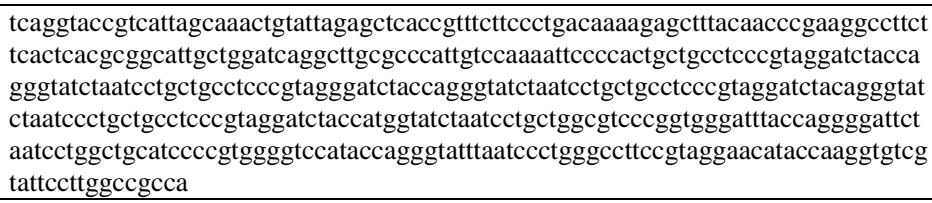 \\
\hline 7 & $\begin{array}{l}\text { Anthracite } \\
\text { Backwash }\end{array}$ & $\begin{array}{l}\text { Polaromonas } \\
\text { naphthalenivorans } \\
\text { strain CJ2 16S } \\
\text { ribosomal RNA } \\
\text { gene, complete } \\
\text { sequence }\end{array}$ & $\begin{array}{c}\text { Proteobacterial } \\
\text { Betaproteobacteria }\end{array}$ & 95 & 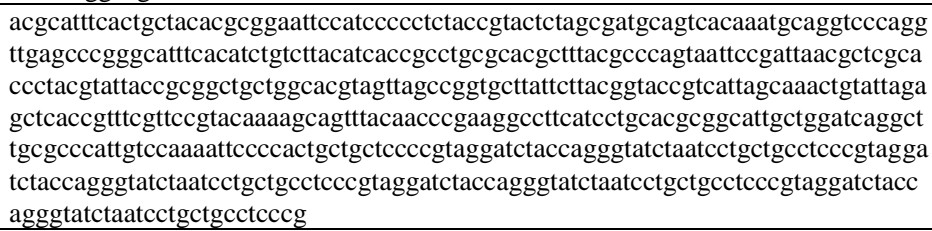 \\
\hline 9 & $\begin{array}{l}\text { Anthracite } \\
\text { Before } \\
\text { Backwash }\end{array}$ & $\begin{array}{l}\text { Albidiferax } \\
\text { ferrireducens strain } \\
\text { T118 16S ribosomal } \\
\text { RNA gene, complete } \\
\text { sequence }\end{array}$ & $\begin{array}{c}\text { Proteobacterial } \\
\text { Betaproteobacteria }\end{array}$ & 96 & 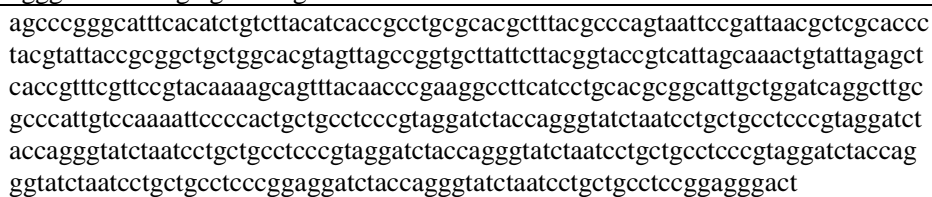 \\
\hline 10 & $\begin{array}{l}\text { Anthracite } \\
\text { Before } \\
\text { Backwash }\end{array}$ & $\begin{array}{l}\text { Curvibacter } \\
\text { delicatus } \text { strain } 146 \\
16 \text { S ribosomal RNA } \\
\text { gene, partial } \\
\text { sequence }\end{array}$ & $\begin{array}{c}\text { Proteobacteria/ } \\
\text { Betaproteobacteria }\end{array}$ & 95 & 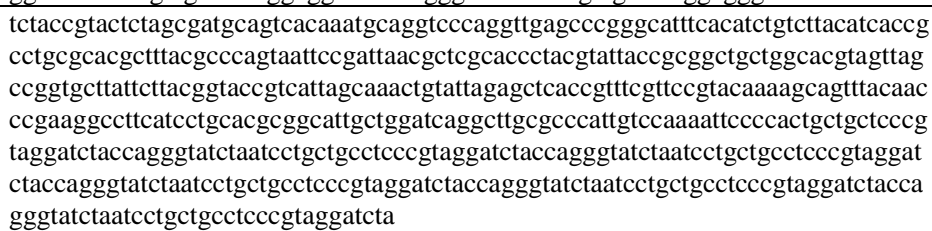 \\
\hline 11 & Raw Water & $\begin{array}{l}\text { Rhizobium tropici } \\
\text { strain CIAT } 89916 \mathrm{~S} \\
\text { ribosomal RNA } \\
\text { gene, complete } \\
\text { sequence }\end{array}$ & $\begin{array}{c}\text { Proteobacteria/ } \\
\text { Alphaproteobacteria }\end{array}$ & 99 & 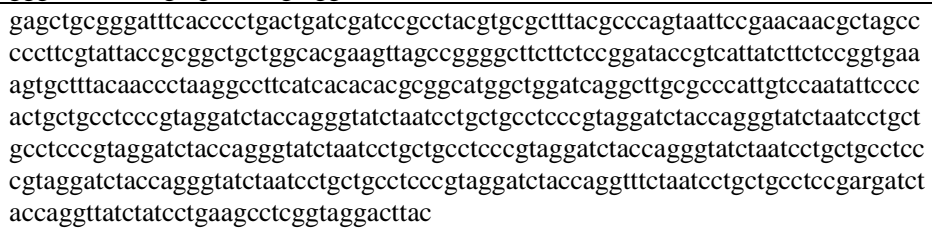 \\
\hline 13 & $\begin{array}{l}\text { GAC Before } \\
\text { Backwash }\end{array}$ & $\begin{array}{l}\text { Malikia spinosa } \\
\text { strain NBRC } \\
103164 \text { 16S } \\
\text { ribosomal RNA } \\
\text { gene, partial } \\
\text { sequence }\end{array}$ & $\begin{array}{c}\text { Proteobacteria/ } \\
\text { Betaproteobacteria }\end{array}$ & 97 & 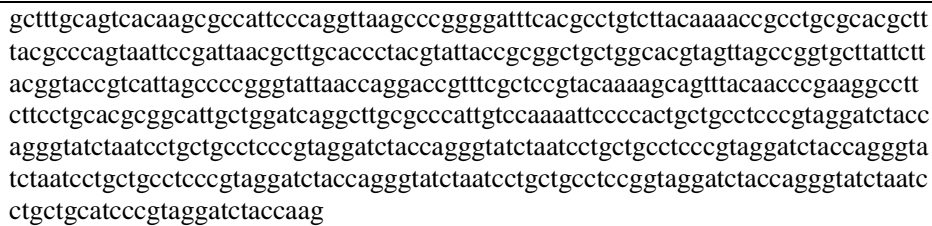 \\
\hline
\end{tabular}




\begin{tabular}{|c|c|c|c|c|c|}
\hline 14 & $\begin{array}{l}\text { GAC Before } \\
\text { Backwash }\end{array}$ & $\begin{array}{l}\text { Hydrogenophaga } \\
\text { atypica strain BSB } \\
41.816 \mathrm{~S} \text { ribosomal } \\
\text { RNA gene, complete } \\
\text { sequence }\end{array}$ & $\begin{array}{c}\text { Proteobacterial } \\
\text { Betaproteobacteria }\end{array}$ & 99 & 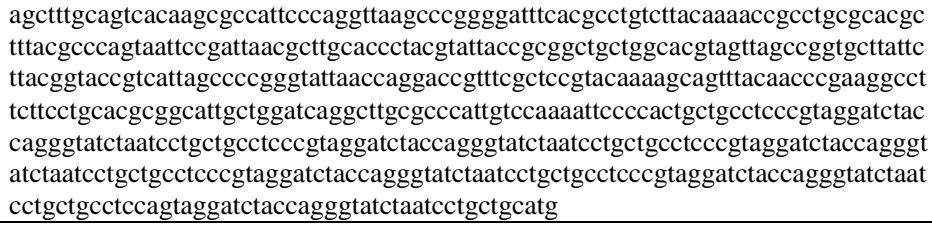 \\
\hline 16 & $\begin{array}{l}\text { GAC Before } \\
\text { Backwash }\end{array}$ & $\begin{array}{l}\text { Hydrogenophaga } \\
\text { defluvii strain BSB } \\
\text { 9.5 } 16 \text { S ribosomal } \\
\text { RNA gene, partial } \\
\text { sequence }\end{array}$ & $\begin{array}{c}\text { Proteobacteria/ } \\
\text { Betaproteobacteria }\end{array}$ & 99 & 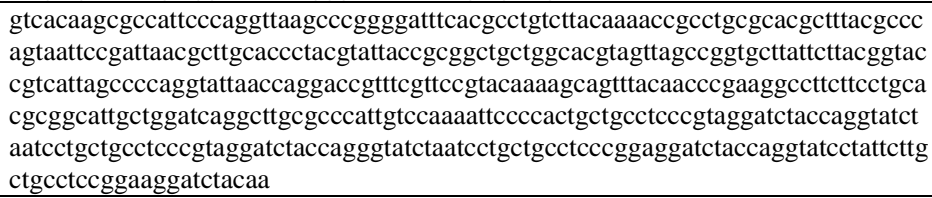 \\
\hline 17 & $\begin{array}{l}\text { GAC Before } \\
\text { Backwash }\end{array}$ & $\begin{array}{l}\text { Hydrogenophaga } \\
\text { bisanensis strain } \\
\text { K102 } 16 \text { S ribosomal } \\
\text { RNA gene, partial } \\
\text { sequence }\end{array}$ & $\begin{array}{c}\text { Proteobacterial } \\
\text { Betaproteobacteria }\end{array}$ & 98 & 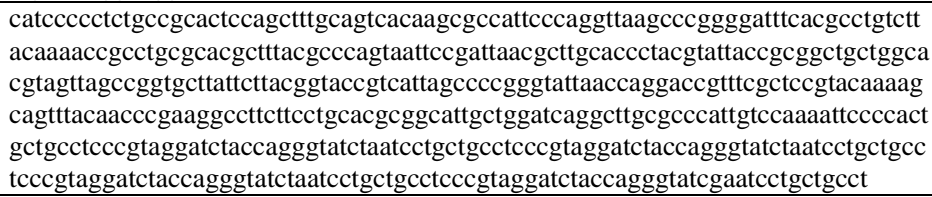 \\
\hline
\end{tabular}




\section{Appendix 3}

\section{Control - No Syto 9}

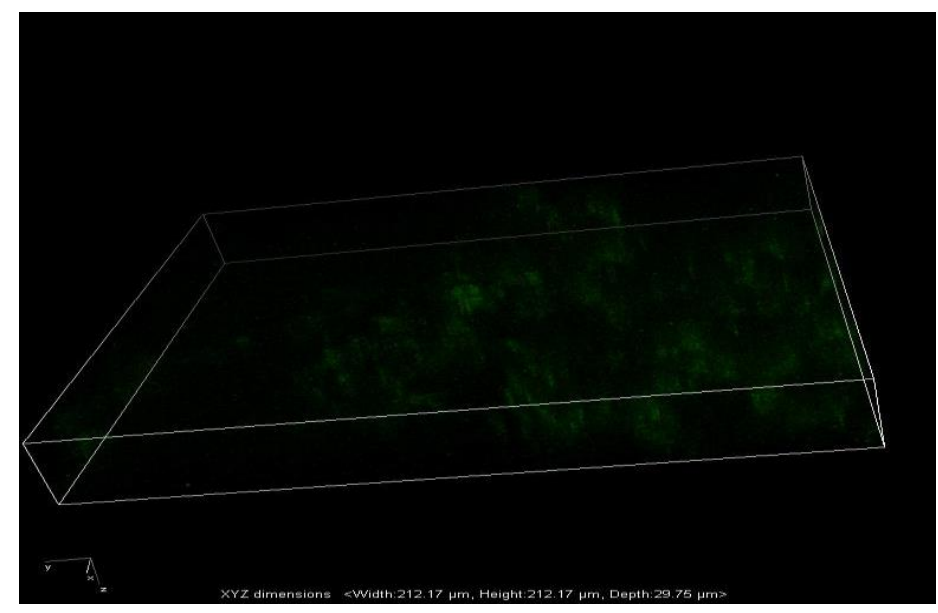

Figure A3.1: Control sample for GAC before backwash

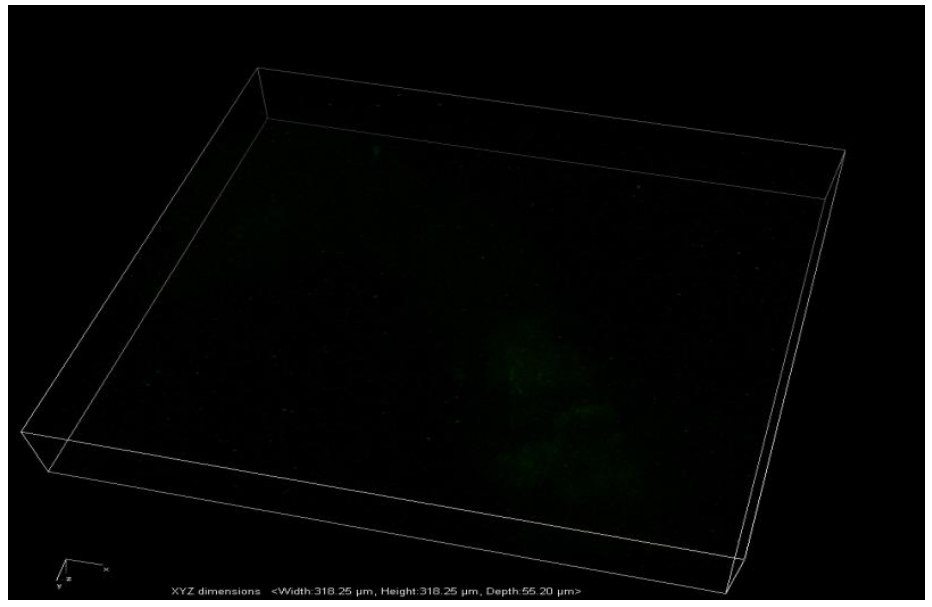

Figure A3.2: Control sample for anthracite before backwash 


\section{Appendix 4}

Table A4.1: Dissolved Oxygen Uptake (mg/L) During High Temperature Ranges

\begin{tabular}{|c|c|c|c|c|c|c|c|c|}
\hline Date & Time & Temp & Filter 1 & Filter 2 & Filter 3 & Filter 4 & Filter 5 & Filter 6 \\
\hline Sept 20, 2013 & $9: 00$ & 17.3 & 1.44 & - & 2.03 & 2.27 & - & 2.54 \\
\hline Sept 20, 2013 & $16: 00$ & 17.3 & - & - & 2.04 & & - & 2.63 \\
\hline Sept 27, 2013 & $11: 00$ & 17.4 & 2.44 & - & - & 2.58 & - & - \\
\hline Sept 30, 2013 & $13: 00$ & 18.3 & 2.84 & 0.48 & - & 3.04 & 0.36 & - \\
\hline Oct 1, 2013 & & 17.9 & 2.78 & - & - & 2.75 & - & - \\
\hline Oct 4, 2013 & $10: 00$ & 16.3 & 2.37 & - & - & - & - & - \\
\hline Oct 9, 2013 & $10: 00$ & 18 & 2.88 & 0.81 & 2.03 & 2.72 & 0.35 & 1.68 \\
\hline Oct 10, 2013 & $10: 00$ & 15.2 & - & - & 1.35 & - & - & 0.96 \\
\hline Oct 16, 2013 & $10: 00$ & 18 & 2.68 & 0.4 & 1.56 & 3.05 & 0.38 & 1.84 \\
\hline Oct 16, 2013 & $15: 00$ & 18 & 2.6 & 0.33 & 1.47 & 2.9 & 0.33 & 1.74 \\
\hline \multicolumn{2}{|c|}{ Average } & $\mathbf{1 7 . 4}$ & $\mathbf{2 . 5}$ & $\mathbf{0 . 5 1}$ & $\mathbf{1 . 7 5}$ & $\mathbf{2 . 7 6}$ & $\mathbf{0 . 3 6}$ & $\mathbf{1 . 9}$ \\
\hline
\end{tabular}

Table A4.1: GAC and anthracite (flow rate of $1.2 \mathrm{~L} / \mathrm{min}$ ) average DOU concentration levels during high temperatures

Table A4.2: Dissolved Oxygen Uptake (mg/L) During Medium Temperature Ranges

\begin{tabular}{|c|c|c|c|c|c|c|c|c|}
\hline Date & Time & Temp & Filter 1 & Filter 2 & Filter 3 & Filter 4 & Filter 5 & Filter 6 \\
\hline Oct 28, 2013 & & 9.7 & 1.18 & 0.13 & 1.03 & 1.1 & 0.14 & 1 \\
\hline Oct 30, 2013 & $14: 30$ & 8.6 & 1.13 & 0.58 & 1 & 1.07 & 0.07 & 1 \\
\hline Oct 31, 2013 & $10: 00$ & 9.1 & 1.27 & - & - & 1.28 & - & - \\
\hline Oct 31, 2013 & $13: 30$ & 9.6 & 1.41 & - & - & 1.34 & - & - \\
\hline Nov 1, 2013 & $9: 25$ & 9.4 & 1.25 & 0.11 & 1 & 1.19 & 0.11 & 0.98 \\
\hline Nov 22, 2013 & $11: 00$ & 9 & 1.13 & 0.18 & 0.97 & 1.27 & 0.14 & 1.07 \\
\hline Nov 22, 2013 & $16: 00$ & 8.9 & - & - & - & - & - & 1.21 \\
\hline Dec 9, 2013 & $11: 00$ & 7.8 & 1.01 & 0.1 & 0.87 & 1.07 & 0.2 & 1.01 \\
\hline \multicolumn{2}{|c|}{ Average } & $\mathbf{9}$ & $\mathbf{1 . 2}$ & $\mathbf{0 . 2 2}$ & $\mathbf{0 . 9 7}$ & $\mathbf{1 . 1 9}$ & $\mathbf{0 . 1 3}$ & $\mathbf{1 . 0 5}$ \\
\hline
\end{tabular}

Table A4.2: GAC and anthracite (flow rate of $1.2 \mathrm{~L} / \mathrm{min}$ ) average DOU concentration levels during medium temperatures

Table A4.3: Dissolved Oxygen Uptake (mg/L) During Low Temperature Ranges

\begin{tabular}{|c|c|c|c|c|c|c|c|c|}
\hline Date & Time & Temp & Filter 1 & Filter 2 & Filter 3 & Filter 4 & Filter 5 & Filter 6 \\
\hline Jan 17, 2014 & $10: 50$ & 4.9 & 0.82 & 0.19 & 0.79 & 0.82 & 0.17 & 0.81 \\
\hline Jan 20, 2014 & $9: 00$ & 5.1 & 1.08 & 0.23 & 0.9 & 0.97 & 0.3 & 0.88 \\
\hline Jan 20, 2014 & $15: 00$ & 5.1 & - & - & 1.02 & - & - & 0.95 \\
\hline Jan 21, 2014 & $13: 00$ & 4.2 & 0.85 & -- & - & 0.82 & - & - \\
\hline Jan 23, 2014 & $12: 00$ & 4.6 & 0.83 & - & - & 0.84 & - & - \\
\hline March 12, 2014 & $10: 00$ & 3.8 & 0.71 & 0.21 & 0.78 & 1.39 & 0.12 & 0.82 \\
\hline March 19, 2014 & $10: 30$ & 4.2 & 0.43 & 0.17 & 0.65 & 0.45 & 0.12 & 0.73 \\
\hline March 19, 2014 & $14: 00$ & 4.2 & - & 0.16 & 0.76 & - & 0.08 & 0.66 \\
\hline March 21, 2014 & $11: 00$ & 4.2 & 0.58 & 0.21 & 0.9 & 0.49 & 0.13 & 0.71 \\
\hline March 24, 2014 & $9: 00$ & 4.1 & 1.45 & 0.22 & 0.92 & 1.47 & 0.13 & 0.78 \\
\hline \multicolumn{2}{|c|}{ Average } & $\mathbf{4 . 4}$ & $\mathbf{0 . 8 4}$ & $\mathbf{. 2}$ & $\mathbf{0 . 8 4}$ & $\mathbf{0 . 9 1}$ & $\mathbf{0 . 1 5}$ & $\mathbf{0 . 7 9}$ \\
\hline
\end{tabular}

Table A4.3: GAC and anthracite (flow rate of $1.2 \mathrm{~L} / \mathrm{min}$ ) average DOU concentration levels during low temperatures 


\section{Appendix 5}

Table A5.1: Total Organic Carbon Uptake (mg/L) During High Temperature Ranges

\begin{tabular}{|c|c|c|c|c|c|c|c|c|}
\hline Date & Time & Temp $\left.\mathbf{~}^{\mathbf{0}} \mathbf{C}\right)$ & Filter 1 & Filter 2 & Filter 3 & Filter 4 & Filter 5 & Filter 6 \\
\hline Aug 11, 2014 & $15: 40$ & 15.3 & 0.62 & 0.25 & 0.88 & - & - & - \\
\hline Aug 12, 2014 & $10: 00$ & 19.2 & 0.68 & 0.47 & 0.78 & 0.32 & 0.21 & 0.28 \\
\hline Aug 13, 2014 & $10: 00$ & 16.7 & 1.08 & 1.12 & 1.22 & 0.24 & 0.16 & 0.22 \\
\hline Aug 13, 2014 & $15: 00$ & 12.6 & 1.32 & 1.28 & 1.34 & 0.4 & 0.36 & 0.54 \\
\hline Aug 15, 2014 & $11: 00$ & 15.4 & 1.1 & 1.03 & 1.13 & - & - & - \\
\hline Sept 17, 2014 & $15: 00$ & 13.9 & 0.37 & 0.3 & 0.44 & 0.34 & 0.25 & 0.37 \\
\hline \multicolumn{2}{|c|}{ Average } & $\mathbf{1 5 . 5}$ & $\mathbf{0 . 8 6}$ & $\mathbf{0 . 7 4}$ & $\mathbf{0 . 9 7}$ & $\mathbf{0 . 3 8}$ & $\mathbf{0 . 2 5}$ & $\mathbf{0 . 4 6}$ \\
\hline
\end{tabular}

Table A5.1: GAC and anthracite (flow rate of $1.2 \mathrm{~L} / \mathrm{min}$ ) average TOCU concentration levels during high temperatures

Table A5.2: Total Organic Carbon Uptake (mg/L) During Medium Temperature Ranges

\begin{tabular}{|c|c|c|c|c|c|c|c|c|}
\hline Date & Time & Temp $\left.\mathbf{(}^{\mathbf{0}} \mathbf{C}\right)$ & Filter 1 & Filter 2 & Filter 3 & Filter 4 & Filter 5 & Filter 6 \\
\hline Aug 14, 2013 & $9: 00$ & 9.1 & 0.37 & 0.23 & 0.38 & 0.19 & 0.08 & 0.29 \\
\hline Aug 16, 2013 & $15: 15$ & 9.3 & 0.24 & 0.12 & 0.31 & 0.11 & - & 0.18 \\
\hline Dec 11, 2013 & $9: 00$ & 7.4 & 0.32 & 0.14 & 0.37 & 0.49 & 0.15 & 0.56 \\
\hline Dec 11, 2013 & $10: 00$ & 7.5 & 0.31 & -0.03 & 0.32 & - & - & - \\
\hline Dec 11, 2013 & $14: 30$ & 7.6 & 0.1 & 0 & - & 0.37 & - & - \\
\hline Dec 13, 2013 & $9: 30$ & 6.9 & 0.02 & -0.14 & 0.05 & 0.37 & 0.23 & 0.36 \\
\hline \multicolumn{2}{|c|}{ Average } & $\mathbf{8}$ & $\mathbf{0 . 2 3}$ & $\mathbf{0 . 0 6 4}$ & $\mathbf{0 . 2 9}$ & $\mathbf{0 . 3 1}$ & $\mathbf{0 . 1 5}$ & $\mathbf{0 . 3 5}$ \\
\hline
\end{tabular}

Table A5.2: GAC and anthracite (flow rate of $1.2 \mathrm{~L} / \mathrm{min}$ ) average TOCU concentration during medium temperatures

Table A5.3: Total Organic Carbon Uptake (mg/L) During Low Temperature Ranges

\begin{tabular}{|c|c|c|c|c|c|c|c|c|}
\hline Date & Time & Temp $\left({ }^{\mathbf{0}} \mathbf{C}\right)$ & Filter 1 & Filter 2 & Filter 3 & Filter 4 & Filter 5 & Filter 6 \\
\hline Jan 20, 2014 & $9: 00$ & 5.1 & 0.15 & 0 & 0.2 & 0.18 & 0.03 & 0.22 \\
\hline Jan 23, 2014 & $9: 00$ & 4.8 & 0.24 & 0.06 & 0.22 & 0.22 & 0.11 & 0.25 \\
\hline March 19, 2014 & $9: 00$ & 4.2 & 0.15 & 0.02 & 0.11 & 0.03 & 0 & 0.12 \\
\hline March 21, 2014 & $11: 00$ & 4.2 & 0.24 & 0.15 & 0.37 & 0.14 & 0.01 & 0.09 \\
\hline March 24, 2014 & $9: 00$ & 4.1 & 0.33 & -0.01 & 0.27 & 0.12 & 0.02 & 0.11 \\
\hline \multicolumn{2}{|c|}{ Average } & $\mathbf{4 . 5}$ & $\mathbf{0 . 2 2}$ & $\mathbf{0 . 0 4 4}$ & $\mathbf{0 . 2 3}$ & $\mathbf{0 . 1 4}$ & $\mathbf{0 . 0 3 4}$ & $\mathbf{0 . 1 6}$ \\
\hline
\end{tabular}

Table A5.3: GAC and anthracite (flow rate of $1.2 \mathrm{~L} / \mathrm{min}$ ) average TOCU concentration levels during low temperatures 


\section{Appendix 6}

\section{ANOVA tests for biovolume}

\section{Linear Models}

The GLM Procedure

Least Squares Means

Adjustment for Multiple Comparisons: Tukey-Kramer

\begin{tabular}{|l|l|l|r|}
\hline Filter_Biomass & Season_Biomass & Backwash_Biomass & Log_Biomass LSMEAN \\
\hline Anthracite & Summer & No & 0.05730284 \\
\hline Anthracite & Summer & Yes & 0.00644130 \\
\hline Anthracite & Winter & No & 0.04657043 \\
\hline Anthracite & Winter & Yes & 0.03298384 \\
\hline GAC & Summer & No & 0.14387223 \\
\hline GAC & Summer & Yes & 0.01031239 \\
\hline GAC & Winter & No & 0.08776530 \\
\hline GAC & Winter & Yes & 0.02206502 \\
\hline
\end{tabular}

\begin{tabular}{|c|c|c|c|c|c|c|c|}
\hline \multicolumn{8}{|c|}{$\begin{array}{c}\text { Least Squares Means for effect Filter*Season*Backwa } \\
\text { Pr }>\text { |t| for H0: LSMean(i)=LSMean(j) } \\
\text { Dependent Variable: Log_Biomass }\end{array}$} \\
\hline i/j & 1 & 2 & 3 & 4 & 5 & 6 & 7 \\
\hline 1 & & 0.0312 & 0.9983 & 0.8084 & $<.0001$ & 0.0602 & 0.5778 \\
\hline 2 & 0.0312 & & 0.2853 & 0.7315 & $<.0001$ & 1.0000 & 0.0002 \\
\hline 3 & 0.9983 & 0.2853 & & 0.9947 & $<.0001$ & 0.4120 & 0.3189 \\
\hline 4 & 0.8084 & 0.7315 & 0.9947 & & $<.0001$ & 0.8575 & 0.0484 \\
\hline 5 & $<.0001$ & $<.0001$ & $<.0001$ & $<.0001$ & & $<.0001$ & 0.0299 \\
\hline 6 & 0.0602 & 1.0000 & 0.4120 & 0.8575 & $<.0001$ & & 0.0004 \\
\hline 7 & 0.5778 & 0.0002 & 0.3189 & 0.0484 & 0.0299 & 0.0004 & \\
\hline 8 & 0.4491 & 0.9831 & 0.8903 & 0.9986 & $<.0001$ & 0.9970 & 0.0130 \\
\hline
\end{tabular}

Figure A6.1: Statistical Analysis of 3 way ANOVA for biomass variable tested with 3 independent factors of season, filter media type, and backwashing 


\section{Appendix 7}

\section{ANOVA tests for average thickness}

\section{Linear Models \\ The GLM Procedure \\ Least Squares Means}

Adjustment for Multiple Comparisons: Tukey-Kramer

\begin{tabular}{|l|l|l|r|r|}
\hline Filter_thick & Season_thick & Backwash_thick & Log_thickness LSMEAN & LSMEAN Number \\
\hline Anthracite & Summer & No & 0.54360165 & 1 \\
\hline Anthracite & Summer & Yes & 0.13362986 & 2 \\
\hline Anthracite & Winter & No & 0.50673874 & 3 \\
\hline Anthracite & Winter & Yes & 0.43836239 & 4 \\
\hline GAC & Summer & No & 0.55932232 & 5 \\
\hline GAC & Summer & Yes & 0.17803326 & 6 \\
\hline GAC & Winter & No & 0.83678731 & 7 \\
\hline GAC & Winter & Yes & 0.39278711 & 8 \\
\hline
\end{tabular}

\begin{tabular}{|c|c|c|c|c|c|c|c|}
\hline \multicolumn{8}{|c|}{$\begin{array}{l}\text { Least Squares Means for effect Filter }{ }^{*} \text { Season*Backwa } \\
\text { Pr }>|t| \text { for H0: LSMean(i)=LSMean(j) } \\
\text { Dependent Variable: Log_thickness }\end{array}$} \\
\hline i/j & 1 & 2 & 3 & 4 & 5 & 6 & 7 \\
\hline 1 & & 0.0005 & 0.9999 & 0.9549 & 1.0000 & 0.0035 & 0.0631 \\
\hline 2 & 0.0005 & & 0.0047 & 0.0386 & 0.0002 & 0.9996 & $<.0001$ \\
\hline 3 & 0.9999 & 0.0047 & & 0.9974 & 0.9993 & 0.0238 & 0.0391 \\
\hline 4 & 0.9549 & 0.0386 & 0.9974 & & 0.9092 & 0.1400 & 0.0057 \\
\hline 5 & 1.0000 & 0.0002 & 0.9993 & 0.9092 & & 0.0020 & 0.0937 \\
\hline 6 & 0.0035 & 0.9996 & 0.0238 & 0.1400 & 0.0020 & & $<.0001$ \\
\hline 7 & 0.0631 & $<.0001$ & 0.0391 & 0.0057 & 0.0937 & $<.0001$ & \\
\hline 8 & 0.8026 & 0.1650 & 0.9592 & 0.9999 & 0.7123 & 0.4029 & 0.0024 \\
\hline
\end{tabular}

Figure A7.1: Statistical Analysis of 3 way ANOVA for average thickness variable tested with 3 independent factors of season, filter media type, and backwashing 


\section{Appendix 8}

\section{ANOVA tests for roughness}

\section{Linear Models \\ The GLM Procedure \\ Least Squares Means \\ Adjustment for Multiple Comparisons: Tukey-Kramer}

\begin{tabular}{|l|l|l|r|r|}
\hline Filter_rough & Season_rough & Backwash_rough & Square_roughness LSMEAN & LSMEAN Number \\
\hline Anthracite & Summer & No & 0.45220106 & 1 \\
\hline Anthracite & Summer & Yes & 0.47405655 & 2 \\
\hline Anthracite & Winter & No & 0.45720844 & 3 \\
\hline Anthracite & Winter & Yes & 0.45965353 & 4 \\
\hline GAC & Summer & No & 0.43496185 & 5 \\
\hline GAC & Summer & Yes & 0.47126834 & 6 \\
\hline GAC & Winter & No & 0.42785095 & 7 \\
\hline GAC & Winter & Yes & 0.46924338 & 8 \\
\hline
\end{tabular}

\begin{tabular}{|c|c|c|c|c|c|c|c|}
\hline \multicolumn{8}{|c|}{$\begin{array}{c}\text { Least Squares Means for effect Filter*Season*Backwa } \\
\text { Pr }>|t| \text { for H0: LSMean(i)=LSMean(j) } \\
\text { Dependent Variable: Square_roughness }\end{array}$} \\
\hline i/j & 1 & 2 & 3 & 4 & 5 & 6 & 7 \\
\hline 1 & & 0.0097 & 0.9947 & 0.9368 & 0.0961 & 0.0454 & 0.0077 \\
\hline 2 & 0.0097 & & 0.1602 & 0.2738 & $<.0001$ & 0.9996 & $<.0001$ \\
\hline 3 & 0.9947 & 0.1602 & & 1.0000 & 0.0238 & 0.3863 & 0.0018 \\
\hline 4 & 0.9368 & 0.2738 & 1.0000 & & 0.0047 & 0.5743 & 0.0003 \\
\hline 5 & 0.0961 & $<.0001$ & 0.0238 & 0.0047 & & $<.0001$ & 0.9430 \\
\hline 6 & 0.0454 & 0.9996 & 0.3863 & 0.5743 & $<.0001$ & & $<.0001$ \\
\hline 7 & 0.0077 & $<.0001$ & 0.0018 & 0.0003 & 0.9430 & $<.0001$ & \\
\hline 8 & 0.1914 & 0.9945 & 0.6905 & 0.8527 & $<.0001$ & 1.0000 & $<.0001$ \\
\hline
\end{tabular}

Figure A8.1: Statistical Analysis of 3 way ANOVA for roughness coefficient variable tested with 3 independent factors of season, filter media type, and backwashing 


\title{
Appendix 9
}

\section{ANOVA tests for surface to volume}

\author{
Linear Models \\ The GLM Procedure \\ Least Squares Means \\ Adjustment for Multiple Comparisons: Tukey-Kramer
}

\begin{tabular}{|l|l|l|r|r|}
\hline Filter_SA & Season_SA & Backwash_SA & Surface_Area LSMEAN & LSMEAN Number \\
\hline Anthracite & Summer & No & 7.61189444 & 1 \\
\hline Anthracite & Summer & Yes & 8.44162300 & 2 \\
\hline Anthracite & Winter & No & 6.76000667 & 3 \\
\hline Anthracite & Winter & Yes & 8.16766714 & 4 \\
\hline GAC & Summer & No & 7.19690556 & 5 \\
\hline GAC & Summer & Yes & 9.34069778 & 6 \\
\hline GAC & Winter & No & 8.72545000 & 7 \\
\hline GAC & Winter & Yes & 7.26065000 & 8 \\
\hline
\end{tabular}

\begin{tabular}{|c|c|c|c|c|c|c|c|}
\hline \multicolumn{8}{|c|}{$\begin{array}{c}\text { Least Squares Means for effect Filter*Season*Backwa } \\
\text { Pr }>\mid \text { |t| for H0: LSMean(i)=LSMean(j) } \\
\text { Dependent Variable: Surface_Area }\end{array}$} \\
\hline $\mathbf{i} / \mathbf{j}$ & 1 & 2 & 3 & 4 & 5 & 6 & 7 \\
\hline 1 & & 0.9703 & 0.9841 & 0.9985 & 0.9996 & 0.4533 & 0.9158 \\
\hline 2 & 0.9703 & & 0.6040 & 1.0000 & 0.7928 & 0.9544 & 1.0000 \\
\hline 3 & 0.9841 & 0.6040 & & 0.8437 & 0.9998 & 0.1298 & 0.5018 \\
\hline 4 & 0.9985 & 1.0000 & 0.8437 & & 0.9580 & 0.8923 & 0.9989 \\
\hline 5 & 0.9996 & 0.7928 & 0.9998 & 0.9580 & & 0.1955 & 0.6852 \\
\hline 6 & 0.4533 & 0.9544 & 0.1298 & 0.8923 & 0.1955 & & 0.9971 \\
\hline 7 & 0.9158 & 1.0000 & 0.5018 & 0.9989 & 0.6852 & 0.9971 & \\
\hline 8 & 0.9999 & 0.9008 & 0.9997 & 0.9833 & 1.0000 & 0.3585 & 0.8153 \\
\hline
\end{tabular}

Figure A8.1: Statistical Analysis of 3 way ANOVA for surface to volume ratio variable tested with 3 independent factors of season, filter media type, and backwashing 


\section{References}

Abdulqadir, J.N.(2014). "Preparation and Characterization of Modified Activated Charcoal based on Ferula Communis and its Adsorptive Behavior". Master of Science in Chemistry, Eastern Mediterranean University Gazimağusa, North Cyprus.

Anderson, M. (2015). Premium water filers-replacement GAC activated carbon media for water filters., 2015, from from http://www.premium-water-filters.com/backwashing-carbon-filters /carbon.html

Andersson, S. (2009): Characterization of Bacterial Biofilms for Wastewater Treatment. School of Biotechnology, Royal Institute of Technology (KTH), Sweden.

Bai, Y., Zhang, Jie., Li, Y., Gao, Y., Li, Y.(2004). Biomass and microbial activity in a biofilter during backwashing. Journal of Zhejiang University Science. 6B(5), 427-432.

Bellenberg, S., Díaz, M., Noël, N., Sand, W., Poetsch, A., et al. (2014). Biofilm formation, communication and interactions of leaching bacteria during colonization of pyrite and sulfur surfaces. Research in Microbiology. 165, 773-781.

Bernardet, J.F., Bowman, J. P. (2013). International Committee on Systematics of Prokaryotes Subcommittee on the taxonomy of Flavobacterium and Cytophaga-like bacteria. International Journal of Systematics and Evolutionary Microbiology, 63 (7), 2752-2754.

Bryers, J.D. (1988) Modeling biofilm accumulation, in: Physiological models in microbiology (ed.: Bazin, M.J. and Prosser, J.I.), pp. 109-144

Buitron, G. and Gonzalez, A. (1996). Characterization of the microorganisms from an acclimated activated sludge degrading phenolic compounds. Water Science and Technology, 34(5-6), 289-294.

Cecen, F., Aktas, O. (2011). Activated Carbon for Water and Wastewater Treatment: Integration of Adsorption and Biological Treatment. In F. Cecen \& O. Atkas (Ed.), Determination of Biomass and Microbial Activity in BAC Filters. Weinheim, Germany: Wiley.

Chaudhary D.S., Vigneswara S., Ngo H., Shim W.G., and Moon H. (2003). Biofilter in water and wastewater treatment. The Korean Journal of Chemical Engineering, 20(6), 1054-1065.

Chmielewski, R.A.N. and Frank, J.F. (2003). Biofilm formation and control in food processing facilities. Comprehensive Reviews in Food Science and Food Safety, 2(1), 22-32.

City of Toronto. (2015). R.C. harris water treatment process., 2014, from http://www1.toronto.ca/wps/portal/contentonly?vgnextoid=e73cfe4eda8ae310 VgnVCM10000071d60f89RCRD 
City of Toronto. (2015). Water quality tap water safety., 2015, from http://www1.toronto.ca/wps/portal/contentonly?vgnextoid=dca807ceb6f8e310V gnVCM10000071d60f89RCRD\&vgnextchannel=6df01b9c6a85f310VgnVCM1000 0071d60f89RCRD

Cochran, J. (2008). Evaluation of pre and post treatment filtration performance of kinetico macrolite ${ }^{\circledR}$ ceramic media compared to traditional sand/anthracite and GAC filters in drinking water treatment process. Doctoral dissertation, The University of Alabama at Birmingham, United States.

Cohen, Y. (2001). Biofiltration - the treatment of fuids by microorganisms immobilized into the filter bedding material: A review. . Bioresource Technology, 77, 257-274.

Davey, M. E., and A. G. O’Toole. (2000). Microbial biofilms: From ecology to molecular genetics. . Microbiology and Molecular Biology Reviews, 64(4), 847-867.

Davis, J. L., and Shaw, G. (2006). Impacts of eutrophication on the safety of drinking and recreational water. Journal of Water and Health, 11

Eiler, A., and S. Bertilsson. (2004). Composition of freshwater bacterial communities associated with cyanobacterial blooms in four Swedish lakes. Environmental Microbiology. $6,1228-1243$.

Fang, W., Hu, J., and Ong, S. (2009). Influence of phosphorus on biofilm formation in model drinking water distribution systems. Journal of Applied Microbiology, 106(4), 1328-1335.

Gadgil, A. (1998). Drinking water in developing countries. Annual Review of Energy and the Environment, 23, 253-286.

Gleick, P. H., (1996). U.S. Geological Society. Water resources. In Encyclopedia of Climate and Weather, ed. by S. H. Schneider, Oxford University Press, New York, 2, 817-823.

Gillogly T., Snoeyink V., Vogel J., Wilson C., Royal E. (1999). Determining GAC bed life. American Water Works Association, 91(8), 98-110.

Graba, M., Sauvage, S., Majdi, N., Mialet, B., Moulin, F. Y., Urrea, Sanchez-Pérez, J. (2014). Modelling epilithic biofilms combining hydrodynamics, invertebrate grazing and algal traits. Freshwater Biology, 59(6), 1213-1228.

Gyaneshwar, P., Hirsch, M., Moulin, L., Chen, M., Elliott, N., Bontemps, C., et al. (2011). Legume-nodulating betaproteobacteria: diversity, host range, and future prospects. Molecular Plant Microbe Interactions. 24(11), 1276-88. 
Hallé, C., 2009. Biofiltration in Drinking Water Treatment: Reduction of Membrane Fouling and Biodegradation of Organic Trace Contaminants. Doctoral dissertation, Department of Civil and Environmental Engineering, University of Waterloo, Canada. www.uwspace.uwaterloo.ca/handle/10012/5022.

Harrison, J. J., Turner, R. J., Marques, L. L. R., and Howard, C. (2005). Biofilms. American Scientist, 93(6), 508-515.

Henne, K., Kahlisch, L., Höfle, M.G., Brettar, I. (2013). Seasonal dynamics of bacterial community structure and composition in cold and hot drinking water derived from surface water reservoirs. Water Research, 47(15), 5614-5630.

Health Canada (2014). Guidelines for Canadian Drinking Water Quality-Summary Table. Water and Air Quality Bureau, Healthy Environments and Consumer Safety Branch, Health Canada, Ottawa, Ontario.

Heydorn, A., Nielsen, A., Hentzer, M., Sternberg, C., Givskov, M., Ersboll, B., Molin, S., (2000). Quantification of biofilm structures by the novel computer program COMSTAT. Microbiology, 146, 2395-2407.

HomePlus. (2015). Granular activated carbon (GAC) and carbon block filters., 2015, from http://www.home-water-purifiers-and-filters.com/carbon-water-filter.php

Jan, D., Petch, D., Huzel, N., Butler, M. (1996). The Effect of Dissolved Oxygen on the Metabolic Profile of a Murine Hybridoma Grown in Serum-Free Medium in Continuous Culture. Biotechnology and Bioengineering. 54(2), 153-164.

Jensen, G., Hansen, B., Eilenberg, J., Mahillon, J. (2003). The hidden lifestyles of bacillus cereus and relatives. Environmental Microbiology, 5(8), 631-640.

Kampfer, P., Schulze, R., Jackel, U., Malik, K., Amann, R., Spring, S. (2005). Hydrogenophaga defluvii sp. nov. and hydrogenophaga atypica sp. nov., isolated from activated sludge. International Journal of Systematic and Evolutionary Microbiology, 55, 341-344.

Kelly, J., Minalt, N., Culotti, A., Pryor, M., Packman, A. (2014). Temporal Variations in the Abundance and Composition of Biofilm Communities Colonizing Drinking Water Distribution Pipes. PLoS ONE, 9(5) e98542.

Kloc, J. and González I. (2012). The Study of Biological Wastewater Treatment through Biofilm Development on Synthetic Material vs. Membranes.

Kubitschek, H. (1990). Cell volume increase in Escherichia coli after shifts to richer media. Journal of Bacteriology 172 (1): 94-101. 
Kurisu, F. and Yagi, O. (2010). Bioremediation of soil and ground water contaminated by volatile organic compounds. Sustainability in food and water (pp. 411-416). Springer Netherlands

Lane, C. A. (2011). "Pure-culture and mixed community biofilm responses to carbon-starvation and $U V$-C exposure. Master of Applied Science Dissertation, Department of Environmental Science and Management, Ryerson University, Toronto, Canada.

Leffel, J.M. and Green, G.S. American Filtration and Separations Society Conference (conference). Development of Evaporative Emissions Filters for Automotive Applications, Reno, Nevada. (2003). http://www.afssociety.org/filtration-media/66-hydrocarbonevaporative-emissions-a-control-for-automotives.

Lehto, L. P., Hill, H. B. (2013). The effect of catchment urbanization on nutrient uptake and biofilm enzyme activity in lake superior (USA) tributary streams. Hydrobiologia, 713, 35-51.

Li, X., G. Upadhyaya, W. Yuen, J. Brown, E. Morgenroth, and L. Raskin. (2010). Changes in the structure and function of microbial communities in drinking water treatment bioreactors upon addition of phosphorus. Applied and Environmental Microbiology, 76(22), 7473-7481.

Miettinen, I., Vartiainen, T., and Martikainen, P. (1997). Phosphorus and bacterial growth in drinking water. Applied and Environmental Microbiology, 63(8), 3242-3245.

Mir, A. Biofilters and Control of Air Pollution (lecture). North-Easter Hill University. (2013) http://www.slideshare.net/AabidMir/biofilters-and-air-pollution-controll

Mols, M., De Been, M., Zwietering, M., Moezelaar, R., Abee, T. (2007). Metabolic capacity of bacillus cereus strains ATCC 14579 and ATCC 10987 interlinked with comparative genomics. Environmental Microbiology, 9, 2933-2944.

Muurholm S, Cousin S, Päuker O, Brambilla E, Stackebrandt E. (2007). Pedobacter duraquae sp. nov., pedobacter westerhofensis sp. nov., pedobacter metabolipauper sp. nov., pedobacter hartonius sp. nov. and pedobacter steynii sp. nov., isolated from a hard-water rivulet. International Journal of Systematic and Evolutionary Microbiology, 57(10), 22212227.

Muyzer, G., De Waal, E. C., and Uitterlinden, A. G. (1993). Profiling of complex microbial populations by denaturing gradient gel electrophoresis analysis of polymerase chain reaction amplified gene coding for 16S rRNA. Applied Environmental Microbiology. 59, 695-700.

Newton, R., Jones, S., Eiler, A., McMahon, K., Bertilsson, S. (2011). A guide to the natural history of fresh water lake bacteria. American Society for Microbiology. 75(1), 14-49.

Nicholson, P. S., \& Hirsch, P. R. (1998). The effects of pesticides on the diversity of culturable soil bacteria.Journal of Applied Microbiology, 84(4), 551-558. 
Niquette, P., Servais, P., Savoir, R., (2001). Bacterial dynamics in the drinking water distribution system of Brussels. Water Research. 35, 675-682.

O'Connor, D. Ministry of the Environment, (2002). Report of the walkerton inquiry: The events of may 2000 and related issues. Queens, Ont.: Ontario Ministry of the Attorney General.

Parry, J. D., Holmes, A. K., Unwin, M. E., and Laybourn-Parry, J. (2007). The use of ultrasonic imaging to evaluate the effect of protozoan grazing and movement on the topography of bacterial biofilms. Letters in Applied Microbiology, 45(4), 364-370.

Paul PJ, Jhadhav S. Value Added Products from Gasification: Activated Carbon (lecture). The Combustion, Gasification and Propulsion Laboratory (CGPL) at the Indian Institute of Science (IISc) (2010). http://cgpl.iisc.ernet.in/

Passarelli, C., Meziane, T., Thiney, N., Boeuf, D., Jesus, B., Ruivo, M., Jeanthon, C., Hubas, C. (2014). Seasonal variations of the composition of microbial biofilms in sandy tidal flats: Focus of fatty acids, pigments and exopolymers. Estuarine, Coastal and Shelf Science, 153, 29-37.

Petroff, A., Wu, T., Liang, B., Mui, J., Guerquin-Kern, J., Vali, H., Rothman, D., Bosak, T. (2011). Reaction-diffusion model of nutrient uptake in a biofilm: Theory and experiment. Journal of Theoretical Biology, 289, 90-95.

Picioreanu, C., van Loosdrecht, M., Heijnen, J. (2000). Two-Dimensional Model of Biofilm Detachment Caused by Internal Stress from Liquid Flow. Biotechnology and Bioengineering. 72(2), 205-218.

Rai, H. (2009). Tackling seasonal taste and odour events in drinking water. Environmental Science and Engineering Magazine, 26-31.

Reese, S. and Guggenheim, B. (2007). A novel TEM contrasting technique for extracellular polysaccharides in in vitro biofilms. Microscopy Research and Technique, 70, 816-822.

Reichenbach, H. (1974) Order II Cytophagales nomen novum. In: Bergey's Manual of Systematic Bacteriology. 8 edition. Springer p.99-122 $2^{\text {nd }}$

Rosche, B., Li, X., Hauer, B., Schmid, A., Buehler, K. (2009). Microbial biofilms: a concept for industrial catalysis. Trends in Biotechnology, 27(11), 636-643.

Sawada H, Kuykendall LD, Young JM. (2003). Changing concepts in the systematics of bacterial nitrogen-fixing legume symbionts. Journal of General and Applied Microbiology, 49(3), 155-179.

Schindlbacher, A., Rodler, A., Kuffner, M., Kitzler, B., Sessitsch, A., Zechmeister-Boltenstern, S. (2011). Experimental warming effects on the microbial community of a temperate mountain forest soil. Soil Biology and Biochemistry. 43, 1417-1425. 
Shang, C., Cheung, L. M., Ho, C., \& Zeng, M. (2009). Repression of photoreactivation and dark repair of coliform bacteria by TiO2-modified UV-C disinfection. Applied Catalysis B: Environmental, 89(3-4), 536-542.

Sileshi, R., Pitt, R., Clark, S. (2010). Enhanced Biofilter Treatment of Stormwater by Optimizing the Residence Time. American Society of Civil Enginners. (pp 522-532).

Simões, M., \& Simões, L. (2012). Biofilms in drinking water: Problems and solutions. RSC Advances, 2013(8), 2520-2533.

Smil, V. (2008). Climate change. In Cambridge, MA : MIT Press, C2008. (Ed.), Global catastrophes and trends: The next 50 years (pp. 190-220)

Sneath, P.H.A., Mair, N.S., Sharpe, M.E. \& Holt, J.G. (eds., 1986). Bergey's Manual of Systematic Bacteriology, 1st ed., vol. 2, Williams \& Wilkins, Baltimore.

Song Z., Borgwardt L., Høiby N., Wu H., Sørensen T., and Borgwardt A. (2013). Prosthesis infections after orthopedic joint replacement: the possible role of bacterial biofilms. Orthopedic Reviews. 5(2), e14

Statistics Canada, 2011, Environment Accounts and Statistics Division, Agricultural Water Survey (survey number 5145). Retrieved from http://www.statcan.gc.ca/pub/16-402x/2011001/part-partie1-eng.htm

Stewart, P. (1992). A model of biofilm detachment. Biotechnology and Bioengineering. 41, 111117.

Thiel, P., Zappia, L., Warton, B.,Nolan, P., Scott, D., Alessandrino, M., Franzmann, P., Hiller, B., Heitz, A., Masters, D. (2006). Activated carbon vs anthracite as primary dual media filters - a pilot plant study. 69th Annual Water Industry Engineers and Operators' Conference Bendigo Exhibition Centre. 8-14.

Tilman, D., 1999. The ecological consequences of changes in biodiversity: a search for general principles. The Robert H. MacArthur Award Lecture. Ecology, 80, 1455.

United States Environmental Protection Agency. (2009, May). National Primary Drinking Water Regulations. Retrieved From the Environmental Protection Agency website: http://water.epa.gov/drink/contaminants/\#List

United States Environmental Protection Agency. (2009, May). Natural Resources and Environmental Protection Act (Administrative Rules Part 4, P.A. 451). Retrieved From the Environmental Protection Agency website: http://www.epa.gov/safewater/mcl.html

Vilain, S., Luo, Y., Hildreth, M., and Brozel, V. (2006). Analysis of the life cycle of the soil Saprophyte bacillus cereus in liquid soil extract and in soil. Applied Environmental Microbiology, 72(7), 4970-4977. 
Vu, B., Chen, M., Crawford, R., Ivanova, E. (2009). Bacterial Extracellular Polysaccharides Involved in Biofilm Formation. Molecules. 14, 2535-2554.

Wang, J.W., Summers, R. C. and Miltner, R. J. Biofiltration performance: Part 1, relationship to biomass. American Water Works Association, 87(12), 55.

Wendt, C., Ives, R., Hoyt, A., Conrad, K., Longstaff, S. (2015). Microbial removals by a novel biofilter water treatment system. The American Society of Tropical Medicine and Hygiene, 92(4), 765-772.

Williams, K. P., Gillespie, J. J., Sobral, B. W. S., Nordberg, E. K., Snyder, E. E., Shallom, J. M., et al. (2010). Phylogeny of gammaproteobacteria. Journal of Bacteriology, 192(9), 23052314.

Wingender, J., \& Flemming, H. (2010). The biofilm matrix. Nature Reviews Microbiology, 8, 623-633.

Young, W.F., Horth, H., Crane, R., Ogden, T., and Arnott, M., 1996. "Taste and Odour Threshold Concentrations of Potential Potable Water Contaminants." Water Research, $30(2), 331$. 